\title{
FASHION DESIGNERS' HOME INTERIORS: EXTENDING THEIR BRAND IMAGE AND AESTHETIC THROUGH MAGAZINE FEATURES
}

\author{
By \\ Lauren Petroff \\ Bachelor of Commerce, McGill University, 2010
}

\author{
A Major Research Paper \\ presented to Ryerson University \\ in partial fulfillment of the \\ requirements for the degree of \\ Master of Arts \\ in the Program of \\ Fashion \\ Toronto, Ontario, Canada, 2012 \\ C(Lauren Petroff) 2012
}




\section{AUTHOR'S DECLARATION FOR ELECTRONIC SUBMISSION OF A THESIS}

I hereby declare that I am the sole author of this Major Research Paper (MRP). This is a true copy of the MRP, including any required final revisions, as accepted by my examiners.

I authorize Ryerson University to lend this thesis to other institutions or individuals for the purpose of scholarly research

I further authorize Ryerson University to reproduce this thesis by photocopying or by other means, in total or in part, at the request of other institutions or individuals for the purpose of scholarly research.

I understand that my MRP may be made electronically available to the public. 


\section{Abstract of The Major Research Paper \\ submitted to Ryerson University \\ in partial fulfillment of the requirements for the degree of \\ Master of Arts in the program of Fashion \\ EXPLORATORY STUDY OF FASHION DESIGNERS' HOME INTERIOR AS BRANDING STRATEGIES THROUGH MAGAZINE DISSEMINATION}

\section{By}

\section{Lauren Petroff}

May 2012

Supervisor: Osmud Rahman

Fashion designers, serving as the face and namesake of their brands, periodically present their homes in magazines. This exploratory study investigates whether this provides a unique opportunity to assist consumers in forming associations with the existing brand. An interdisciplinary literature review provided a thematic foundation, examining: 1) the presentation of self and how this concept can be symbolized through objects in the home; 2) visual culture and visual rhetoric; 3) and the concepts of brand identity, brand image, the "associative network memory model," and flagship-store image. Content analysis of six in-depth, qualitative interviews was employed to collect relevant and meaningful information. Study informants examined and discussed images of the homes, flagship stores and current runway collections of Ralph Lauren, Tory Burch and Alexander Wang. Findings suggest that viewers are able to attribute associated lifestyles to the home, store or clothing being observed. When the perceived home image was congruent with the viewer-held brand conception, it seemed to reinforce the image. If the perceived home image contrasted with the viewer-held brand conception, it seemed to weaken the image. Two major recommendations were presented: 1) ensure that the home is a clear visual and cognitive representation of the designer's intended brand identity; 2) establish a clear visual link between homes and brand offerings. 


\section{ACKNOWLEDGEMENTS}

The completion of this major research paper could not have been realized without the help of many people. First of all, I thank my Program Director, Sandra Tullio-Pow, and all faculty members of the Ryerson University School of Fashion involved in the Masters of Arts in Fashion program for their dedicated focus and perseverance through the pioneering year of Canada's first post graduate fashion program. I also thank my professors whom have guided me through the engaging course work and encouraged me to push my creative and academic boundaries: Dr. Alison Matthews-David, Professor Susan Barnwell, Dr. Janna Eggebeen, Professor Alice Chu, Dr. Lu Ann Lafrenz, Dr. Kimberly Wahl and Professor Joseph Medaglia. With great gratitude I thank my faculty supervisor, Professor Osmud Rahman for helping formulate my ideas, research design, and providing me with guidance about theory. His suggestions and attention helped me create a study that I am truly proud of. I also thank my second reader, Professor Alice $\mathrm{Chu}$, for being a great support and source of encouragement.

I thank my fellow classmates in both first and second year. Together we conquered many late nights and long days. As a group we made it through the journey that is graduate school.

Finally, I thank my friends and family, but especially my parents, Neil and Leanne Petroff. Because of their unconditional love and support through my life and education I am proud of what I have achieved. 


\section{TABLE OF CONTENTS}

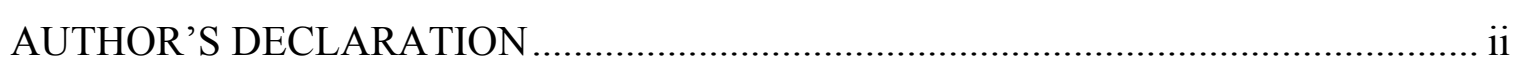

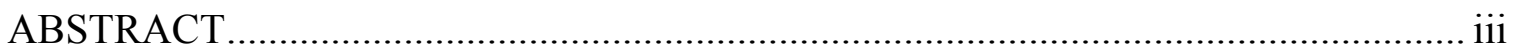

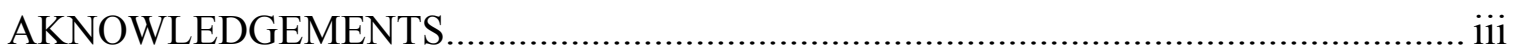

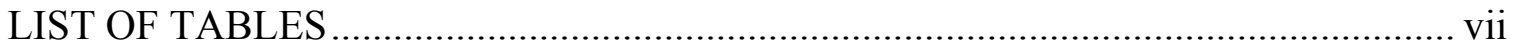

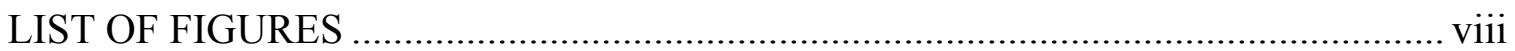

\section{CHAPTER}

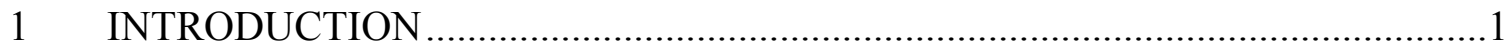

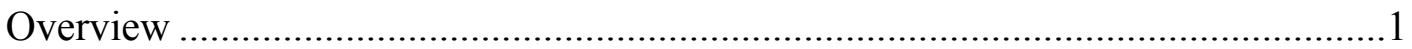

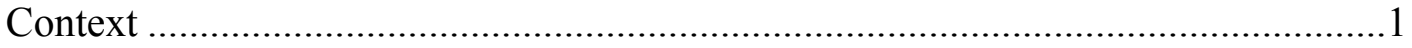

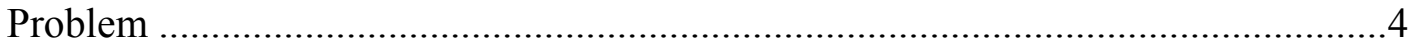

2 LITERATURE REVIEW ........................................................................

Presentation of Self ................................................................................

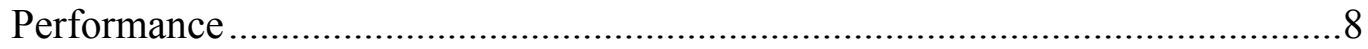

Objects of the Home as Symbols of the Self .................................................. 9

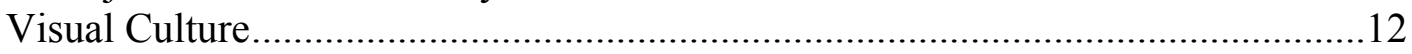

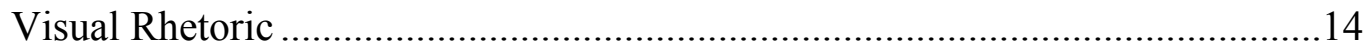

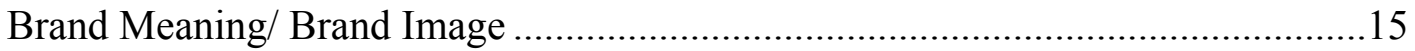

Integrated Marketing Communication...........................................................16

Brand Identity and Brand Image ............................................................ 16

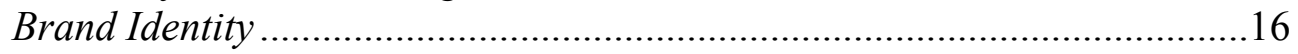

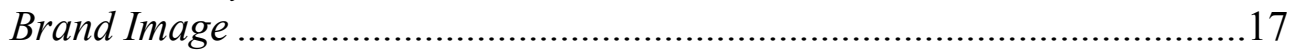

Associative Network Memory Model ….....................................................18

Flagship Store Image ........................................................................19

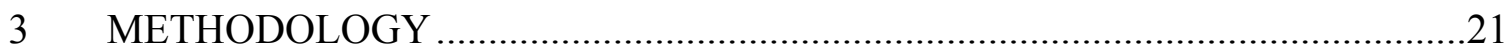

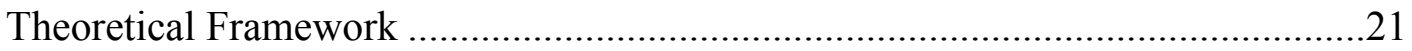

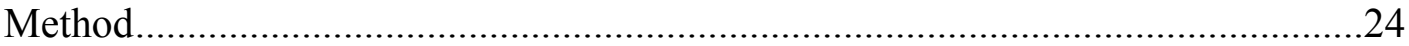

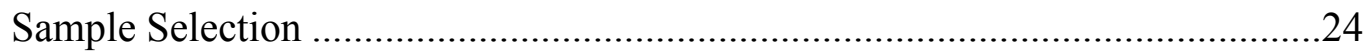

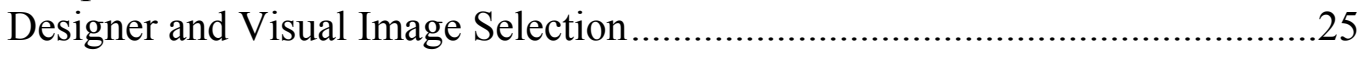

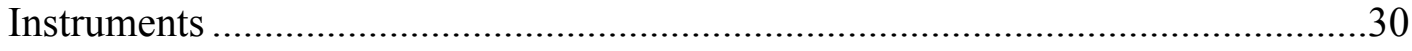

Free Elicitation and Projective Techniques .....................................................

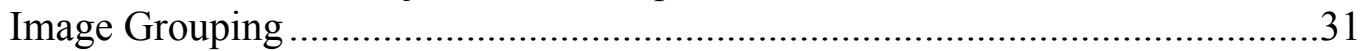

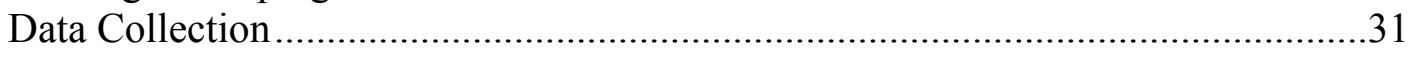

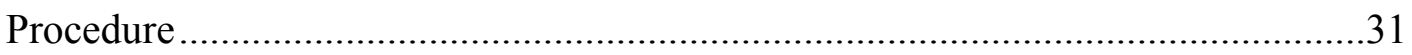

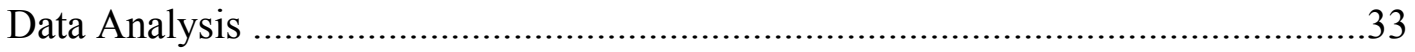

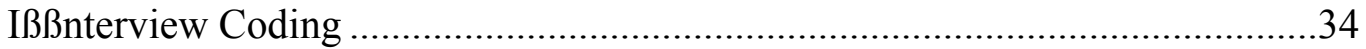


Informants' Profiles, Brand Perception and Familiarity ......................................36

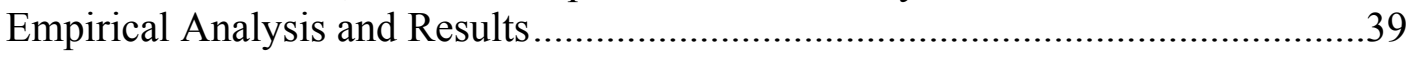

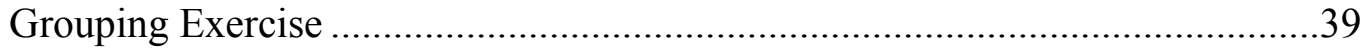

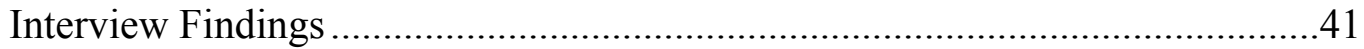

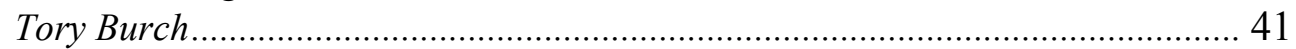

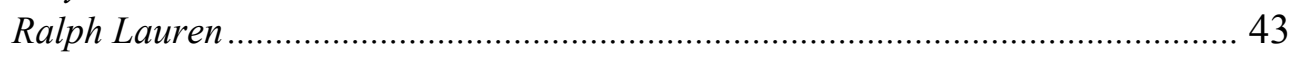

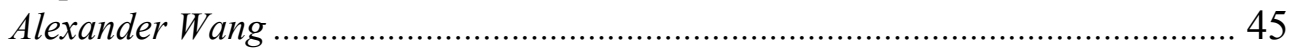

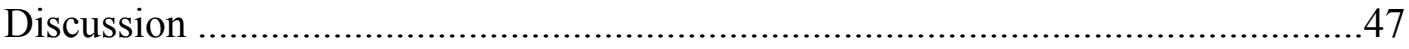

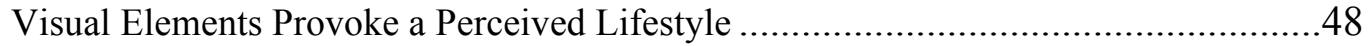

The Designer's Home in Connection with Their Brand Image .................................51

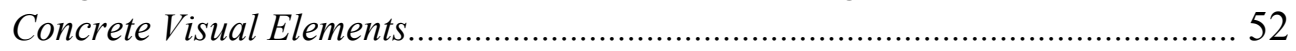

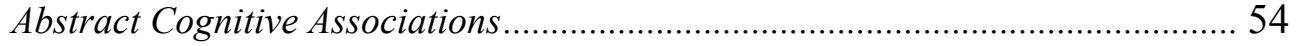

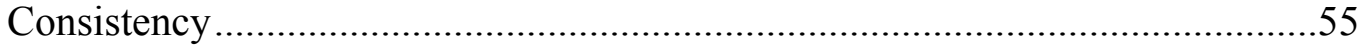

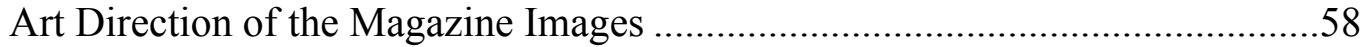

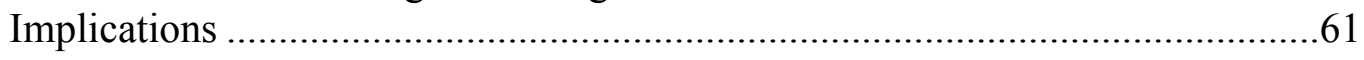

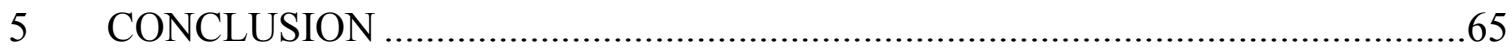

APPENDIX

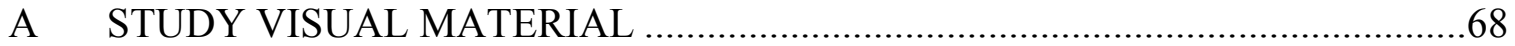

B SUMMARY OF EACH IMAGE GROUPING EXERCISE ................................94

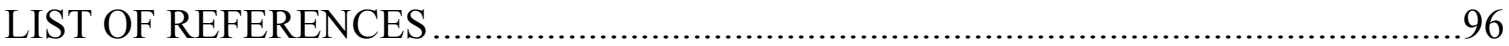




\section{LIST OF TABLES}

Table

T-1 Visual Stimuli - Designer's Store, Home and Collection .................................27

T-2 Summary of Informants' Profile \& Preliminary Interview Questions...................37

T-3 Summary of Image Grouping Results.......................................................94 


\section{LIST OF FIGURES}

Figures

A-1 Tory Burch's Home Interior .68

A-2 Tory Burch's New York Flagship Store Interior. . .71

A-3 Tory Burch's Collections ...................................................................................73

A-4 Ralph Lauren's Home Interior........................................................................75

A-5 Ralph Lauren's New York Flagship Store Interior ...................................................78

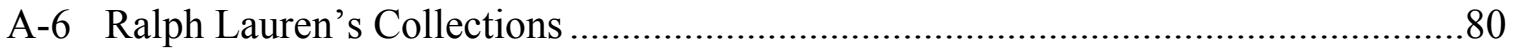

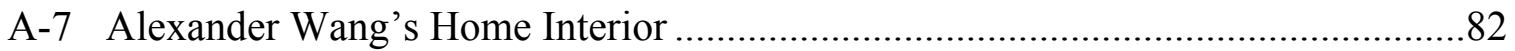

A-8 Alexander Wang's New York Flagship Store Interior ...........................................85

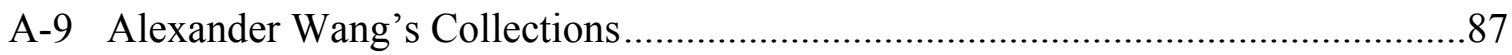




\section{CHAPTER 1 \\ INTRODUCTION}

\section{Overview}

One increasingly popular feature in magazines and entertainment features on television and the internet is to invite readers or viewers into the homes of designers and other celebrities, offering them a peek into the private space of an individual with a public presence. It is my theory that reading and viewing these articles is not merely an entertaining activity, but also an important touch-point to arouse interest and engage consumers in the designer's products. The way that fashion designers present their homes, lifestyles and persona in magazine features such as these should be considered and categorized as part of a larger communication strategy of their company and not simply as a frivolous or vain decision. Indeed, it is my belief that the active participation in a magazine feature should be viewed as a form of publicity, regardless of whether that started as the designer's intention or not.

\section{Context}

In today's highly competitive and rapidly changing markets, fashion companies often need to differentiate themselves in the minds of consumers. They can do this by creating an effective brand image and identity. The integrated marketing communications (IMC) approach emphasizes the importance of a company’s creating a consistent message across all channels (Rowley). As many previous researchers (Duncan \& Moriarty; Solomon \& Englis) suggested, IMC can be used to reinforce a brand message and positively influence consumer's perceptions towards a brand. In order to build a strong identity, both planned and unplanned communication strategies must convey a consistent and coherent message. As Duncan and Moriarty (7) asserted, "Recognizing and managing 
the indirect, implied, and hidden communication dimensions at all marketing and corporate-level brand contacts is necessary if a company wants to maximize profitable brand relationship." For IMC to help a company develop its message into a cognitive and tangible experience for consumers, brand identity must be established and then reinforced through consistent use. "Brand identity" is how the company sees itself or how it wants its brand to be perceived. Brand identity can be manifested through physical qualities of the company's product, but it also includes but is not limited to its retail environments, print advertisements, and websites, all of which represent what the brand stands for (Cagan \& Vogel). "Brand image," on the other hand, is how consumers perceive the brand. It includes the associations and perceptions that consumers have about a particular brand, and it reflects the current relationship between the product/company and the consumer (Vaid 186).

Brand image can be viewed as an overall impression that consumers receive from many sources, and in many cases it may be more important in terms of consumer choices than are the technical facts about the product (Nandan 266). Keller (70) notes that brand image consists of the customer-based associations that are formed around encounters of any kind with a brand.

To gain a perspective about how brand image is formed in the minds of consumers, the information-based conception of brand meaning can be applied (Allen, Fournier \& Miller 784). Through this approach, associative models focus on a knowledge structure of brand-relevant information that exists in the minds of consumers (Batey 4; Keller 64). Consumer-held associations can be understood through the "associative network memory model", which views memory as consisting of a network of nodes and 
connecting links (Keller 64). In this model, brand associations are nodes of information that are perceived and stored in the brain, based on stimuli from any encounter that a consumer may have with the brand. From this perspective, any communicative attributes related to the brand can be viewed as brand association. In other words, association is not merely restricted to company sponsored marketing communication. Hence, each and every interaction that a consumer or prospective consumer has with a brand - every occasion in which that person comes into contact with the brand - is considered a "touch point" for the creation of meaning.

My consideration of the exposure of a designer's home as an indirect form of brand communication is grounded in the assumption that a person's material possessions serve as a means of self-expression. Products or possessions often serve as "props" for the expression of self-image. Through the symbolic consumption of material objects such as clothing or furniture, an individual may manifest his or her self-concept (Holbrook, Solomon \& Bell 6). Furthermore, home interiors, furniture and decorative elements can be considered as signifiers, or non-verbal communicators, providing symbolic clues to viewers about the owner's identity, class, aesthetic preferences, and personality traits (Cupchick, Ritterfield \& Levin 191).

When designers expose their homes through mass-market platforms, they may consider it simply as content for the magazine and inspiration and entertainment for the readers. However, this study argues that closer corporate consideration should be given to such decisions. When welcoming the public into their private domains, designers are also inviting their consumers to ask, "Does the name behind the label actually live the image and lifestyle that his or her brand preaches?" In exposing their homes, the designers are 
figuratively setting a stage for an evaluation on the part of consumers that will then be, consciously or subconsciously, connected to their brand image.

Creating a convincing message is an important yet daunting task in today's hyperstimulating society. The consuming public is growing cynical of forms of "manipulative" and blatant advertising. It is my goal to find out whether the integration of strategies such as exposing one's home into other brand-building actions, can offer consumers entertainment while also helping them to build a relationship with the face behind the brand - the one inviting them into their home.

\section{Problem}

This research will specifically study cases in which the designer's name is also the namesake of his or her fashion company. My goal is to understand whether viewing a fashion designer's domestic interior as presented through magazine photographs affects consumers' perceptions about the brand image of the designer's fashion company. The investigation will ultimately explore whether specific visual cues allow viewers to read the images of a designer's home and create cognitive connections between the interior-design aesthetic and the fashion company's stylistic and symbolic identity. The study and analysis will be executed under the assumption that a designer's private image and identity, when displayed publicly, contributes to his or her public persona. Further, it is my belief that this public persona should embody the company's brand image and that therefore any marketing communication involving aspects of the designer's private life should contribute positively to the overall brand concept, and be consistent with it.

This study aims to engage in exploratory research regarding the aforementioned phenomenon, whereby a fashion designer exposes his or her home to consumers through a 
magazine article. Such an investigation will be accomplished through researcher-led, qualitative, semi-structured, in-depth interviews and content analysis. The material addressed in both modes of data collection will consist of specific images that show a designer's home in a fashion or interior design magazine. Images of the interior environment of the brand's flagship store will also be shown to participants, as will images of the company's designs as seen through their most recent fall and spring readyto-wear collections on the New York Fashion Week runways. Since this is an initial exploration of the research interest, the criteria that serves as the justification for the selection of a fashion designer needs to be specific: the brand must have significant North American presence; the designer must be an identifiable, key figure in the company; the designer must serve as a namesake for his or her fashion label; and the magazine feature must include at least four distinct pictures of the designer's home interior. In order to determine the brand and designer image, it will be important to choose designers who have substantial exposure in descriptive texts appearing in print media; therefore, a final criterion for choosing designers is that they have appeared at least ten times in mainstream fashion magazines. The designers chosen for this study on the basis of these criteria were Tory Burch, Ralph Lauren and Alexander Wang.

The research objective is to assess whether viewing a fashion designer's home interior in a magazine article can assist consumers in forming appropriate associations with the brand of which the designer is a primary producer. The following research questions will be of particular relevance in the case studies under consideration:

- Does the way a fashion designer decorates his or her home affect the consumers' perception of their product and brand image? 
- Does the designer's home decor reinforce and/or enhance the consumer's associative network of the brand concept?

- How do consumers perceive and interpret visual elements in the designer's home in relation to perceptions about the visual elements of the interior of the designer's flagship store and the style of the designer's product?

- How does the exposure of a fashion designer's home communicate information about his or her personal/brand image?

The results of this study will provide valuable insights, information and implications to fashion practitioners and marketers on both practical and theoretical perspectives within the context of the visual communication of brands. This exploratory inquiry will also identify opportunities for future research. 


\section{CHAPTER 2}

\section{LITERATURE REVIEW}

The distinct study of individuals' perceptions and responses toward brandassociative imagery of fashion design and interior design is an area that has not been fully investigated and addressed by previous researchers. To date there is no available literature that relates to this study's particular focus on the domestic interior of designers' homes as a mode of communicating the fashion designer's self image and thus brand image. In order to approach such a multifaceted inquiry, the literature review will be divided thematically to cover the various angles related to this research topic. The review of previous scholarship will begin with concepts around the presentation of self, including the performance of 'self' and how concepts of the self can be symbolized through objects of the home. Following will be an evaluation of theories in visual culture. Since a significant component of the research in this study involves magazine photographs, it is important to understand how previous scholars examine the visual experience in the creation of meaning for viewers/ consumers. Building on the concept of meaning creation, the review will then focus on applicable theories of brand meaning, brand identity and brand image. Within the brand section, a specific look at flagship stores will follow.

\section{Presentation of Self}

It is important to understand the thinking of previous scholars in regard to the ways in which individuals mediate their own and others' identity through the presentation of self. Here, we will look specifically at how fashion designers express their personal identity, or concept of self, through public media. We will first examine the "performance of identity," which will be followed by a discussion on the way in which domestic materiality serves as self-expression of personal image. 


\section{Performance}

Irving Goffman (1) famously analyzed social interaction in terms of a "performance" that individuals put on in order to communicate their social characteristics to others. For those involved in the interaction there are many sources of information, and many hosts of social data become available for conveying that information. By gleaning cues from a person's behavior and appearance, individuals on the receiving end can begin to make judgments about people they do no know. A viewer who is familiar with the individual they are observing can largely rely on previously accepted assumptions in order to predict their behavior, while also taking in visual and behavioral cues (Goffman 1). In many cases, when an individual appears before others, he or she will act in a manner according to accepted social codes in order to make an impression that will evoke a desired response. Additionally, the individual will only be successful in fostering trustworthy associations when they are consistent in playing their "part" (Goffman 18). Goffman (18) refers to the part of an individual's performance that regularly operates in a fixed fashion, in order to create a defined situation for observers, as the "front." There are three standard parts of the front: setting (items that make up the background for the performance of human action); appearance of the individual; and manner of the individual. As observers, we generally expect to see coherence among all three.

Goffman's analysis on how people negotiate and validate identities, along with the way in which observers establish "frames" within which to evaluate the meaning of encounters, works on the basis of face-to-face experiences. However, through modern modes of communication, there are new frames of interaction, as well as new problems and opportunities in the presentation of self (Miller 1). According to Hogan (377), self- 
presentation can be split into "performances" and "artifacts", where performances occur in synchronous "situations" and artifacts take place in asynchronous "exhibitions". While Goffman's dramaturgical approach to the presentation of self through performance focuses on situations, the presentation of self in various forms of media communication habitually employs exhibitions (Hogan 377). In these media framed exhibitions, photographs are curated into a story. The artifacts that appear in the images are the result of a past performance that lives on for others to view on their time, while still remaining a presentation of self (Hogan 378).

\section{Objects of the Home as Symbols of the Self}

Other research in the presentation of self that relates to Goffman's analysis on social interactions as performances has shown that products or possessions often serve as "props" for the expression of self-image (Holbrook, Solomon \& Bell 6). Through the symbolic consumption of such objects as clothing or furniture, individuals may display their self-concepts (Holbrook, Solomon \& Bell 6). Further, with regard to furniture and decorative elements, home interiors can serve a symbolic function, providing clues for others about identity, class, aesthetic preferences, personality traits and personal histories of the occupants (Cupchick, Ritterfield \& Levin 191). It is assumed that houses are chosen, modified and decorated in such a way that they are symbolically appropriate for the residents (Sadalla, Versure \& Burroughs 570). Further, environments are socially meaningful in a number of ways: they provide the context for social activity; they are evaluated by individuals and groups; and they are a source of individual and social identification (Stephenson 596). They are socially constructed - relying on people to create them and reveal social qualities. Wilson and Mackenzie (343) noted that much like 
the idea that the style of a certain building can reveal personal information about the architect, the same can be said about individuals in the way they choose the form (layout) and details (decorative elements) for their homes. In fact, a study produced by Sadalla et al. showed that subjects who were presented with images of home interiors were able to infer the homeowner's self-perceived lifestyle, personality and image to a significant degree (584). Further, a study conducted by Bonnes et al. suggested that the creation of a living-room environment not only portrays the owner's aesthetic values but also reflects his or her interpretation of the social activities that would happen there (Wilson \& Mackenzie 343).

A dramaturgical perspective on the presentation and conceptualization of the self is well suited to the idea that a home and its interior objects serve as expressions of identity and self-image. Houses and their contents can be seen as symbols that are part of a gestural language that individuals use to communicate with each other (Sadalla, Versure \& Burroughs 572). They also serve as props that support social behavior and may be regarded tools that are manipulated and used in self-presentation (Sadalla, Versure \& Burroughs 573). Additionally, observers should be able to "read" the social information present in houses and make inferences about messages that the homeowner intends to communicate, based on the observer's knowledge about both the homeowner and the symbolic value of the interior contents (Sadalla, Versure \& Burroughs 572). In Wilson and Mackenzie's (347) study on social attributions based on domestic interiors, they had interview participants freely elicit social constructs based on 26 photographs showing a wide range of living rooms. They found 21 social and personal attributes that participants were able to "read" about imagined owners based on environmental cues (Wilson \& 
Mackenzie 347). The range of constructs (anything from age, status, and wealth to hobbies, aspirations and lifestyles) generated through this study demonstrates that viewers derive a wide variety of judgments from domestic environment cues (Wilson \& Mackenzie 346).

Another useful study was done by Cupchick, Ritterfield and Levin. It involved examining viewer judgments of living rooms and dining rooms presented in interior design magazines. A component of their research asked one group of participants to take a "detached" stance by imagining the inhabitant of the room, and the other group to take an "engaged" stance by imagining themselves as the inhabitant of the room. This method is deemed to be appropriate, since readers have been shown to shift between detached and engaged attitudes when exploring images in magazines (Cupchik, Ritterfield \& Levin 190). A detached attitude is appropriate when people make inferences about the personal qualities of the inhabitants - where decoration, furnishings, and placement of items are assumed to reflect the character and self-image of the inhabitant (Cupchik, Ritterfield \& Levin 191). Readers may become highly engaged when scrutinizing the image to determine whether the furnishings or decoration are the right "fit" to their own self-image. The study concluded that those assuming a detached perspective were able to elicit more social attributions about the inhabitant, and that this facilitated incidental learning about the inhabitant (Cupchik, Ritterfield \& Levin 197).

A slightly different yet useful concept of the material expression of identity was covered in an article by John Potvin entitled "The Velvet Masquerade: Fashion, Interior Design and the Furnished Body". While more anecdotal than scholarly in nature, the article explored the answers to a number of interesting questions, such as: "Do interior 
design, furniture, and fashion emphasize the owner's identity? Does the audience, the subjects perceiving and receiving the performance, play a vital role in the development of meaning? What is the role of interior design and fashion in relation to the public/ private divide and gender?" (Potvin 2) He concluded that all three constructs of interior design, furniture, and fashion share the ability to reveal material traces of what might be broadly characterized as modern identity. Interestingly, he discussed how interior design occupies a liminal space between fashion and architecture: unlike fashion (fleeting and ephemeral), interior design has tended to move rather slowly, while architecture has considerably more permanent and static existence (Potvin 3). As well, Potvin noted that in current contemporary media, we are witnessing an intensified interest in "lifestyle" as a topic, and seek out this information in our media sources, including television, magazine, and the internet. Potvin proclaimed that "fashion and domestic interiors are the sites for both representation and embodiment; distance and proximity; the visual and the haptic; the private and the public" (Potvin 4). Ultimately, fashion and interiors seem to be the materiality of embodied identity and they provide narratives in exposing the home as a vital space that is both private and for public display.

\section{Visual Culture}

An important and overarching component of this research was a discussion of visual culture. It was imperative to understand that seeing and perceiving play a powerful role in the creation of meaning for the viewers of images, and even of daily life. This research focused on photographs in magazines along with viewer interpretation and perception, which was largely created out of the visual component of feature articles.

Nicholas Mirzoeff and Irit Rogoff were notable authors for their influential work 
on visual culture. Mirzoeff discussed how contemporary culture enhances the influence that visual media have on the interface between visual technologies and information, the creation of meaning, as well as pleasure and displeasure that is available to the viewer/ consumer. Visual culture encompasses the idea of visual material as well as the process of visualizing - both in terms of experience, and in terms of conceiving the world as a picture (Mirzoeff 5). Interestingly, he commented on how the modern world is characterized by the reproducibility and circulation of images - as in magazines and other popular media - and that it is especially concerned with everyday life as opposed to moments of formal/structured viewing, such as in an art gallery (Mirzoeff 6).

Irit Rogoff's discussion of visual culture focused on the way in which vision plays a significant role in human relations. Further, she said that the study of visual culture is deeply about the centrality of vision in the formation of cultural meanings and power relations (Rogoff 24). She noted how visual culture is "intertextual" - "images, sounds and spatial delineations are read onto and through one another, lending ever-accruing layers of meanings and of subjective responses to each encounter we might have with..." film, magazines, TV, advertising and any other mediated or unmediated material production (Rogoff 24). The field of visual culture encompasses, images, viewing apparatuses (guided by cultural models such as narratives and/or forms of technology) and subjectivities (points of identification, desire, or abjection). Ultimately, the faculty of visual culture gives primacy to vision as an empirical method of perceiving the world, which is an important perspective on the power of magazines in creating meaning, desirability, and perception. 


\section{Visual Rhetoric}

The concept of "visual rhetoric" was integral to this research because it is a term used to describe the study of visual imagery within the disciplines of rhetoric. Rhetoric is the study of communication through the use of symbols (Foss 141). While traditionally a study of verbal texts, the definition of rhetoric has expanded to include "any human act, process, product, or artifact that may formulate, sustain, or modify attention, perceptions, attitudes, or behavior" (quoted in Foss 141). The study of visual images flourishes in rhetorical studies primarily because the visual image is so pervasive and has such a great impact on contemporary culture. A selection of images that Foss (142) mentioned as constituting a major part of the rhetorical environment includes "advertisements, television, film, architecture, interior design, and dress." Further, the study of imagery from a rhetorical perspective has gained substantial ground with the emerging recognition that visual images can provide access to a greater range of human experience that might not be available through the study of discourse alone (Foss 143).

Within the discipline of rhetoric, the term visual rhetoric has two meanings. It can refer to a visual artifact or object - where visual rhetoric is a product that individuals create as they use visual symbols in communication. It can also refer to a scholarly perspective on the study of visual data that focuses on the process by which images perform communication (Foss 143). While not every visual object is visual rhetoric, there are three criteria that turn a visual object into a communicative artifact: the image must be symbolic; it must involve human intervention; and its purpose must be to communicate with an audience (Foss 144).

An image, as approached in visual rhetoric, "serves as a stimulus, a text or a 
representation that drives cognition, interpretation and preference" (quoted in Shroeder 229). From a psychological standpoint, it is important to first establish what it is that people are looking at. Only then can an attempt be undertaken to discern why, under their specific conditions, they see what they see (Shroeder 229). In his article on "Visual Consumption in the Image Economy", Shroeder was concerned with identifying what the consumer is looking at, and how those images signify. By focusing on visual issues in the consumer landscape, we can appreciate the prominence of the image in brand-building activities and in the visual-consumption process that dominates contemporary culture.

\section{Brand Meaning/ Brand Image}

What is a brand? How is brand meaning created for consumers? It is a widely held conviction that branding is squarely grounded in the discipline of psychology, drawing heavily upon information processing, memory production and retrieval theories. That is, brands exist in the minds of consumers as part of the knowledge structure of information (Allen, Fournier \& Miller 2008). A brand is the consumer's perception and interpretation of a cluster of associations, attributes, benefits and values - a cluster of meanings (Batey, 2008).

Brand meaning, although a useful way to understand how consumers create and develop their brand knowledge, is a rather unstructured and elusive concept. Therefore, there can be a number of ways to break down and test what a brand means. For example, one can focus on: company-managed brand elements such as the name, logo, slogan and packaging; components of the marketing mix, such as the physical product, the price, the channels of distribution, and promotional activities; or the more holistic notions of a brand, such as the brand identity and brand image. 


\section{Integrated Marketing Communication (IMC)}

IMC is a widely acknowledged marketing philosophy. The goal of IMC for any company is to reach its target audience through a range of media and channels. More importantly, it is fundamental that all communication or interaction with consumers delivers the same message in a consistent manner. This message should be closely tied to the brand's identity and be clearly and consistently conveyed through all levels of communication (Morrison; Johnson \& Lee). Although a simple idea, in practice there are often disparities between what a company believes about its brand and what the consumers hold in their mind (Schultz \& Schultz). It is important for a company to create brand recognition and have its brand identity match the brand image that is collectively held in the mind of the consumer.

\section{Brand Identity and Brand Image}

In order to facilitate brand recognition and clear brand associations, a company must create and maintain both brand identity and brand image.

\section{Brand Identity}

Brand identity is a construct that is controlled by marketers and brand managers. It is a company-driven conception that is built through the communication of a brand's individuality and distinctiveness (Nandan 265). This message is largely achieved through a brand's marketing-mix strategy. According to Perry, a brand's identity is its fundamental state of "being itself." He highlights four purposes for brand identity: to bring the brand to life by adding personality through design; to enhance brand recognition among consumers; to differentiate the brand from the competition; to tie all brand elements together with the same look and feel (Perry). In establishing a brand identity, Perry says it 
is wise to start with basic elements that can stimulate brand recognition, such as logos, typography, colours and catchphrases. These elements 1) help create a brand identity for a product or collection, and 2) create a brand image for consumers to grasp (Perry). Maintaining and minding a brand's identity is crucial in an ever-evolving market. To sustain a brand and the loyalty that it has hopefully generated it is important to ensure that the company that is represented by the brand lives up to or exceeds customer expectations. With respect to brand creation and maintenance, the success of design goes beyond the use of colours, logos, and typeface. More importantly, brand consistency through design must address a brand's values and visual identity (Moser 10).

\section{Brand Image}

Brand image is arguably the most important aspect of brand knowledge because it resides in the mind of consumers. It can be described as the "consumer perception and interpretation of a cluster of associated attributes, benefits and values" (Batey 6). As discussed by Gardner, Levy and Herzog, brand image can be defined as an overall impression that consumers receive from many sources, and in many cases it may be more important to the consumer than technical facts about the product (Nandan 266). Keller (70) noted that brand image is the customer-based associations that are formed around encounters of any kind with a brand. Encounters may include direct experience with the product and brand elements, information communicated by the company or other nonpartisan source, word of mouth, and through inference from the identification of the brand with a company, country, channel of distribution, or a particular person, place, or thing (Keller 70). Brand imagery, according to Keller (83), is the extrinsic properties of a product or service. It is the abstract concept that refers to intangible aspects, rather than 
the product performance. Imagery associations can be formed through any encounter with the brand - direct or indirect.

\section{Associative Network Model}

One perspective on how brand image is formed in the mind of consumers is the information-based conception of brand meaning (Allen, Fournier \& Miller 784). Through this approach, associative models focus on a knowledge structure of brand-relevant information that exists in the mind of consumers (Batey 4; Keller 64). The "consumerbased brand equity" model is based on the principle that the meaning of a brand is ultimately what a consumer subjectively perceives as a result of a collection of associations (Batey 6). Consumer-held associations can be understood through the “associative network memory model," which views memory as consisting of a network of nodes and connecting links (Keller 64). Nodes represent stored information or concepts, and links represent the strength of association between the information/concepts (Keller 64). Brand associations are nodes of information that are perceived and stored in the brain, based on stimuli from any encounter that a consumer may have with the brand. This input data adds to the associative network that already exists in the brain for a given brand that has been collected from previous experience or encounters (Batey 7; Keller 64). From the brand perspective, everything communicates, not just company-sponsored marketing communication. Hence, each and every interaction that a customer or potential customer has with a brand - every occasion on which that person comes into contact with the brand, and all that is associated with the brand - is considered a touch point where something about the brand is being communicated (Batey 220-21). 


\section{Flagship Store Image}

An important, influential and highly experiential touch point for many brands is their various flagship stores. It is the "way in which the store is defined in the shopper's mind, partly by its functional qualities and partly by an aura of psychological attributes" (quoted in Brengman \& Willems 346). A flagship brand store can be distinguished by three major characteristics: it carries a single brand of product; it is owned by the brand's manufacturer; and it operates (at least in part) with the intention of building or reinforcing the image of the brand (Kozinets et al. 17). The flagship store is also increasingly popular as a venue where marketers can build relationships with consumers (Kozinets et al. 17). Although there are many attributes of a store that contribute to its perceived image, such as the merchandise, service, clientele, physical facilities, convenience, promotion, store atmosphere, and post transaction satisfaction (Lindquist 31-32), the focuses of the present study are the styling and interior design of the store environment. Because of this aspect, it is important to note that retail marketers have had to pay more attention to aesthetics and to the processes by which consumers make meaning out of their physical and visual experience of a place (Kozinets et al. 17). Brengman and Willems conducted a study in order to identify the determinants of fashion-store personality. They found that although there is some overlap between sources of information for both product and store-brand personality, several sources are specifically attributed to stores (Brengman \& Willems 34). Such elements include the store environment, sales personnel and merchandise carried. Additionally, some sources of inference that are common to both brand and store personality may have different impacts on consumers (Brengman \& Willems 347). Among the elicited determinants of store personality, Brengman and Willems (348) found 
five major categories: store atmosphere; merchandise; reputation; service; and format and location. Of interest to this research study was the store atmosphere, which includes "ambient factors" such as music and lighting (although it is not feasible to investigate the impact of music in this study), "social factors" such as other customers and store personnel, and "store design factors", including functional and aesthetic design aspects such as layout, style and colour (quoted in Brengman \& Willems 348). With regard to atmospheric elements, the results showed the most salient determinants for the five store personality dimensions that were studied. Some atmospheric determinants of a "sophisticated" store, for example, include a pleasing, attractive and nice store interior that is spacious and well organized, may have an exclusive location and may be in a boutique format. Some atmospheric elements of an "enthusiastic" store include colourful and dynamic interiors with somewhat bright lighting and lively music. Some atmospheric elements of a store with "solidity" include spacious and inventive store interior that is well cared for. Some atmospheric elements for a store that is "unpleasant" include ones with outmoded, grayish store interiors that are messy with fluorescent lighting, flashy colours, and intrusive background music (Brengman \& Willem 349-52).

Of considerable interest to my current study was the fact that Brengman and Willem found that the most frequently mentioned class of store personality determinants were aspects of store atmosphere. This contradicts the traditional notion that the notion that store design and social factors are extremely important in the formation of customer perceptions. 


\section{CHAPTER 3 \\ METHODOLOGY}

This exploratory study employed visual stimuli and semi-structured interviews to investigate the following research objective: how does viewing a fashion designer's home interior in magazines assist consumers in forming appropriate associations with the brand of which the designer is a primary producer?

\section{Theoretical Framework}

The overarching framework that guided this research was the "associative network memory model" (ANMM) combined with the theory of "visual rhetoric". As previously mentioned, the ANMM is used to map and understand how meaning is created in the minds of consumers. This model views memory as a network of nodes and connecting pathways. Nodes represent stored information or concepts, while links represent the strength of association between the concepts. Any type of information, with which the consumer has experienced, can be stored in a memory network (Keller 64). The ANMM is a useful theoretical means for representing brand associations.

Visual rhetoric is a theoretical perspective that serves as an analytic tool for approaching an understanding the role of visual data in a way that highlights the communicative dimensions of images (Foss 145). The key aspect of a rhetorical perspective is its focus on a rhetorical response rather than an aesthetic response. An aesthetic response is a viewer's direct perceptual encounter with the sensory aspects of an image; it is simply experiencing the colour, line, texture, form etc. In a rhetorical response meaning is attributed to the image. The basic elements such as colour, line, texture, form etc. provide a basis for the viewer to infer information about what they are seeing images, emotions, and ideas. Visual rhetoric is about understanding the viewers' responses 
to images (Foss 145). Another major feature of a visual-rhetoric perspective is that it conceptualizes the audience as lay viewers - those who do not have technical knowledge about design or aesthetic educations which would guide them to interpret the images based on expert frameworks. Instead, lay viewers construct their responses to images based on their own lived experiences and knowledge of the world (Foss 146). Finally, a rhetorical perspective on visual imagery is characterized by attention to the nature, function, and/or evaluation of the image; of these three areas of concentration, this study will be most concerned with the first two. The nature of the image involves its distinguishing features - the presented elements and the suggested elements. "Presented elements" are the major physical features including the space of the image, the media in which the image is constructed, and the shapes/ forms that are featured in the image. "Suggested elements" are the concepts, ideas, themes, and allusions that the viewer is likely to infer from the presented elements (Foss 146). A next level of focus is to understand the function of the image for the audience. From this perspective, attention is not paid to the intention of the designer of the image. Rather, the function of an image from a rhetorical perspective is the action the image communicates (Foss 147).

The application of a rhetorical perspective to imagery begins with rhetorical constructs and theories, which are used to guide the study of the visual artifact. This approach functions under the assumption that images possess the same communicative characteristics as symbols; the visual image is essentially treated as a language-like symbol.

The above framework was applied to this study for a composite of reasons. First, of utmost importance to the investigation was the question of how consumers create brand 
meaning based on lived encounters and experiences. The current research examined whether viewers could acquire meaning about a fashion brand by looking at pictures of the domestic interiors of the primary producer for that brand - namely, the designer - and, if so, how? By using the ANMM, the researcher was able to identify existing memory networks that the consumer held about a brand and to determine whether specific experiences, such as viewing photos of the designer's home, created associations that were congruent with ideas already held in their memory. Additionally, participants were shown other visual stimuli in the form of images of store interiors and images of the brand's most current ready-to-wear collections. Based on various elements that were presented in the images, viewers discussed their interpretation of what those objects meant to them.

Through a framework of ANMM and visual rhetoric, the researcher engaged in detailed content analysis of a variety of texts in order to make connections and understand the viewers' interpretation and deduction of meaning based on the presented images alone. A "text" is anything capable of being decoded, such as a page of writing, a painting, a picture of a situation, or the way somebody dresses; from the brand perspective, everything communicates (Batey 208). In this research study, the 'text' consists of a variety of images - those from the selected magazine features, interior photographs of each brand's flagship store and each brand's most recent ready-to-wear runway collections. The images served as the primary focus and visual stimulus for a series of indepth qualitative interviews. They also served as the material for objective visual content analysis conducted by the researcher. 


\section{Method}

\section{Sample Selection}

For the purpose of this research, convenience sampling of Torontonian adults (female; age 18-40) was used, and in-depth interviews were employed. Convenience sampling is a type of non-probability sampling technique, which is done based on the judgment of the researcher ("Convenience Sampling: And Overview”). In total, six female subjects were recruited for this study and the sample size deemed to be sufficient for generating themes and categories in this type of qualitative study. As McCracken (17) suggested in The Long Interview: Qualitative Research Methods, "The first principle is that 'less is more.' It is more important to work longer, and with greater care, with a few people than more superficially with many of them. For many research projects, eight respondents will be perfectly sufficient."

Convenience sampling was used because having access to the population, while also having a mix of people was important; therefore, informants were approached from within Toronto, Ontario. All informants were recruited through friends and casual acquaintances. The selection criteria for informants were based on their lifestyle and propensity to appreciate fashion and interior design. A younger age range was chosen because these consumers generally tend to be more fashion conscious (Beaudoin, Lachance \& Robitaille; Chen-Yu \& Seock) and often connect with fashion retailers through various medium such as magazines, internet and store display. To ensure each informant met these criteria, they were asked a series of screening questions before the interview was conducted. Further, females were the subjects of inquiry as their interest in fashion is characteristic (Bregman \& Willems 347). Sampling was done in order to elicit a 
relevant range of participants from the wider population on a theoretical basis; that is, they were selected according to how likely it was that their interviews would contribute to the development of meaningful and relevant information to the current study (Byrne 186-87).

\section{Designer and Visual Image Selection}

As a guideline for choosing the focal designers of this study, purposive sampling was used. While there was a stringent set of criteria for the selection of designers, purposive sampling is one in which the researcher uses personal judgment to determine if a certain item of a population best serves the purpose of the study (Barber \& Burt). Purposive sampling is especially useful when "you want to ... describe a phenomenon, or develop something about which only a little is known" (Kumar 179). As such, the selection of focal designers was guided by the following parameters:

- Their brand has significant North American presence.

- They are an identifiable key figure in the company and serve as a namesake for their fashion label.

- They appear in a mainstream magazine feature consisting of at least five distinct pictures of their home interior within the past three years (such images were used as visual material).

- They appear at least ten times in mainstream fashion magazines within the past three years.

- They have a branded flagship store in New York City.

The final selection of designers was Tory Burch, Ralph Lauren and Alexander Wang. Their homes appeared as follows: Tory Burch's Manhattan apartment appeared in an August 2009 issue of Elle USA; Ralph Lauren's Manhattan apartment appeared in a 
September 2010 issue of Elle Décor; Alexander Wang's Manhattan apartment appeared in a May 2011 issue of $W$ magazine. For the purpose of this study, digital versions of the images were taken from each magazine's website. Images that showed the designer in their home were digitally altered to blur their appearance. This was done so the interviewees were able to focus on the physical environment and their responses were not influenced by the owner's presence. As well, some images showed the designers, while others did not, so doing this created consistency among the visual material used.

Purposive sampling was also employed to select the images that were used to depict each company's New York flagship store. For the purpose of this study, images of each store were used in substitution for a direct experience. The images were selected based on the clarity, image resolution and context. It was important for each image to show as much of the interior of the store as possible, rather than being a detail shot. Further, the absence of customers was also a close consideration so that the informants were not influenced by their appearance.

Finally, a systematic selection procedure was conducted in order to maintain representational consistency across all images of the each brand's fashion products. This method was used in attempts to represent a designer's aesthetic style without having any selection bias. The following parameters were established in order to select six images for each designer:

- Each look is from the Fall 2011 (three images) and Spring 2012 (three images) Ready-to-Wear collections as shown at New York Fashion Week.

- Images of each look were selected from www.style.com (Style.com) - the first, middle and last looks from each show. 
TABLE 1.

Visual Stimuli - Designer's Store, Home and Collection

(See Appendix A for larger images)

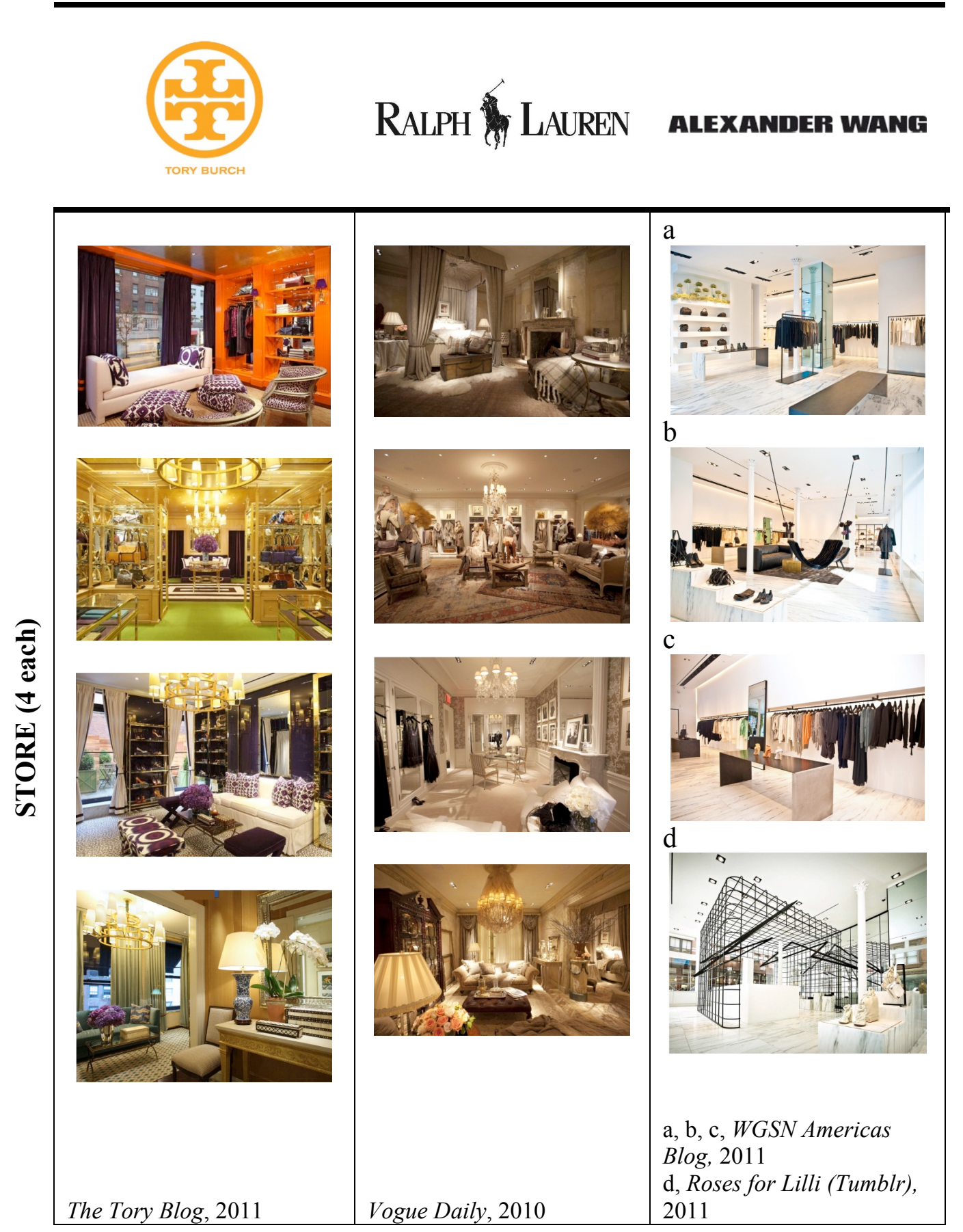


TABLE 1 (CONTINUED)

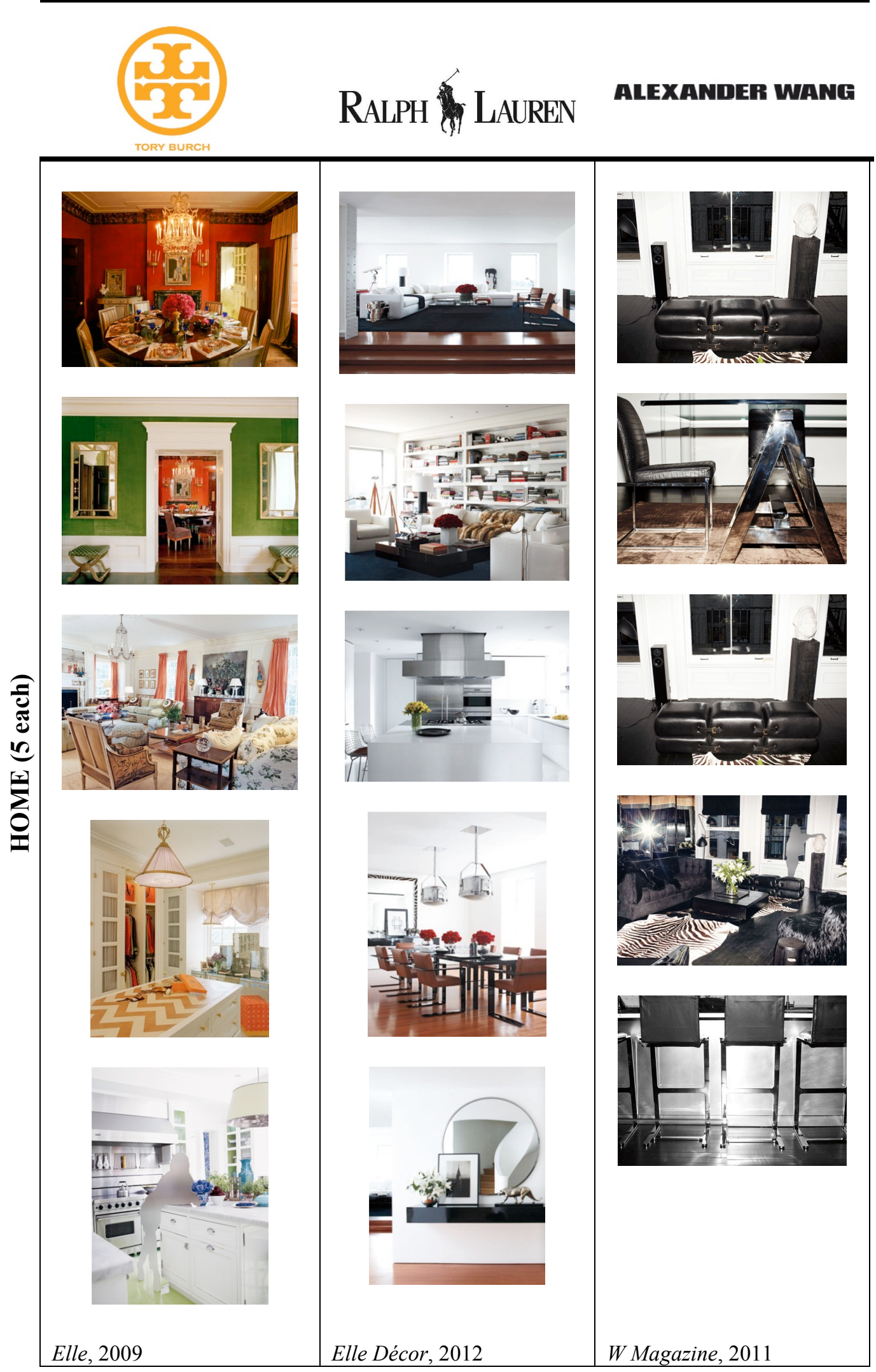




\section{RaLPH LaUReN alexander wanes}

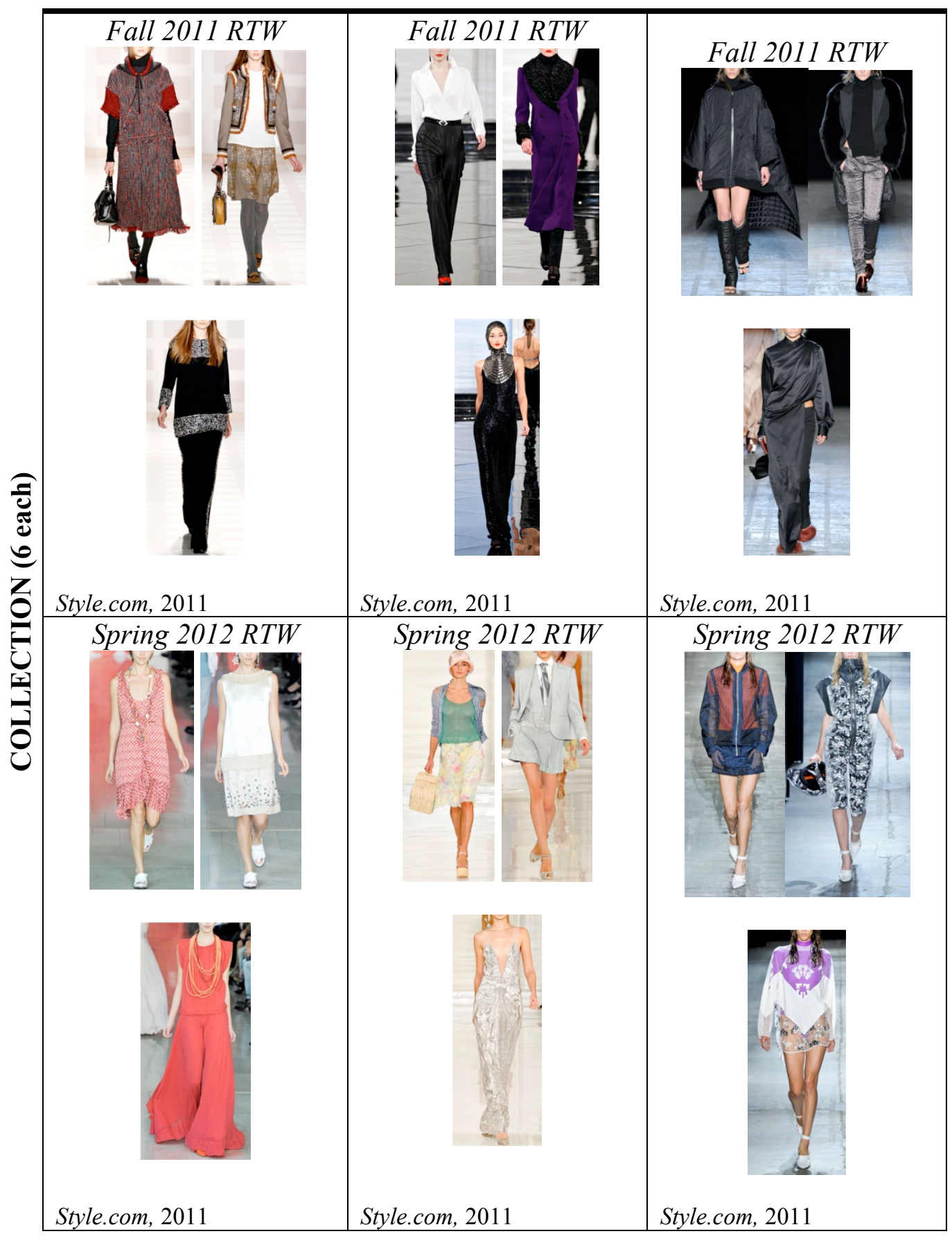




\section{Instruments}

The images of each fashion designer's home, flagship store and collection looks were carefully selected to serve as an integrated model for this study. It is imperative for the fashion practitioners and marketers to move beyond expert's (editor, photographer) interpretation in order to understand how people think (cognition), feel (emotion) and act (behavior). In total, six interviews were conducted to gain a deeper understanding of how viewers/consumers interpret and perceive those images. Various approaches and techniques were employed for cross-examination, and semi-structured interviews were used to inquire information related to their demographics/ psychographics, opinions/ values, and visual perceptions.

\section{Free Elicitation and Projective Techniques}

To fully understand each informant's perceptions and impression pertaining to the visual stimuli as well as their current knowledge structure about each brand, several procedures were undertaken. First, participants were asked to freely elicit any associations they may have with the brands in order to collect information from their first impression and perception. Free-elicitation method has been widely used in the field of marketing and consumer behavior. Olson and Muderrisoglu (7) define this method as "a procedure in which respondents are free to say anything and everything that comes to mind when presented with a stimulus probe cue." Following that, they were given a series of questions that asked them to project associations for the brand. Projective technique often used in marketing research to uncover consumer's inner perspective including feelings, beliefs, attitudes and motivation (Webb 125-126, Loudon \& Della 619). For example, they were asked, "When you think of Tory Burch, what type of animal does the brand 
represent?" Together these seemingly simple questions were used to shed light on each participant's basic associative network memory with respect to the three designer brands.

\section{Image Grouping}

Another instrument used was an image grouping exercise. Each participant was presented with all 45 images (without any description), in a random order. They were required to group all of the images of homes, stores, and collection looks into three groups based on designer association. For example, which images of the home, store and fashion products belong to each designer involved in the study? The purpose of this exercise was to illustrate how consumers make judgment based on visual cues, while engaging their existing knowledge structure of the brand concept.

\section{Data Collection}

During the interviews, data was collected through interview activities and openended questions as well as questions that probed for deeper descriptions. Interviews were digitally audio-recorded, which was then transcribed verbatim. A camera was also used to capture the process and results of each image grouping activity that took place in each interview. In addition, field notes of observations were taken whenever necessary during the interview.

\section{Procedure}

The interview consisted of four stages and comprised of a variety of techniques and questions allowed for a cohesive representation of participants' perceptions, inferences and associations.

Stage One: The interview began with screening questions that established whether and in what capacity the informant was familiar with the study's focal designers, and 
determined their propensity for reading fashion, interior design or lifestyle-themed magazines. This was followed by brief questions to gain demographic information, including age, occupation, and income.

Stage Two: Each informant was asked to discuss their perceptions toward each brand image. First, they were asked to freely elicit brand associations. Second, they were asked to engage in a projective technique, which allowed for a created means of eliciting brand associations. For Tory Burch, Ralph Lauren and Alexander Wang they were asked to name their associations based on what car, animal, colour, city, fabric, and activity or pastime came to mind when they thought of each brand.

Stage Three: The informant was then presented with all 45 images involved in the study - five images of each designer's Manhattan home, four images of each designer's New York City flagship store, and six looks from each designer's current fall and spring ready-to-wear collections. Participants were asked to group these images according to their guesses of which belonged to each brand/ designer. This exercise took around ten to fifteen minutes for each participant to complete. Their in-process comments were recorded using a digital audio device and photographs were taken during the sorting process as well as of their final groupings. Once completed, the researcher re-arranged the images into the correct groups and invited the informants to make comments. These supplementary recordings and pictures assisted in formulating results.

Stage Four: In-depth, semi-structured qualitative interview was used following the image grouping. First, the designer's home was looked at. Questions pertained to the viewers' reaction, assessment and inferences about the space and they were also asked, 
when possible, to note which elements may have lead them to those feelings. Similar questions were asked about each brand's flagship store interior and runway looks.

To conclude each interview the researcher asked a summative question about the experience. For example, participants were asked to reflect on how seeing a designer's home affected perceptions of them in connection with their fashion brand.

\section{Data Analysis}

In order to generate meaningful and significant results, interviews were transcribed and content analysis was employed for this study. Content analysis is a "systematic, replicable technique for compressing many words of text into fewer content categories" (Stemler 1) and allows for "making inferences by objectively and systematically identifying specific characteristics of messages" (quoted in Stemler 1). According to this definition, content analysis may be applied to areas beyond basic written text, such as photographs.

While quantitative research deals with processes that are deductive, objective and theory-testing, qualitative content analysis is appropriate for this study because it employs inductive, subjective and theme or theory-generating processes (McNabb). Qualitative content analysis aims at being structured and systematic, but still analytic by looking at the depth and breadth of the data being analyzed. In addition, four primary advantages of qualitative content analysis have been outlined: it is unobtrusive; it is context sensitive, which allows the researcher to process data that is significant, meaningful, informative and representational of others; it can cope with large and varied volumes of data; and it is unstructured, which preserves the conceptions of the data's sources (Krippendorff). Additionally, beyond doing a simple word-frequency count, qualitative content analysis 
allows for emergent findings that are nuanced, rich and meaningful. Particularly, it allows for categorizing of the data, which constitutes "a group of words with similar meaning or connotation" (quoted in Stemler 2) rather than frequency alone.

\section{Interview Coding}

A primary strategy behind qualitative content analysis is coding. The goal of coding is to take data and "rearrange them into categories that facilitate comparison between things in the same category and that aid in the development of theoretical concepts" (Maxwell 96). This research employed emergent coding conducted by two researchers. Following a preliminary examination of the data, a provisional checklist was outlined based on the interview transcripts and associated data as well as the research questions driving the study. Based on the transcripts, semantic scales and grouping commentary and observations, an initial checklist was devised in order to conduct the first stage of coding. Using In Vivo and descriptive codes the interview responses were analyzed using the following method (Saldaña 6):

- In correspondence with each picture, home, store, or collection being viewed, descriptive codes of concrete features (such as shape, pattern or colour) were recorded;

- These descriptors were then noted in correspondence with verbalized, expressive, abstract values (such as cold, harmonious, feminine, etc.);

- Finally, any implicative explanations were noted (such as, "It reminds me of someone who would like to have a dinner party").

A second stage of coding followed; it remained open to all possible directions while also aiming to develop meaningful answers to the research questions. For any 
answers or concepts that did not fit into the first coding structure this round allowed for an accounting of responses that were more affective (value and evaluative codes) and holistic (emotional, connective and assertive codes) in order to gauge the informants' experiences and perceptions (Saldaña 89-120). Consistently, In Vivo and descriptor codes were used.

Following this first round of interview analysis, the information was categorized based on patterns and significance. Patterns were categorized as showing similarity, difference, frequency, correspondence and causation (Saldaña 6). Ultimately, the outcome of this coding process was to identify significant patterns and themes. 


\section{CHAPTER 4 \\ RESULTS \& DISCUSSION}

The results portion of this study will address findings that emerged from qualitative content analysis of the six interviews conducted. As noted, the interviews were comprised of various instruments that, together, aided in the production of associative themes for each fashion designer's home, store and collection.

\section{Informants' Profiles, Brand Perceptions and Familiarity}

In total, six female informants participated in one-on-one, researcher-led interviews. All respondents reported that they were familiar, if not very familiar, with the study's central designers, with only one that cited an unfamiliarity with Alexander Wang (although she recognized the name). All respondents stated that they read and buy mainstream fashion magazines, such as Vogue, InStyle, Elle and Harpers Bazaar. Most informants also read mainstream interior-design magazines, with a variety of titles being reported. Four out of the six respondents also said that they gain information about fashion from online sources, such as magazine websites and blogs (see Table 2).

In order to establish a general idea about how the informants perceived each designer's brand image, they were asked to first freely elicit their top-of-mind brand association. They were then asked to respond to probed projective techniques, which allowed the researcher to understand expressive associations. 
TABLE 2.

Summary of Informant's Profile \& Preliminary Interview Questions

\begin{tabular}{|c|c|c|c|c|c|c|}
\hline Pseudonym & Age & Occupation & $\begin{array}{l}\text { Familiar } \\
\text { Designers }\end{array}$ & Familiarity & $\begin{array}{l}\text { Brand Image Associations; } \\
\text { car, animal, colour, city, } \\
\text { fabric, activity }\end{array}$ & $\begin{array}{l}\text { Interview } \\
\text { Duration }\end{array}$ \\
\hline \multirow[t]{2}{*}{ Mary Izen } & 39 & $\begin{array}{l}\text { Charity } \\
\text { employee }\end{array}$ & $\begin{array}{l}\text { Tory } \\
\text { Burch }\end{array}$ & $\begin{array}{l}\mathrm{TV} \text {, in magazines, } \\
\text { been to Las Vegas } \\
\text { store, purchased } \\
\text { products }\end{array}$ & $\begin{array}{l}\text { Buckles; hybrid, small urban } \\
\text { dog, pink, Nantucket, linen, } \\
\text { hanging out with family }\end{array}$ & $\begin{array}{l}1 \mathrm{Hr}, \\
16 \mathrm{Min}\end{array}$ \\
\hline & & & $\begin{array}{l}\text { Ralph } \\
\text { Lauren }\end{array}$ & $\begin{array}{l}\mathrm{TV} \text {, magazines, been } \\
\text { to a New York store, } \\
\text { purchased products }\end{array}$ & $\begin{array}{l}\text { Denim; } \\
\text { convertible/Mercedes, horse, } \\
\text { beige, New York, chambray, } \\
\text { polo/ lounging }\end{array}$ & \\
\hline \multirow[t]{3}{*}{ Beth Smith } & 28 & Architect & $\begin{array}{l}\text { Tory } \\
\text { Burch }\end{array}$ & $\begin{array}{l}\text { Magazines, fashion } \\
\text { week, media, blogs, } \\
\text { websites, been to Las } \\
\text { Vegas and Florida } \\
\text { stores }\end{array}$ & $\begin{array}{l}\text { Colourful, classic, feminine; } \\
\text { Mercedes SUV, cat, pink, } \\
\text { LA, silk, shopping }\end{array}$ & $58 \mathrm{Min}$ \\
\hline & & & $\begin{array}{l}\text { Ralph } \\
\text { Lauren }\end{array}$ & $\begin{array}{l}\text { Magazines, fashion } \\
\text { week, media, blogs, } \\
\text { websites, been to } \\
\text { Ralph Lauren and } \\
\text { Polo Ralph Lauren } \\
\text { stores }\end{array}$ & $\begin{array}{l}\text { All-American, preppy, } \\
\text { conservative; Mercedes } \\
\text { sedan, dog, blue, West Palm } \\
\text { Beach, linen, polo }\end{array}$ & \\
\hline & & & $\begin{array}{l}\text { Alexander } \\
\text { Wang }\end{array}$ & $\begin{array}{l}\text { Magazines, fashion } \\
\text { week, media, blogs, } \\
\text { websites, department } \\
\text { stores }\end{array}$ & $\begin{array}{l}\text { Structured, younger, edgy, } \\
\text { feminine; Range Rover, } \\
\text { snake, black, New York, } \\
\text { leather, silk, dining out }\end{array}$ & \\
\hline \multirow[t]{3}{*}{ Sarah Frank } & 23 & $\begin{array}{l}\text { Commercial } \\
\text { real estate } \\
\text { analyst }\end{array}$ & $\begin{array}{l}\text { Tory } \\
\text { Burch }\end{array}$ & $\begin{array}{l}\text { Owns a couple items, } \\
\text { reads about her, seen } \\
\text { products in } \\
\text { department stores }\end{array}$ & $\begin{array}{l}\text { Modern classic; BMW } \\
\text { convertible, parrot, hot pink, } \\
\text { LA, linen, shopping }\end{array}$ & $\begin{array}{l}1 \mathrm{Hr} \\
12 \mathrm{Min}\end{array}$ \\
\hline & & & $\begin{array}{l}\text { Ralph } \\
\text { Lauren }\end{array}$ & $\begin{array}{l}\text { Owns clothes, been in } \\
\text { a number of stores }\end{array}$ & $\begin{array}{l}\text { Classic; four door Mercedes, } \\
\text { spaniel (dog), navy blue, } \\
\text { South Hampton, tweed, } \\
\text { cotton, polo }\end{array}$ & \\
\hline & & & $\begin{array}{l}\text { Alexander } \\
\text { Wang }\end{array}$ & $\begin{array}{l}\text { Owns a few items, } \\
\text { reads about his } \\
\text { clothes }\end{array}$ & $\begin{array}{l}\text { Edgy; black Range Rover, } \\
\text { panther, black, New York, } \\
\text { leather, photography }\end{array}$ & \\
\hline
\end{tabular}


TABLE 2 (CONTINUED)

Summary of Informant's Profile \& Preliminary Interview Questions

\begin{tabular}{|c|c|c|c|c|c|c|}
\hline Pseudonym & Age & Occupation & $\begin{array}{l}\text { Familiar } \\
\text { Designers }\end{array}$ & Familiarity & $\begin{array}{l}\text { Brand Image } \\
\text { Associations; car, animal, } \\
\text { colour, city, fabric, } \\
\text { activity }\end{array}$ & $\begin{array}{l}\text { Interview } \\
\text { Duration }\end{array}$ \\
\hline \multirow[t]{3}{*}{$\begin{array}{l}\text { Jane } \\
\text { Edwards }\end{array}$} & \multirow[t]{3}{*}{24} & \multirow[t]{3}{*}{$\begin{array}{l}\text { Graduate } \\
\text { student/ } \\
\text { Fashion } \\
\text { store retail } \\
\text { associate }\end{array}$} & $\begin{array}{l}\text { Tory } \\
\text { Burch }\end{array}$ & $\begin{array}{l}\text { Studies in fashion } \\
\text { school, seen in stores, } \\
\text { magazines, magazine } \\
\& \text { industry websites, } \\
\text { blogs, }\end{array}$ & $\begin{array}{l}\text { Up-town, socialite; } \\
\text { Mercedes, small "frou-frou" } \\
\text { dog, orange, New York, } \\
\text { printed silk, walking small } \\
\text { dog }\end{array}$ & \multirow[t]{3}{*}{58 Min } \\
\hline & & & $\begin{array}{l}\text { Ralph } \\
\text { Lauren }\end{array}$ & $\begin{array}{l}\text { Studies in fashion } \\
\text { school, seen in stores, } \\
\text { magazines, magazine } \\
\& \text { industry websites, } \\
\text { blogs }\end{array}$ & $\begin{array}{l}\text { Classic, equestrian; Lexus, } \\
\text { horse, green, brown, New } \\
\text { York, plaid } \\
\text { Polo }\end{array}$ & \\
\hline & & & $\begin{array}{l}\text { Alexander } \\
\text { Wang }\end{array}$ & $\begin{array}{l}\text { Owns products, } \\
\text { studies in school, } \\
\text { stores, magazines, } \\
\text { magazine \& industry } \\
\text { websites, blogs, }\end{array}$ & $\begin{array}{l}\text { Downtown, edgy; Range } \\
\text { Rover, fox, black, New } \\
\text { York, leather, jersey, going } \\
\text { out to a bar }\end{array}$ & \\
\hline \multirow[t]{3}{*}{ Sally Hall } & \multirow[t]{3}{*}{23} & \multirow[t]{3}{*}{$\begin{array}{l}\text { Online } \\
\text { account } \\
\text { manager }\end{array}$} & $\begin{array}{l}\text { Tory } \\
\text { Burch }\end{array}$ & $\begin{array}{l}\text { More familiar', been to } \\
\text { store in Florida, } \\
\text { magazines, company } \\
\text { website }\end{array}$ & $\begin{array}{l}\text { Feminine, patterns - fun but } \\
\text { still classic; white Land } \\
\text { Rover, cat, orange, LA, } \\
\text { silk, shopping }\end{array}$ & \multirow[t]{3}{*}{$\begin{array}{l}1 \mathrm{Hr} \\
7 \mathrm{Min}\end{array}$} \\
\hline & & & $\begin{array}{l}\text { Ralph } \\
\text { Lauren }\end{array}$ & $\begin{array}{l}\text { More familiar', been to } \\
\text { store in Florida, } \\
\text { magazines, company } \\
\text { website }\end{array}$ & $\begin{array}{l}\text { Conservative, classic, all- } \\
\text { American; Lexus, dog, } \\
\text { navy, New York, cotton } \\
\text { tennis, golf }\end{array}$ & \\
\hline & & & $\begin{array}{l}\text { Alexander } \\
\text { Wang }\end{array}$ & $\begin{array}{l}\text { Less familiar', } \\
\text { magazines }\end{array}$ & $\begin{array}{l}\text { Edgy, high-fashion, New } \\
\text { York models; Black } \\
\text { Mercedes G500, zebra, } \\
\text { black, New York, silk, } \\
\text { going to museums or art } \\
\text { galleries }\end{array}$ & \\
\hline \multirow[t]{3}{*}{ Laura Lee } & \multirow[t]{3}{*}{38} & \multirow[t]{3}{*}{$\begin{array}{l}\text { Part-time } \\
\text { nurse }\end{array}$} & $\begin{array}{l}\text { Tory } \\
\text { Burch }\end{array}$ & $\begin{array}{l}\text { Notices more } \\
\text { handbags and } \\
\text { accessories, magazines }\end{array}$ & $\begin{array}{l}\text { Structured, eclectic with } \\
\text { patterns and textures, } \\
\text { feminine, younger style, } \\
\text { city chic; Mercedes } \\
\text { convertible, saluki dog, } \\
\text { orange, New York, silk, } \\
\text { shopping }\end{array}$ & \multirow[t]{3}{*}{$\begin{array}{l}1 \mathrm{Hr}, 12 \\
\text { Min }\end{array}$} \\
\hline & & & $\begin{array}{l}\text { Ralph } \\
\text { Lauren }\end{array}$ & $\begin{array}{l}\text { Been to store in Aspen } \\
\text { and Chicago, drawn to } \\
\text { RL section in stores, } \\
\text { owns clothes }\end{array}$ & $\begin{array}{l}\text { Classic, outdoor style, } \\
\text { natural, cowboy hats; } \\
\text { Range Rover, horse, brown, } \\
\text { Aspen, Denim, riding } \\
\text { horses on the ranch }\end{array}$ & \\
\hline & & & $\begin{array}{l}\text { Alexander } \\
\text { Wang }\end{array}$ & Magazines & $\begin{array}{l}\text { Runway, edgy, dark- } \\
\text { downtown, not accessible; } \\
\text { Porsche, panther, black, } \\
\text { downtown New York, } \\
\text { leather, nightlife }\end{array}$ & \\
\hline
\end{tabular}




\section{Empirical Analysis and Results}

\section{Image Grouping Exercise}

In each interview, the informants were asked to take part in an image-grouping exercise based on their knowledge of each designer, and the visual cues of each picture. Their instructions were to arrange all 45 images involved in the study into three groups based on their judgment of which Manhattan home interior, flagship store interior and ready-to-wear collection appeared to them to belong to Tory Burch, Ralph Lauren or Alexander Wang. (See Appendix B for a complete list of image-grouping results).

It took between 12 and 19 minutes for each interviewee to complete the exercise. Each noted that the task was more difficult than expected (without explicit knowledge of which designer went with which space). Interestingly, only one person [Beth Smith] grouped the designers' home images and store images correctly, while only one other person [Jane Edwards] grouped the collection images correctly. Further, most participants did not follow the stated guideline of there being five home images and four store images; for many final groupings, there were either too many or too few images. For example, one participant grouped seven images together for Alexander Wang's home (four correct, three incorrect). Aside from the single person that was correct, all participants grouped zero correct home interior pictures for Ralph Lauren. Half of the participants grouped four or more correct home interior pictures for Tory Burch. Five participants grouped all home interiors for Alexander Wang correctly.

The most confusion arose between Tory Burch's and Ralph Lauren's home and store images. Many participants incorrectly attributed Tory Burch's home images to Ralph 
Lauren, while the images of Ralph Lauren's home were generally incorrectly perceived and extrapolated as belonging to Tory Burch or Alexander Wang. The reasoning for these grouping decisions was that a) Tory Burch's more traditional looking residence was congruent with a more traditional, classic image that they perceived as Ralph Lauren, and b) Ralph Lauren's more contemporary residence either did not fit with the participants' perceived image of Ralph Lauren, or it did fit with the participants' image of Tory Burch or Alexander Wang. Additionally, four respondents identified two images of Ralph Lauren's store as his home. The general reasoning for this was 1) that the design and style of the space fit with their idea of Ralph Lauren's image, and 2) there was no visible merchandise to signal that it was a retail space. This rationale also resulted in most respondents only grouping two Ralph Lauren retail spaces correctly. With respect to the other designers' flagship stores, every participant grouped three or more correctly for Alexander Wang, and five grouped three or more correctly for Tory Burch.

For each designer's collections, respondents showed no clear pattern or explicit reasoning for making correct or incorrect grouping decisions. While only one respondent accurately grouped all six runway looks, the majority of informants were able to accurately group three or more looks.

When discussing the rationale for making image-grouping decisions, respondents generally said they had relied on what they already perceived about the designers' image and brand image. They also used perceived visual similarities between images to reason through the inclusion or exclusion of a picture from any group. Aside from the above explanations many also noted that some images ended up in certain groups by process of elimination, which is seen to be indicative of the study methodology. 
While the majority of informants' groupings were incorrect, once the researcher re-arranged the images, the respondents showed no difficulty discussing each category as it pertained to each individual designer.

\section{Interview Findings}

When asked to discuss images of each fashion designer's home, store and collections, participants were able to describe physical design elements that they noticed, expressive abstract values that they perceived from looking at the images, and ultimately, the cognitive implications that developed from being exposed to the visual stimuli.

Based on the image, a number of themes emerged for each designer.

\section{Tory Burch}

Based on the images that the informants were shown of Tory Burch's Manhattan apartment [see Appendix A-1], many said they found it to be a space that was "super" traditional in its design aesthetic. However, respondents also noted that, while the holistic impression was traditional, there were details that had a more contemporary flair. The deep saturated colours, such as red, green, and orange on expansive surfaces, such as walls and curtains, were said to be formal elements. Additionally, the decidedly traditional shape of the furniture, specifically in the dining room [A-1: Fig. b] and the overstuffed seating in the living room [A-1: Fig. d], formal arrangement of furniture, use of rooms, floral and brocade patterns, and indulgent use of fabric and upholstered furniture contributed to this atmosphere. Hints of modernity entered the space through the use of graphic prints and airier colours. The informants also said that Tory Burch's domestic environment felt like a family home that belonged to an up-town socialite who enjoyed entertaining and having dinner parties. They said that the highly functional kitchen [A-1: 
Fig. a], with professional appliances, large work surfaces and personal accessories, as well as the inviting dining area, with a traditional round dining table, conjure up an idea of close gatherings. Additionally, informants said that the ample seating in the living room allowed for comfortable social gatherings. It was also noted that there was an emotional energy to the space, which was attributed to the layers of texture, warm colours, plush furniture, and personal collections of seemingly treasured items.

Based on the images that the informants were shown of Tory Burch's New York flagship store [see Appendix A-2], all said that they found it to be a luxurious and feminine space. The way each room differed slightly in design from the others, the perception that there were areas dedicated to different activities, the presence of upholstered seating clusters and unconventional retail furniture, evoked a highly residential feel to this environment. The personality of the store was said to be fun, yet sophisticated, which was echoed in the description of the design style as a mix of traditional and contemporary. While elements such as the furniture style, heavy drapery, golden glow and indulgent molding present a traditional aesthetic, the playful mix of bold prints and bright colours created a youthful feel. As one informant said, "The space is contemporary, not in a way where there are straight lines and hard edges. It is a modern take on traditional design, where new ideas are paired with traditional, formal design" (Laura). Specific design elements noted to be contemporary were the deep purple ikatpatterned pillows and benches, the leopard carpet and chair, and the brave application of bright orange lacquer on the walls [A-2: Fig. a, c]. One informant described the retail space as a "jewel box ... each room is its own little shop. And the display case and the lighting make me imagine a jewel box. It's glowing. It's great, it makes everything look 
more important and gives place of prominence to each thing that is placed on the shelf' (Mary).

In terms of the fashion that Tory Burch produced for recent ready-to-wear runway shows [see Appendix A-3], informants said that they imagined the wearer to be young and fun, yet desirous of projecting a preppy, sophisticated image. The silhouettes of both the Fall 2011 and Spring 2012 garments were said to be classic. Specifically, the summer dress [A-3: Fig d], evening dress [A-3: Fig. e], tunic [A-3: Fig. c] and shrunken jacket [A3: Fig. b] referenced tried-and-true shapes. Modern elements, such as glittery surface embellishment, flirty patterns and warm bright colours injected a youthful appeal to what might otherwise have been mature outfits.

\section{Ralph Lauren}

Based on the images that the informants were shown of Ralph Lauren's Manhattan apartment [see Appendix A-4], many expressed that they found it to be very contemporary, with certain elements referencing a mid-century modern design aesthetic. Further, it was felt to be very clean, organized, and rational, which created a powerful, masculine, yet sleek impression. Most informants interpreted the space based on holistic elements. The colour palette, dominated by white (architectural elements and major furniture pieces) and anchored with black (carpets, tables, and small fixtures) was accented with pops of warm tones (the rich brown of the floor and red of the flowers and books). It felt airy because of the high ceilings and abundance of bright, natural light. Informants said that these elements created a harmonious appeal and a contemporary, rational and sleek-looking space. Such an atmosphere was also enhanced by the shape of the furniture and major fixtures such as the large sectional couch [A-4: Fig. d], kitchen 
cabinets and counter [A-4: Fig. b], shelving [A-4: Fig. c] and the dining-room furniture [A-4: Fig. a]. These details all follow a very linear plane: everything was said to be either on a horizontal or vertical plane, with crisp edges and geometric shapes. This minimal space was also perceived as more on the masculine side, because of the perceptions that it was very clean, lacked a lot of personality or cues about the inhabitant (except for some decorative artifacts such as the telescopes), and had heavy elements and hard lines.

Based on the images that the informants were shown of Ralph Lauren's New York flagship store [see Appendix A-5], all expressed that they found it to be overwhelmingly traditional in its design aesthetic. The whole store represented a residential space with rooms that resembled common areas found in a home. There was minimal merchandise, with only two images showing any noticeable products. Because of this, the informants said they found a consistent and well-defined lifestyle associated with the store - be it that of the imagined shopper, or that of the imagined inhabitant if it were a home. To the informants, the space evoked the image of a country home that had historic and old-world appeal. While one room in particular [A-5: Fig. a] conjured the idea of a grand hunting lodge with its natural materials (wood, cotton and leather) and muddy tones, the remainder of the store induced the idea of an upper-class "WASP-y" family that belonged in the world of all-American aristocracy. Informants said that the space seemed both preppy and opulent with an overall, feminine, mature, warm, romantic and somewhat stuffy feeling. These cohesive inferences were based on a number of concrete factors. The warm neutral colour palette that flowed harmoniously through the store, and the abundant use of fabric and plush upholstery, produced a holistic style. Informants also said that each space was very full of furniture, details and texture that had traditional shapes and patterns (floral, 
brocade). Specific design elements that contributed to the abstract values noted by the interview participants included the wainscoting and other architectural molding, wall paper, abundance of crystal chandeliers with delicate lampshades, fireplaces [A-5: Fig. c, d], a canopy bed [A-5: Fig. c], china cabinet and fresh roses [A-5: Fig. b]. Certain merchandise such as leather boots, hound's-tooth sport coats and leather satchels were said to evoke impressions of a rugged, sporty lifestyle. Specific design elements such as the natural wood, plaid chairs and worn, overlapping carpets painted an outdoorsy yet sophisticated idea of a country cottage [A-5: Fig. a].

In terms of the fashion that Ralph Lauren produced, informants were asked to discuss looks from his Fall 2011 and Spring 2012 ready-to-wear runway shows [see Appendix A-6]. A clear sentiment expressed by interviewees was that the clothes had a classic aesthetic with preppy and sophisticated connotations. Overall, the clothing and accessories had clean lines and simple, wearable silhouettes. The spring outfits, with the soft colours, floral pattern and natural fibers evoke femininity and whimsy. The fall outfits, with the structured, crisp lines and deep colours evoke elegance, maturity and dominance.

Alexander Wang

Based on the images that the informants were shown of Alexander Wang's Manhattan apartment [see Appendix A-7], many expressed that they found it to be masculine, urban, edgy and indulgent. They said that his home conjured up a hip, rockand-roll lifestyle full of partying and late nights. The blatant display of electronics (TV and speakers) and original art (statue) [A-7: Fig a, d] created a space that was perceived to be extravagant, vain, creative and immature. Informants said that the overall design 
aesthetic was decidedly contemporary based on the experimental mix of hard and soft elements. The modern chrome and glass of pieces, such as tables and chair bases, coupled with the abundant use of animal skins, furs and hides in pieces such as the crocodile dining chair, zebra rug, fur blanket and shaggy living room chair, created a very distinct space. Additionally, informants said that the lack of colour, dark look and high contrast between the overall black-and-white elements created a cold and uncomfortable feeling. Many felt it was clearly an adult space that was not suitable for children or a family; however, it was not perceived as being mature, homey or welcoming.

Based on the images that the informants were shown of Alexander Wang's New York flagship store [see Appendix A-8], most felt that it was a successful retail environment and that it was more inviting than his home. The overall aesthetic was said to be industrial and modern. The "stepped, geometric" display cases, sharp edges, and clean, hard surfaces created an angular appeal. Informants said that the space felt edgy and cool, and it conjured a creative, alternative, fashionable and indulgent lifestyle. The materials used for the more permanent elements in the space, such as the large-format white slabs of marble on the floor, the "hand-crafted" stainless steel display tables, the bright white walls, high ceilings and restored Corinthian columns evoked a modest yet luxuriously designed retail environment. These expensive and classic materials were said to be defiantly contrasted by the presence of unique and extravagant pieces such as a fur swing suspended from the ceiling by heavy black chains [A-8: Fig. a], and a large cage-like installation [A-8: Fig d]. These elements "add a pop of edginess. It's a little cheeky in such an obviously expensive space to throw up a hammock and a cage, which seems so... I don't know, artistic, and more creative" (Sarah). 
Informants said that they imagined the fashion that Alexander Wang produces [see Appendix A-9] to be worn by a confident, youthful, cool and edgy woman. She was perceived to be skinny and rich, with a rock-and-roll persona. The perceived wearer was described by one informant as an "edgy and cool New Yorker that lives a fast-paced, stylish lifestyle ... I see her wearing it day-to-night: to work and then to drinks after work" (Beth). While informants acknowledged that the fashion was designed for a female wearer, they felt the appearance was decidedly masculine and androgynous. For both collections, the designs were said to be unique, contemporary and had hard edges. The Fall 2011 apparel was said to be dominated by the colour black and the use of luxurious materials such as silk and fur. Informants said that the Spring 2012 looks had a sportswear influence, but were deemed largely un-wearable, which was based on the garments' unflattering and "different" silhouettes and patterns. Overall, it was agreed that the execution of the design and details was thoughtful and impressive.

\section{Discussion}

When asked to discuss reactions, perceptions and subsequent associations produced when looking at images of either a fashion designer's Manhattan home (as shown in a magazine), flagship store and recent ready-to-wear fashion collections, respondents felt they could identify a number of implications. The inferences varied among designers; however, a number of themes emerged.

\section{Visual Elements Provoke a Perceived Lifestyle}

Whether it was based on the designer's home, their brand's store, or looks from their most recent runway collections, it was clear that informants were able to develop and articulate a conceivable persona, lifestyle, or social scenario. Depending on the image 
category, these mental pictures were attributed to the homeowner, shopper, wearer, or eponymous designer. While certain distinct elements, such as a chair or a colour, were frequently said to be the reason for such a conclusion, the specific element in context with the rest of the room, style or whole environment was more likely the true reason.

Perceiving a lifestyle was a reasonable inference to make when viewing a designer's home, store, or product. These sites served as stages for a "performance" by individuals in which they were able to communicate their social characteristics to others (Goffman 1). For the viewer, there were many sources of information and many agents became available for conveying that information. Further, products or possessions served as "props" for the expression of one's self-image (Holbrook, Solomon and Bell 6).

Because of this psychology, viewers were able to view, interpret and make conclusions about a designer's self-image by looking at pictures of clothes and furniture that were intrinsically connected to the designer.

In the case of Tory Burch, interview informants that viewed images of her home imagined the inhabitant was a socialite who enjoyed spending time with her family, decorating and entertaining friends. Interviewees said: "[She] likes having guests over and likes sharing her personality through her space" (Beth); "It definitely seems like this person is interested in decorating, since there are a lot of decorative features, and it looks like a lot of thought went into to making sure all the patterns work well together" (Sarah); "[She] likes entertaining ... [her home] seems very on show" (Laura); "It really seems like the type of space that she's having people over to fabulous parties... with people that use the word 'fabulous' a lot" (Beth). The persona perceived when viewing the Tory Burch store was "a younger, fun, flirty girl in her twenties or thirties. [The store is] sophisticated 
and opulent, but still playful. It's not oppressive, and I don't feel like a young woman would feel out of place in this setting" (Jane). On the basis of the Tory Burch fashion collections, interviewees imagined the wearer was "feminine and very girly. She would want to live the classic, traditional lifestyle of settling down with a guy, getting married and having babies" (Jane). She was also seen to be "a woman who jet-sets for parties in exclusive places like West Palm Beach or the Hamptons, and likes entertaining and going to parties" (Beth).

In the case of Ralph Lauren, it was interesting that while informants were able to imagine a lifestyle when viewing images of his home, there was little consistency in what was perceived. One informant said that she assumed the person that lived there "was a woman who's well educated, who maybe works from home or, has clients, like a personal one-on-one business - someone who spends a lot of time in the home without being, a housewife" (Beth). Another interesting sentiment was that the home actually didn't look like anyone lived there: "It looks like this is someone's pied à terre ... like his city home"(Sarah). This feeling was echoed by other informants who said that "It looks like it's unlived in, like a show-room"(Sally), and "The extreme cleanliness and emptiness of the kitchen makes the home seem un-lived in" (Mary). On the other hand, when looking at images of the Ralph Lauren flagship store, informants were able to identify a clear persona: "A country house lifestyle with ponies and dogs and kids running around in their tweed jackets" (Mary); “A carefree, sporty, country lifestyle ... you could go in there with your boots on and throw your coat on the ground like a hunting lodge or cottage" (Sarah); "Someone that has a romantic side and they like the outdoors. If this is a reflection of their city home, then they go to the country on the weekends. They might go up to cottages, or 
the Hamptons... but they like luxuries, it wouldn't be a log cabin, it would be a luxurious seaside home ... [owned by] an older, more established person because it looks quite rich and sophisticated" (Laura). Based on the images of Ralph Lauren's fashion collections, informants imagined the wearer to be, what Sarah verbalized as "a wealthy, polished and put-together woman who appreciates beautiful clothes. She's busy, but not necessarily with a busy career. Her days are filled with various activities and nights are filled with social engagements" (Sarah).

In the case of Alexander Wang, interviewees viewing images of his home were able to attribute an image of a cool, urban guy that lived an edgy, rock-and-roll lifestyle. One informant said, "I could picture people, like partying and doing drugs in this living room" (Sally). Another noted, "The fact that these meticulously thrown carpets, the fact that none of the furniture matches - it just goes - it just reminds me of a place where musicians hangout ... and I guess for successful musicians, I see them as being able to afford, you know, such expensive things, but they do it in a little bit of a nonchalant way" (Jane).

The persona respondents perceived when viewing the Alexander Wang store was “a guy or a girl that's super into fashion; definitely edgier, like not a lot of femininity in there except for maybe the more ornate columns" (Sarah); "[They are] forward-thinking, modern, edgy" (Jane) and "slightly alternative" (Sarah). Based on the images of Alexander Wang's fashion collections, the wearer was imagined to be a confident, individualistic person who was not concerned with following mainstream trends. Informants said that a person who chose to wear these unusual, edgy pieces, didn't care what others thought of their style. 
This research interpretation strongly suggest that, based on visual cues, viewers were able to cognitively construct an associative lifestyle to the designer's home, their brand's flagship store, and the fashions that they produce. While the home and fashion products were clear examples of "props" that served as the expression of a self-image, it can be argued that the flagship store environment was visually "read" in the same way. The store atmosphere, and more specifically "store design factors," including functional and aesthetic design aspects such as layout, style and colour, were the most important factors in eliciting a brand personality or image for customers (Brengman and Willems 348).

\section{The Designer's Home in Connection with Their Brand Image}

When viewing images of a fashion designer's home, the study informants were able to make visual and cognitive connections between the domestic environment and the designer's brand image. Through the analysis process, respondent-perceived brand image for all three fashion designers was established based on 1) the initial brand-image elicitation and association exercise 2) the lifestyle, impression and abstract values that were attributed verbally by the interviewees to the fashion-collection looks and the brand's flagship store. This allowed the researcher to understand the associative network of memory nodes that the participants held for each fashion brand. The question therefore remained, "How did seeing the designer's home fit into or influence the collective network of established brand knowledge that each viewer held in their mind?"

\section{Concrete Visual Elements}

When looking at the images involved in the study, all participants discussed concrete visual elements that they noticed. Additionally, based on their existing network 
of information for each designer, they were able to extract certain features (detailed and holistic) that were deemed to "fit" with their perception of each designer's aesthetic style and brand image. They were also able to verbalize aspects of certain spaces that they felt did not "fit" with their perception of each designer's aesthetic style and brand image.

Study participants found Tory Burch and Alexander Wang's home, store and designs to be aesthetically consistent with its designer. For example, Tory Burch's home was seen to be in harmony with her store and fashions through the use and mixture of bold colours and graphic patterns. Additionally, the study participants agreed that Burch is known for mixing traditional shapes with contemporary details and embellishments. In her home, Jane said that "Reds, oranges, and creams is a colour palette that she usually uses,"; Beth said "The graphic chevron, mixed with other patterns, along with the mix of traditional and contemporary elements creates a visual consistency between her brand and personal style." Her store was seen to be "very much like her home - the interweaving of traditional bones and contemporary elements"(Sally), and was "similar in feel to her home with the eclectic mix and match of patterns and colours" (Laura). Again, in her collection, Sarah said, "there are certain outfits that I identify with the Tory Burch brand [because of the] feminine details and bright, warm colours."

Informants saw Alexander Wang's home to be in harmony with his store and fashions through the heavy use of black, creative experimentation with luxurious materials and textures, as well as the presence of contemporary and alternative shapes. When looking at his home, the informants "expect the darkness, ruggedness and the contemporary, hard-edges with minor feminine details" (Sarah, Jane). His flagship store was perceived to be "the same idea as his house - bare with high contrast between black 
and white" (Laura). Informants also said that there was consistent "experimentation with hard and soft materials, [which follow] the same style as his home and fashion" (Beth). When discussing looks from his runway collections, informants identified elements that were seen to be indicative of Alexander Wang designs: "The black and metallic of the fall clothes ... is very Alexander Wang" (Sarah); and, "[There is a] correlation between the materials that he is drawn to when decorating his home and the materials he uses in his fall collection - fur" (Jane).

Study informants found Ralph Lauren's home, store and fashion designs to be aesthetically inconsistent with one another. His home was said to be clean, crisp and contemporary, which was noted to have some consistencies with his fashion collections. However, his store was said to be rich, warm, densely filled and undoubtedly a traditional country home. "His home has much more of an industrial feel than I would expect ... Ralph Lauren just embodies preppiness, and there's no element of preppiness [in his home]" (Sarah). His home was also said to be "visually inconsistent with the style of the Ralph Lauren flagship store" (Beth), and "different from what I think of his clothes" (Laura). Informants said that the "store is just so obviously Ralph Lauren" (Jane), and was “definitely more how I would have imagined [his] home. It seems more historic and traditional” (Jane). When observing looks from Ralph Lauren's runway collections, certain stylistic elements were said to be indicative of his design aesthetic: "classic daywear looks" (Sally), "tailoring ... and putting a woman in a suit" (Mary, Jane).

\section{Abstract Cognitive Associations}

As previously discussed, study informants were able to mentally construct descriptive lifestyles, to imagine social scenarios and to attribute expressive values when 
looking at images of the homes, stores and collections of Tory Burch, Ralph Lauren and Alexander Wang. For Tory Burch and Alexander Wang, the separate lifestyles that were verbalized and attributed to each space shared many similarities for each designer respectively. The study informants inferred the lifestyle connected to Tory Burch's home, store and clothes to be a feminine woman who was fun yet sophisticated. She enjoyed spending time with her family and entertaining guests. She was often described as a socialite, who liked the art of design and "beautiful things". In the case of Alexander Wang, the study participants inferred a lifestyle connected to his home, store and collections to be an edgy, confident and dominating person who was part of a fast-paced downtown New York City lifestyle. The wearer of his fashion designs and shopper of his store was said to be a woman who was drawn to luxurious materials such as silk and fur, but they were generally in dark colours and part of modern and alternative designs. On the other hand, for Ralph Lauren, the separate lifestyles that were conjured by each space did not share many similarities and were even seen to be opposing. When looking at images of his home, participants actually found it difficult to envision the image of the inhabitant. Those who were able to express a lifestyle noted that the apartment was lived in by a successful woman who worked from home. Otherwise, informants felt that it wasn't a primary residence. The Ralph Lauren flagship store had the study informants connecting the look and feel of the store to a preppy and traditionally rooted family of American aristocracy. It was imagined that the store could be their country home where they engaged in leisure and sporting activities such as riding horses, playing with dogs and hunting - all done with an air of luxury. Ralph Lauren's fashion collections conjured the image of a successful polished woman who lived in a more urban environment. 


\section{Consistency}

For Tory Burch and Alexander Wang, the consensus of the study was that there were clear visual and mental congruities between each designer's home and their store and fashion collections. Additionally, participants expressed that beyond the visual stimuli presented during the study, Tory Burch and Alexander Wang's home interiors were congruent with what the interviewees perceived their brand image to represent. The sentiment of all study participants was that seeing Tory Burch and Alexander Wang's home interiors strengthened each designer's brand image. For Tory Burch, it was said that "It's one design applied to a residential setting, a commercial setting, and a fashion collection" (Beth). Seeing her home "strengthens her brand image because everything is so consistent. You're seeing that she's doing what she loves, and her influence affects everything she touches - she's living within a consistent realm" (Jane). Laura echoed the same opinion, stating, "I think that her home and her store and her clothes are all similar. I think that she likes a lot of different contrasts of textures and colours ... I think she very much lives the image of her brand... she certainly has a direction." Many of the above responses were directed the consistency between Alexander Wang's home, store and fashion as well. Further, Sarah said that Alexander Wang's "home is so indicative of his image and design direction. It reinforces my idea of him because it makes him seem even more authentic - he's living the same image that he's designing for. I could definitely see the same type of person that would hangout in his black living room would be wearing his clothes." Sally concluded her discussion on the designer by saying: "Seeing Alexander Wang's home influenced my perception about his brand. I probably knew the least about him (versus the other designers in the study), but seeing his home, and it having the same 
feeling as his store, I now see him as more creative ... It's definitely a clear style and image."

For Ralph Lauren, there was more confusion about a definite image, but the consensus of the study was that there were visual and mental incongruities between the designer's home and his store and fashion collections. Additionally, informants expressed that beyond the visual stimuli of his store and collections presented during the study, Ralph Lauren's home interior was incongruent with what they perceived his brand image to represent. There were two sentiments that were expressed by the study's interview participants. The first was that seeing Ralph Lauren's Manhattan apartment was surprising, disappointing and even confusing in relation to their idea of the designer's image. For example, Mary said that seeing Ralph Lauren's home "is disappointing ... and it's contradicting what I think of him." Beth echoed this perspective by say that "Seeing the design of his home and the design of his store actually makes me confused about the brand. If he went out of business I wouldn't be surprised. It seems like I'm looking at four different designs from people with different taste. And because I don't see a connection, and there's a lack of connection within the fashion line, it doesn't enhance anything, it weakens it." Sarah felt that she was the most familiar with the Ralph Lauren brand because she's been aware of it the longest, but she said that seeing his home "kind of negatively affected my idea of the brand because it contradicts my idea of who he is and who his clothes are for."

The second sentiment that other informants expressed when seeing Ralph Lauren's home was that it was interesting and lead them to focus more on his runway collection rather than his sporty, mass-market products. "Ralph Lauren's home is a lot more 
contemporary than I picture his brand to be. His home is fairly different from what I think of his clothing line; but it doesn't feel disconnected, it perhaps adds another dimension [to what I think of his brand]" (Laura). Sally was "surprised by the way Ralph Lauren's home looked, which added to the importance of his more runway, couture, evening wear - sleek and very elegant, less preppy and sporty." Further, Jane points out that, "Yes. I might have been surprised by some things, but if I think about seeing that article in a magazine and being told, 'that it's Ralph Lauren's home' ... I think it's interesting to see a side I didn't expect, and I think it made me focus on his more runway, couture designs."

It is apparent that for the informants in this study, seeing the homes of Tory Burch and Alexander Wang reinforced their idea of each designer's brand. Seeing Ralph Lauren's home either weakened their idea of the designer's brand image or diluted it by focusing the participants' attention on the designer's high-fashion designs when their previously held conception of the Ralph Lauren brand had related to his sports-wear. Because each participant in the study has had a number of previous encounters (direct and indirect) with each brand, they were able to conceptualize each brand's image in her mind. Such a perspective on how brand image is formed is the information-based conception of brand meaning (Allen, Fournier and Miller 784). Through this approach, associative models focus on a knowledge structure of brand-relevant information that exists in the mind of consumers (Batey 4; Keller 64), which can be understood through the "associative network memory model." Brand associations are nodes of information that are perceived and stored in the brain, based on stimuli from any and every encounter that a consumer may have with the brand. For a given brand, new input data adds to the associative network that already exists in the brain, which has been collected from previous 
experience or encounters (Batey 7; Keller 64). The results and analysis of this study suggest that when there is congruence, both visual and cognitive, between the existing information held in the mind of the consumer and the new stimuli (through images of the designer's home), brand image is reinforced. When there is incongruence, brand image is confused and potentially weakened. According to Lindstrom, the more elements a consumer can recognize and relate to a brand, the more effective a brand will be in resonating a clear concept. Further, consistency is vital to building a brand through brand communication. It builds familiarity, reliability and in the end, renders a brand trustworthy (Lindstrom 153).

These observations of this study were thought-provoking for the researcher because all six were quite strong in their opinions. While some seemed outraged, the others were more forgiving. All perspectives provided support for interesting recommendations, which will be discussed further in the paper.

\section{Art Direction of the Magazine Images}

The research participants were clearly able to generate meaningful perceptions, inferences and associations based on the various images presented to them. While they largely relied on concrete design elements coupled with their existing memory network of information about each brand, when looking at images of designers' homes there were additional observable elements that did not relate to aspects of the interior design. This information is important to the study because it still influenced how the informants perceived each designer's image. These elements were categorized as "styling," and "photography" and are acknowledged as decisions made to prepare each room to be ready for an appearance in a magazine 
Mention of a stylist intervening on the natural condition of a designer's home environment arose when interview informants specifically noticed the cleanliness of the space and the presence of flowers. Although seemingly trivial, these elements contributed to the way viewers understood the context of the image, and showed how innumerable components work together to produce information about the inhabitant. According to Rogoff, this is reasonable because every element related to visual culture is "read on to and through one another, lending ever-accruing layers of meanings and of subjective responses" (24). Specific examples arose most frequently when respondents were asked to discuss Ralph Lauren and Tory Burch's homes. With respect to Ralph Lauren's home, Mary did not like it. She felt that it was cold, and had a hard time believing anyone lived there: "It's obviously very clean for a photo shoot ... But this kitchen is too empty. If I was looking at this to get an idea of Ralph Lauren ... I'm not getting it." Sally echoed this remark by noting, "It almost looks too clean, like someone doesn't live there - like there aren't any personal touches. Maybe that's just for the shoot, but it isn't comforting." Interestingly, many informants also verbalized inferences about the homeowner based on the flowers present in the pictures. For Ralph Lauren's home, Sarah imagined that a woman inhabited the space because "There's a lot of flowers... which generally seem to represent a lot of femininity." Regarding the same flowers, Jane remarked, "The flowers have a more masculine look... they aren't 'pretty' per se, more deep and powerful... but then again someone just went in for the shoot and put those there. It looks styled, and maybe that's why it looks like a guy lives here ... you don't really see his personality." For Tory Burch's home, the styled elements created a different perception for the informants. "The flowers and pillows could just be styled for the shoot, but it makes it 
seem like a space for entertaining" (Beth). Mary associated a lifestyle to the homeowner because of certain extraneous elements: "She gives dinner parties. Her kitchen, although it's not cluttered, I believe she uses it. The pepper mill and the kettle and the blueberries; I believe that she eats those blueberries ... even though I know a stylist put it there." Whether the interpretation is accurate, or whether it is positive or negative, it is clear that, for these informants, the act of prop styling is influential in creating an image.

The mention of a specific photographic quality, and how it influenced viewer perception, was most notable when focusing on Alexander Wang's home. Aside from the concrete design elements of his space, informants continually discussed how it had a distinct feeling. After closer inspection, many noted that the way the pictures were taken the light was over-exposed, there was a visible flash, pictures were taken at night, and some were obscurely cropped - had varying influences, both positive and negative. For example, Sarah said, "There's something about these pictures that seem uncomfortable. Parts are washed out, there are some weird angles, and you can see the the flash of the camera some of them. It seems kind of amateur, I guess... It adds to the image of a grungy, rock-star lifestyle." Jane said, “They also look like they were taken at night. So they seem like pictures that were taken right before a party or something." The photographic style made Mary feel alienated: "It feels very uninviting. And aside from the room being largely black, it could also just be bad photography because the overexposure of the film and visible flash is not enhancing the room. It's giving it a vibe and that vibe does not fit my 39-year-old self, [which is an] urban, black, 'I'm hipper than you', vibe.' Finally, Laura commented that she felt the style of photography was a deliberate decision: "It's interesting to see the flash of the camera in the mirror and in the table leg. I think it's 
probably purposeful. They want to make it look like a casual shot. The flash makes it look party-ish." As with the prop styling, whether the viewer interpretation is accurate, or whether it is positive or negative, it is clear that a distinct photographic style is influential in creating an image.

\section{Implications}

Based on the fact that the nature of this study was exploratory, the results cannot be generalized to a larger population. However, the findings and subsequent emergent themes can be used to generate meaningful recommendations regarding the overt display of a designer's home in a mainstream magazine.

First, above all, if a fashion designer wishes to show the interior of his or her domestic environment to the judging public, then it should clearly represent his or her intended brand identity. For some, appearing in a magazine might be a simple selfindulgence. Likewise, magazine editors may want to feature a designer's home purely for the entertainment factor for the interest of their readers. However, based on the findings in this study, it is important that the viewer is able to perceive both visual and cognitive consistency between their held idea of a designer's brand image and the magazine pictures of that designer's home. This is especially true when designers are the name-sakes of their brands, because their personal images are inextricably connected with those of their companies. When viewers are confronted with incongruity, more often than not, they are left with a cognitive dissonance. Even if the feeling is brief, any encounter that a brand has with consumers should only work positively to enhance the brand's image. Anything less is irresponsible. 
A second recommendation, closely related to the first, is that the preparation of the home for a photo shoot and other art direction decisions should be carefully considered. Both the contents of the picture and the context through which the home interior is seen appeared to be factors in the formation of viewer perception. As was shown with the cleanliness of Ralph Lauren's home, and the use of flowers and other accessories in Tory Burch's home, viewers tend to grasp onto seemingly transient and inconsequential elements to formulate clear judgments. Even a bowl of blueberries helped the viewer paint an elaborate picture in her mind of the homeowner's lifestyle. Of importance to this research is that once an association is perceived it becomes part of the network of information that is held about the designer's brand image. Props that are brought into the space already carry certain associations. Therefore, anyone involved with the work on the other side of the camera lens should be aware of how various accessories may be perceived, and whether or not that perception is harmonious with the brand's identity. In the case of Alexander Wang, many of the study informants were affected by elements perceived in the photos that were intangible, such as the lighting and photographic quality; however, in combination with concrete elements, this elusive aura contributed to a specific interpretation and feeling about a lifestyle and social activities that were associated with Alexander Wang. The lighting, image cropping, exposure and camera angle ostensibly conjured the image of a rock-star partying in his den. Again, the seemingly simple factor of photography has to be calculated according to the desired image that a designer and their brand managers want to project to viewers.

A third and final recommendation is for designers to make a clear visual link between their home and their brand when the home is being shown in a magazine or other 
media. This can be done on multiple levels, but ultimately, it is important for consumers to connect a designer's home, along with the associated lifestyle image, and their company offerings with ease. Especially when reading a magazine, which does not require a high level of mental exertion, viewers should be confronted with images that are clearly communicating digestible information. At the most basic level, the designer should be shown in their home - living in their space. This simple choice allows a viewer to formulate a quick association between what they know about the designer's brand image (prompted by the presence of the designer) and the perception of the designer's home. Even if the consumer is told that the home belongs to a public personality in the text of the article, a visual connection will resonate in their visual memory. Beyond showing the actual designer in his or her home, creating a visual connection between the domestic space and the retail environment and/or fashion designs can work to make the connection even more obvious. This can be done through the layout of a magazine feature where select images of fashion designs or store interiors are included. In the study, once the informants were clear about the images that belonged to each designer they were able to discuss their perceptions with greater ease. Interestingly, although most participants were surprised by the look of Ralph Lauren's Manhattan apartment, some claimed that seeing it made them think more of his sleek runway collections rather than the preppy mainstream fashion that he is known for. This researcher argues that this result arose from the study design. If images of Lauren's runway collections had not been present, it is believed that respondents may not have made the association. Therefore, it is interpreted that because there was a visual connection made in the study, informants were lead to make the cognitive connection. 


\section{CHAPTER 5 \\ CONCLUSION}

The goal of this study was to explore a very specific phenomenon in which everyday people are welcomed into the private space of a publically recognized fashion designer. The approach taken was to suggest that viewing such information about a fashion designer, who serves as the face and namesake of their brand, creates an important touch-point to communicate with consumers. In order to perform an investigation into the communicative value of a fashion designer's home, this study used qualitative interviews, distinct visual material and content analysis to produce meaningful findings. A framework of both visual rhetoric and the associative network memory model served as a context with which to approach a research question that is defined by the interconnection of many conceptual constructs including brand identity and image, visual culture, and the performance of self through material possessions.

Since an important competitive factor for any company is to differentiate themselves in the minds of consumers, a brand image and identity must be clear, consistent and easily identifiable. Further, any encounter that the consumer has with a brand, direct or indirect, should positively contribute to their perceptions and associations about that brand's image. When designers use their homes as sites for brand-image development and reinforcement, their material possessions serve as non-verbal communicators, providing symbolic clues to the viewers about the owner's identity, aesthetic preferences, and personality traits. This study suggests that when a designer's private image and identity are displayed publicly it contributes to their perceived public persona. Further, a resulting insinuation is that designers' public personas should embody 
their fashion brand's image. Therefore, any marketing communication involving aspects of the designer's private life should contribute positively to the overall brand concept in a consistent fashion.

Although the findings are not conclusive, nor are they able to be generalized, they suggest some interesting connections. Primarily, research participants were able to view images and express abstract values that connected to both the concrete and intangible visual elements present in the pictures. Based on these values, they were also able to construct perceived lifestyles, social scenarios and ideals that were associated with the home, store or clothing being observed. When the designer's home conjured associations that were congruent with what the viewer believed about that designer's brand, the home seemed to reinforce the image. However, when the designer's home elicited inferences that juxtaposed the viewer's pre-established conception of the designer's brand, the home's presentation seemed to have a negative effect. Either the viewer was not able to make a clear connection between the designer's self-image (as perceived thorough their home) and their brand image, or the consumer-based belief about what the brand represented was weakened.

According to these findings, three recommendations were put forth to guide designers and their companies toward maximum impact if they wish to feature their homes in mainstream magazines. First, ensure that the home is a clear representation of the designer's intended brand identity. It should be both visually and cognitively consistent. Second, be aware of the power of styling and photography to both enhance and distract from an intended message. Third, designers should make a clear visual link between their homes and their brands when their home is being presented in magazines or 
in other media. This can be done by photographing the designer in their home, and by presenting pictures of the company's products or other sites of consumer-brand interaction such as retail environments in the magazine article.

In terms of directions for future research, ultimately it is important to first explore the brand-consistency phenomenon in regard to magazine displays of designers' homes with more depth and breath. It is suggested that other designers who have shown their homes in magazines be studied in order to assess whether the findings of this study are supported, and to identify other important themes and implications. It is also suggested that a greater variety of study informants be questioned in order to generate findings from different perspectives. Finally, future research could be done to investigate whether the recommendations posed in this study can serve as a viable marketing strategy for other brands. 


\section{APPENDIX A-1}

Figure a

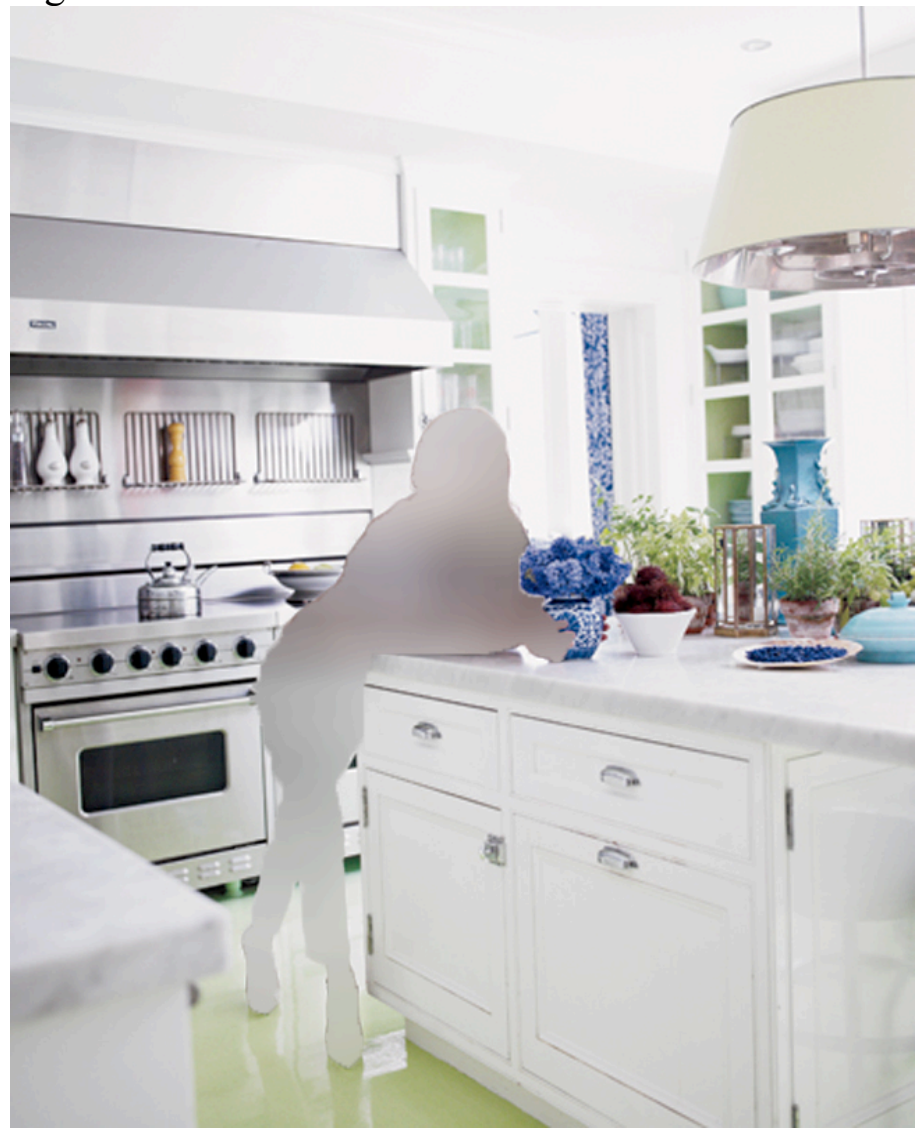

Figure $b$

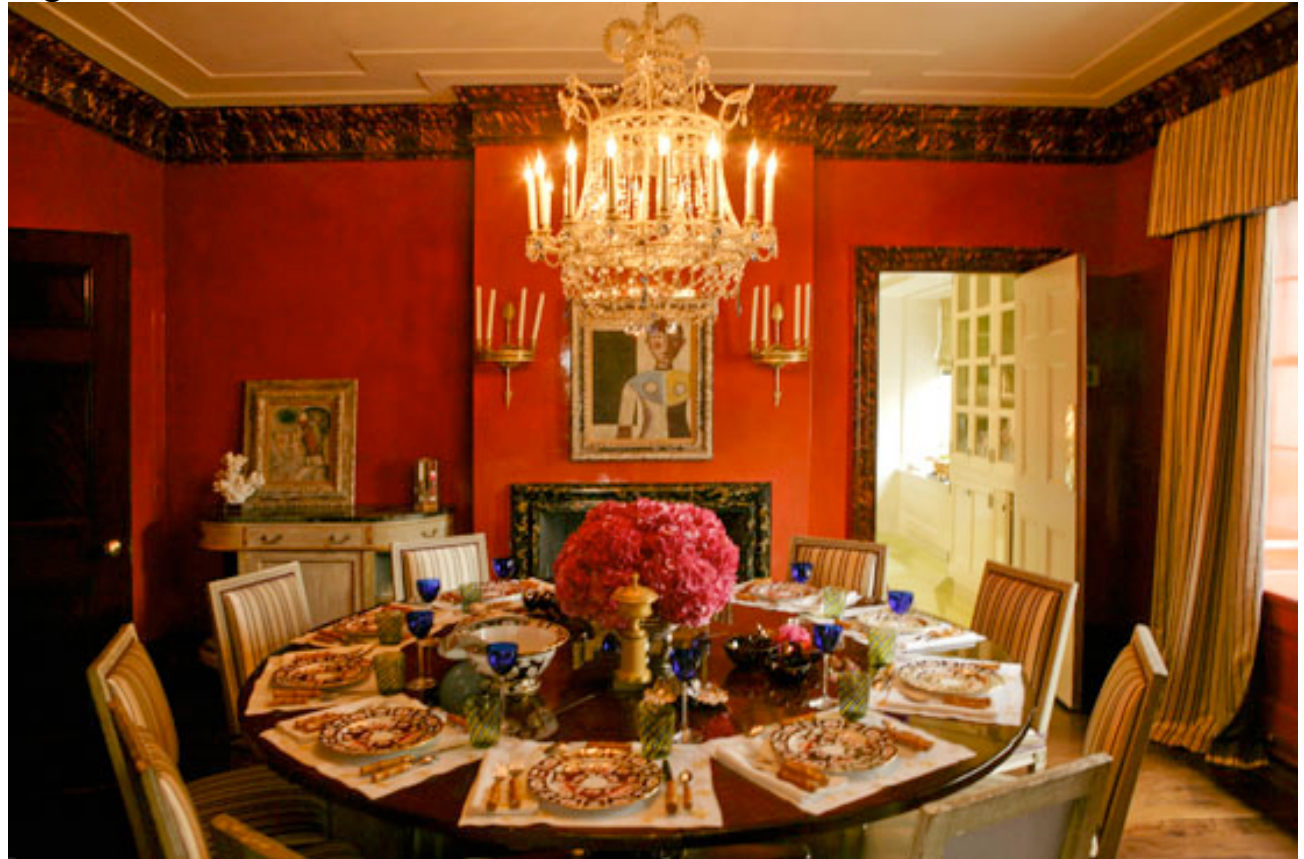

A-1 Tory Burch's Home Interior. [Costello, Paul. Step into Tory Burch's Home. 2009. Photograph. Elle Magazine, New York. Elle. Hearst Communications Inc. Web. Dec.2011.] 
Figure c

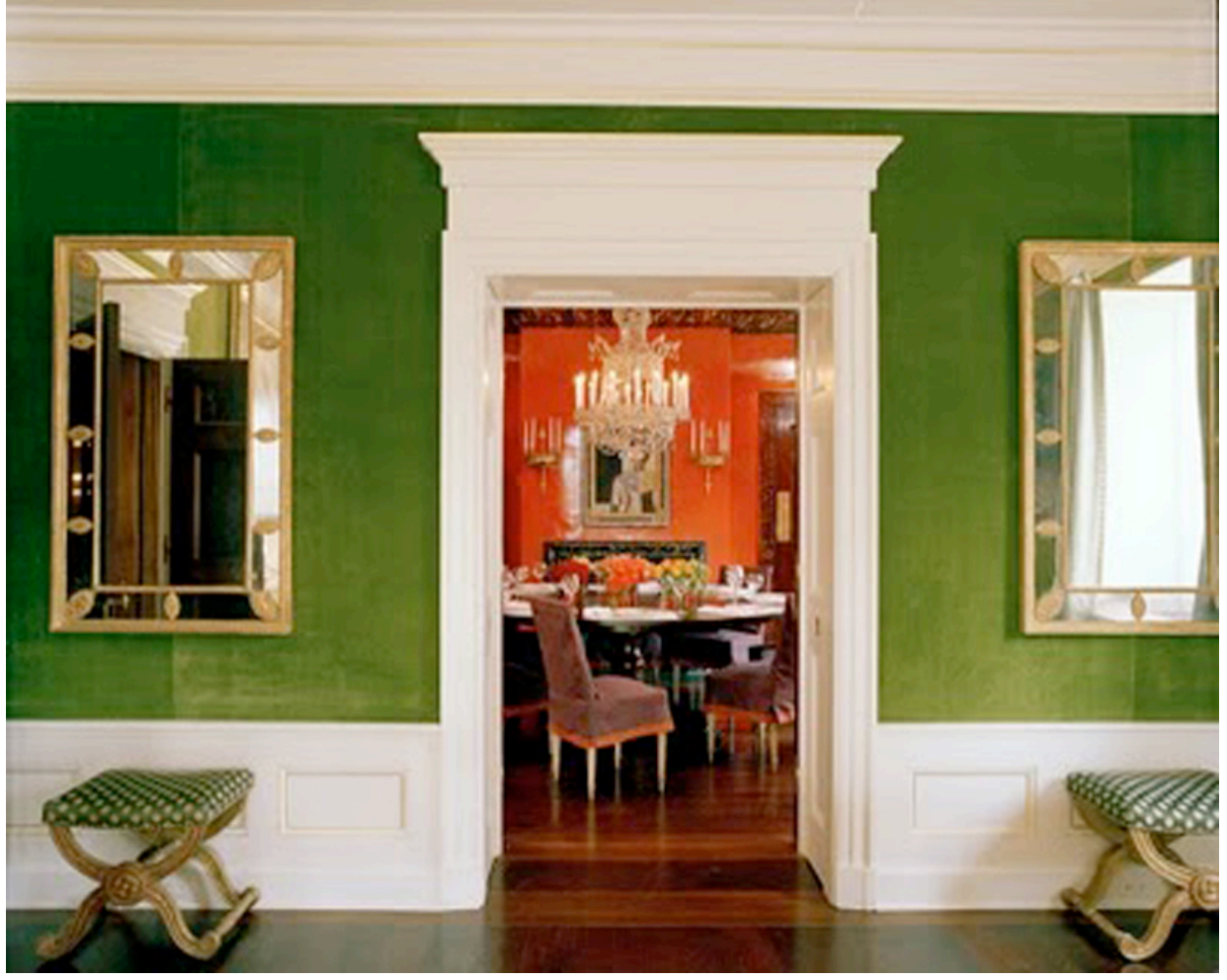

Figure d

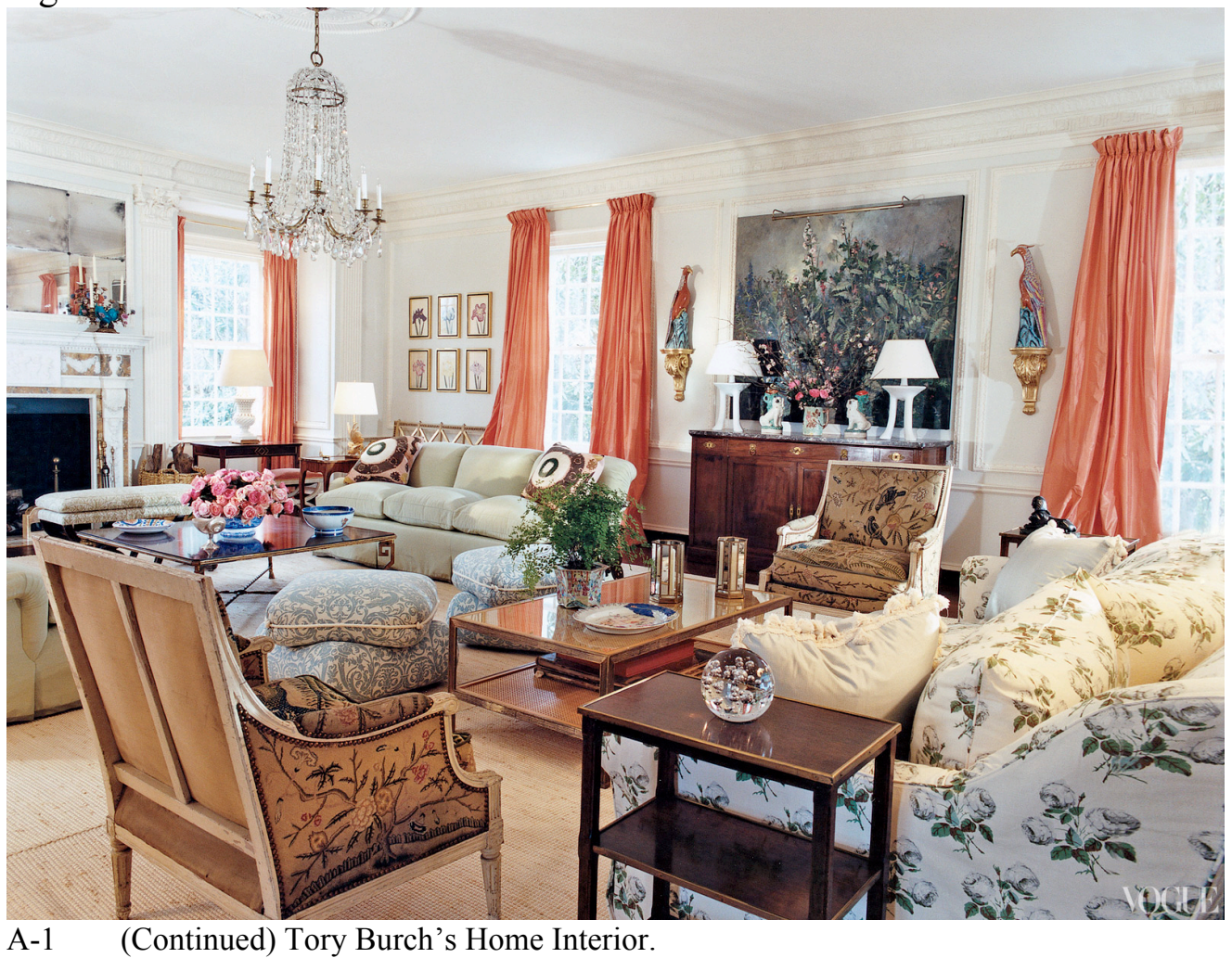


Figure e

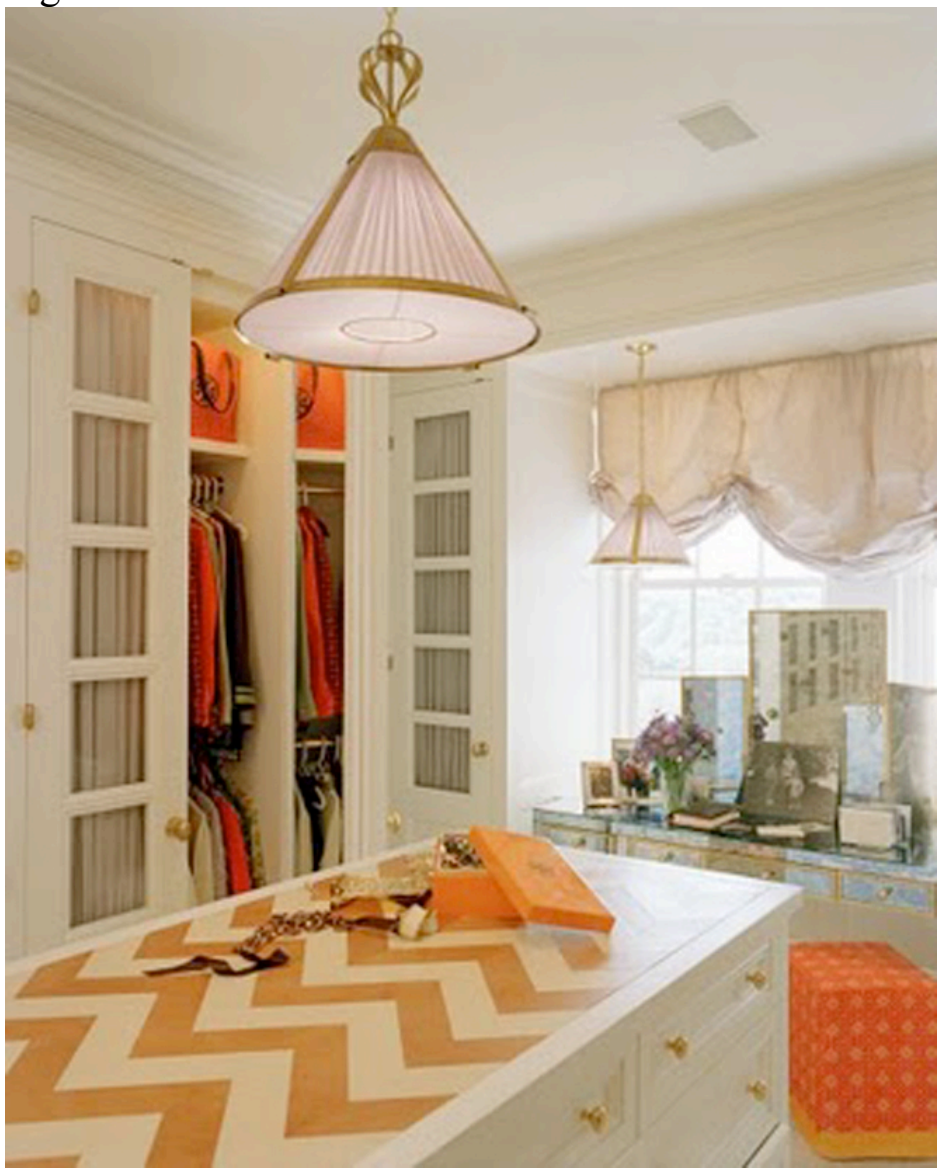

A-1 (Continued) Tory Burch’s Home Interior. 
APPENDIX A-2

Figure a

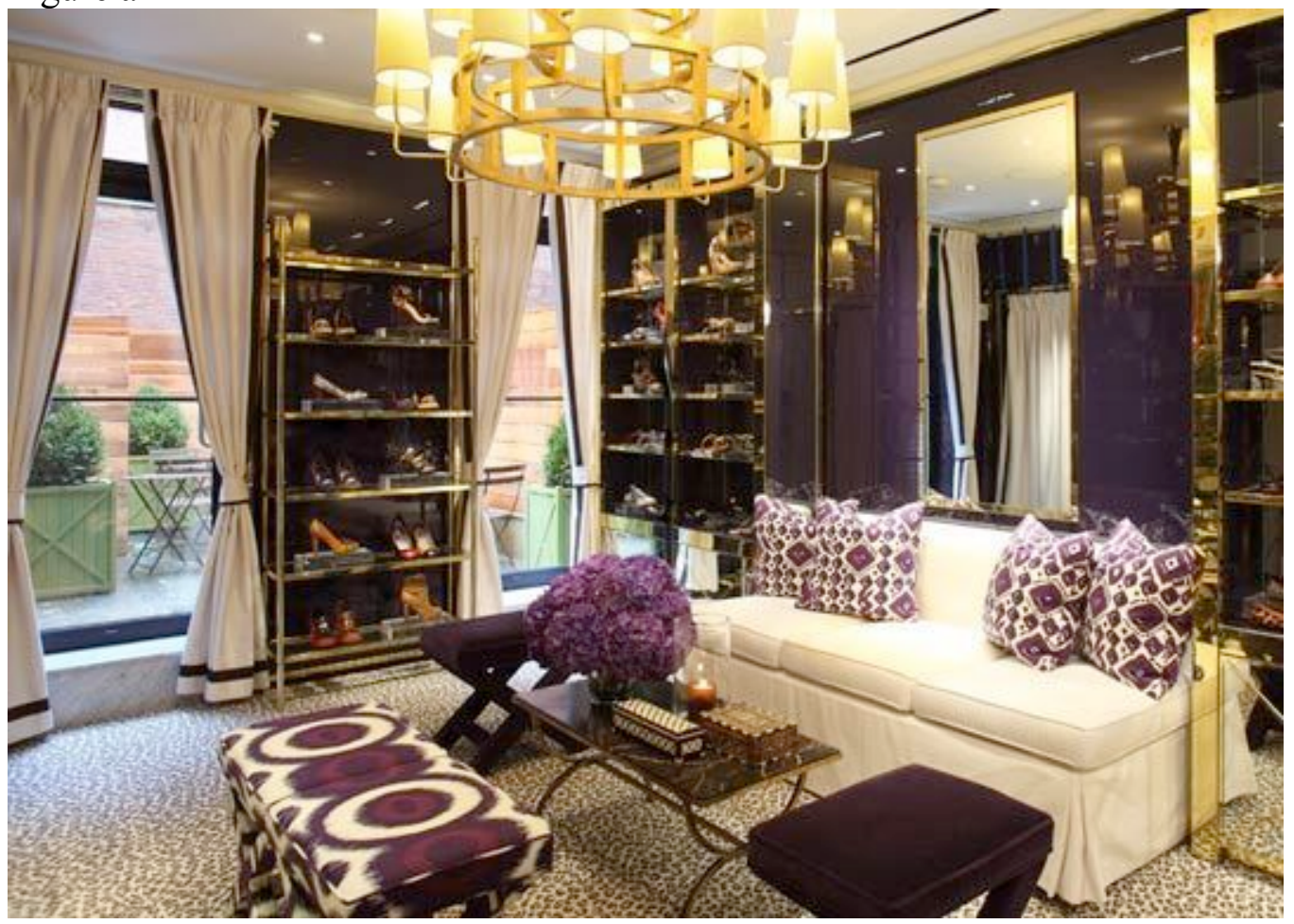

Figure b

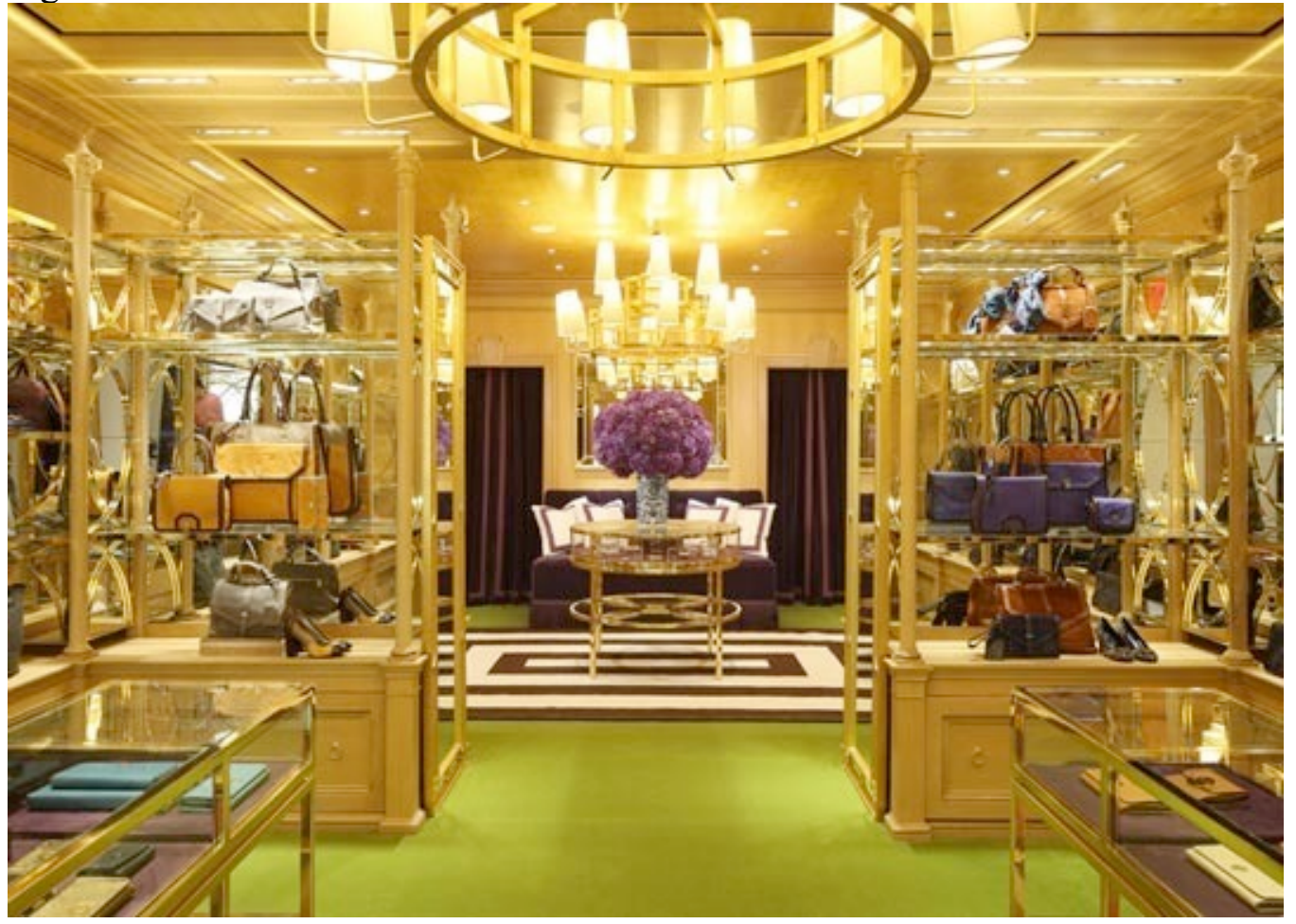

A-2 Tory Burch's New York Flagship Store Interior. [Anonymous. Tory On: 797 Madison Avenue.

2011. Photograph. The Tory Blog. Tory Burch. Tory Burch LLC, 9 Sept. 2011. Web. Dec. 2011.] 
Figure c

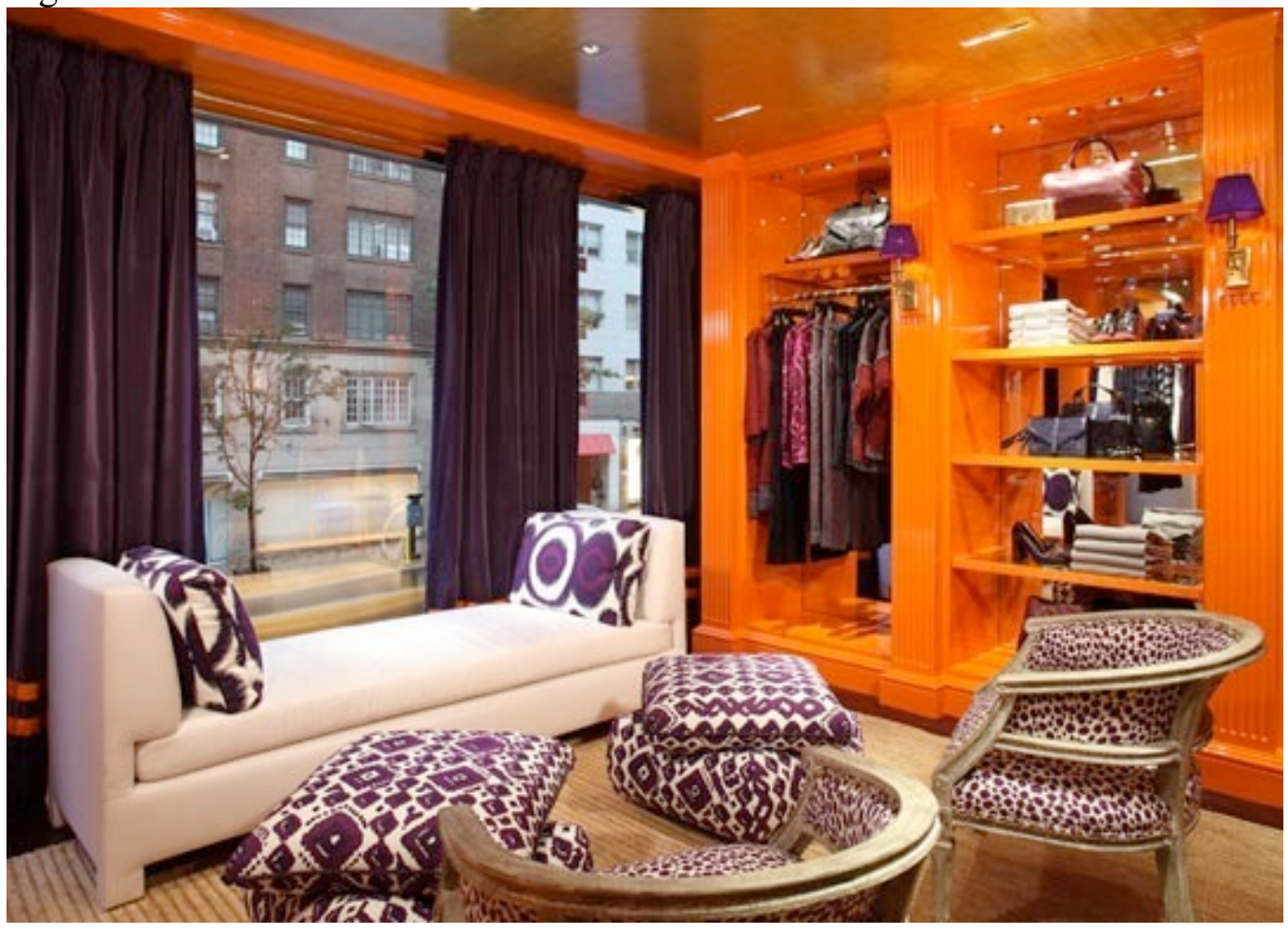

Figure d

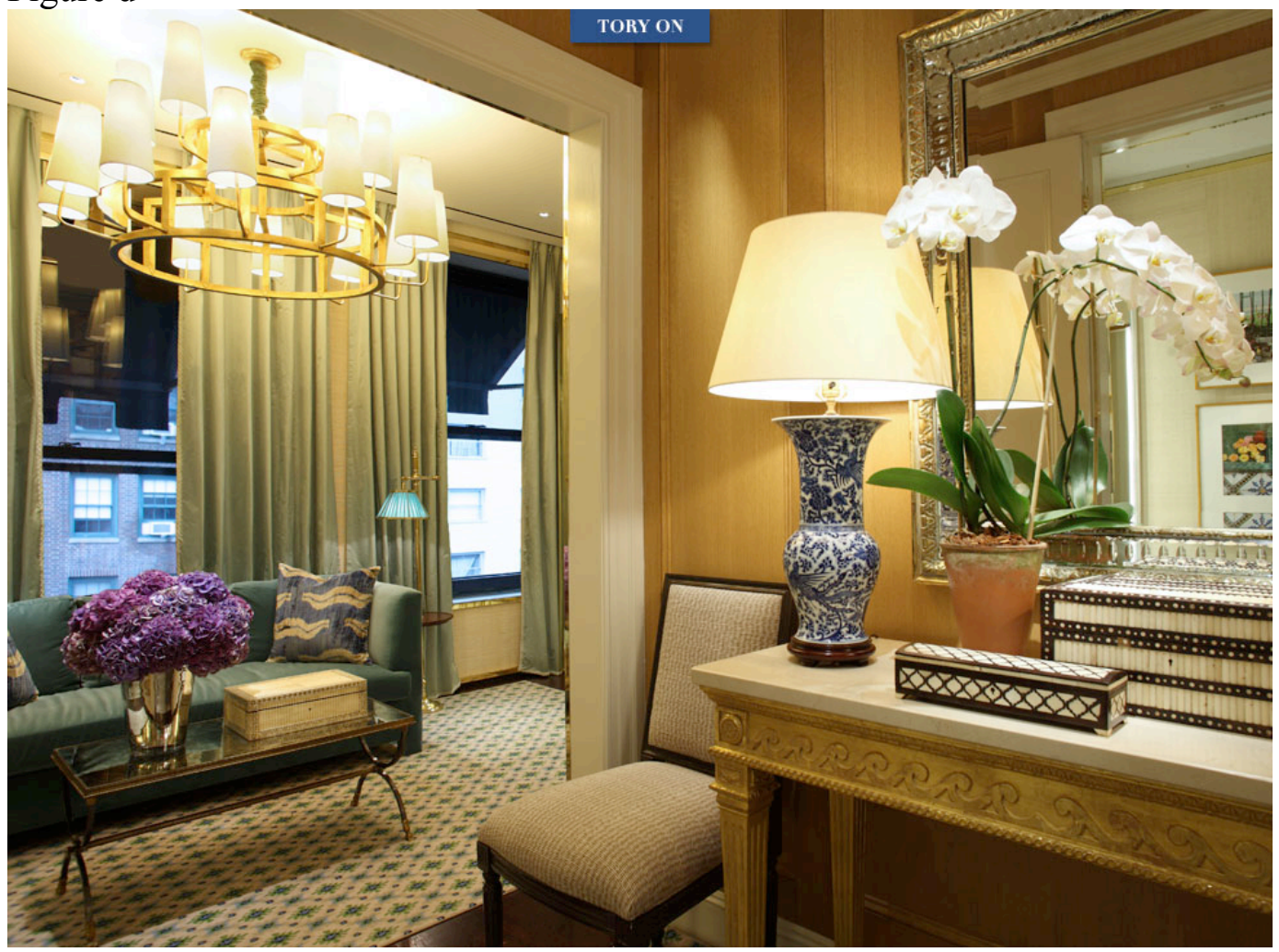

A-2 (Continued) Tory Burch's New York Flagship Store Interior. 


\section{APPENDIX A-3}

Figure a

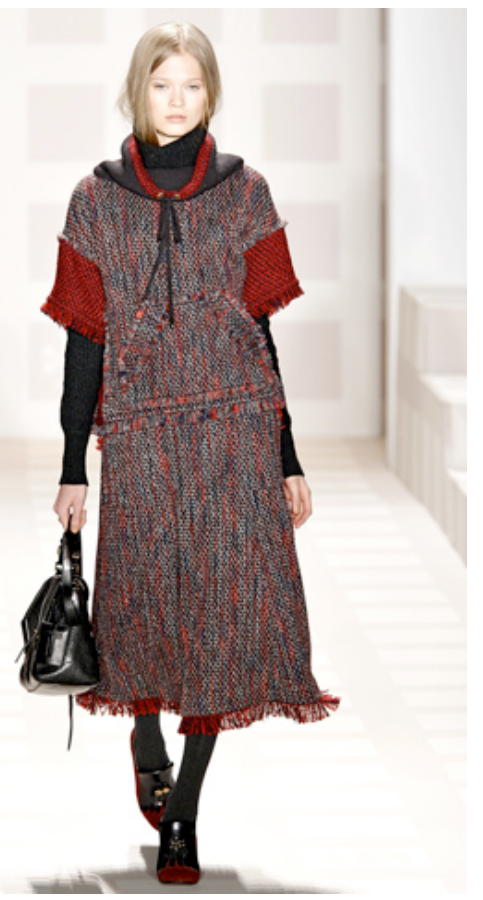

Figure $b$

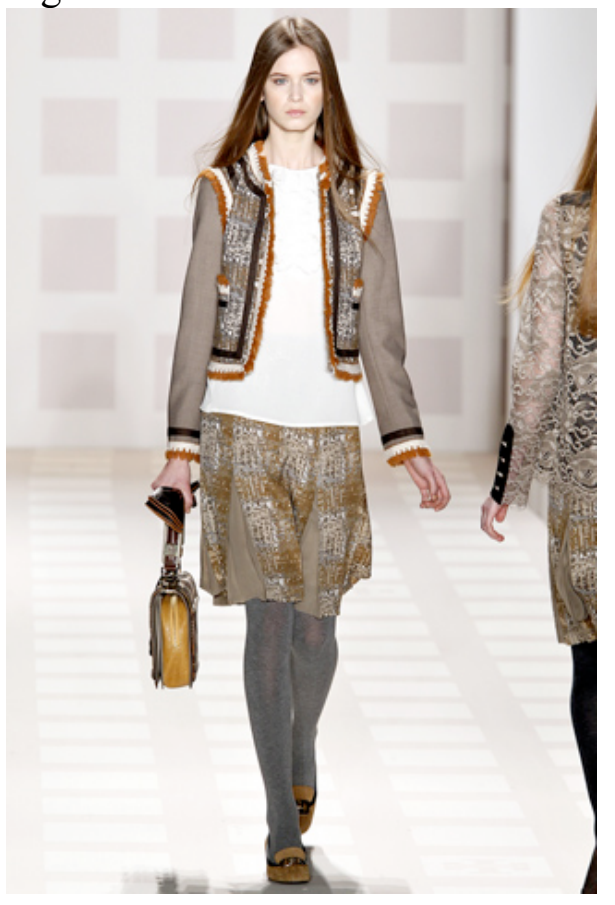

Figure c

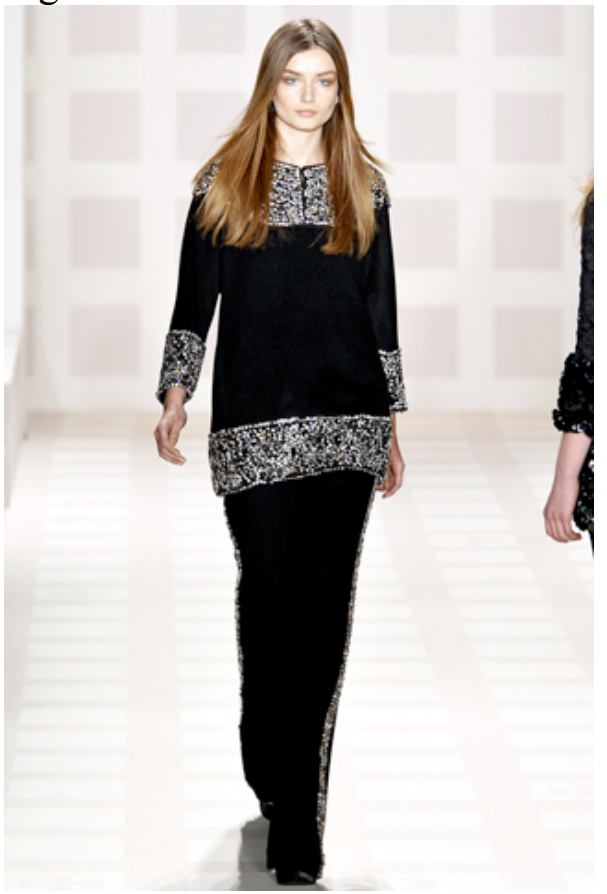

A-3 Tory Burch's Collections Fall 2011 ready-to-wear. A) First look, B) Middle Look C) Last look. [Garofalo, Alessandro. Fall 2011 Ready-to-wear Tory Burch. 2011. Photograph. Style.com. Style.com. Condé Nast. Web. Dec. 2011.] 
Figure d

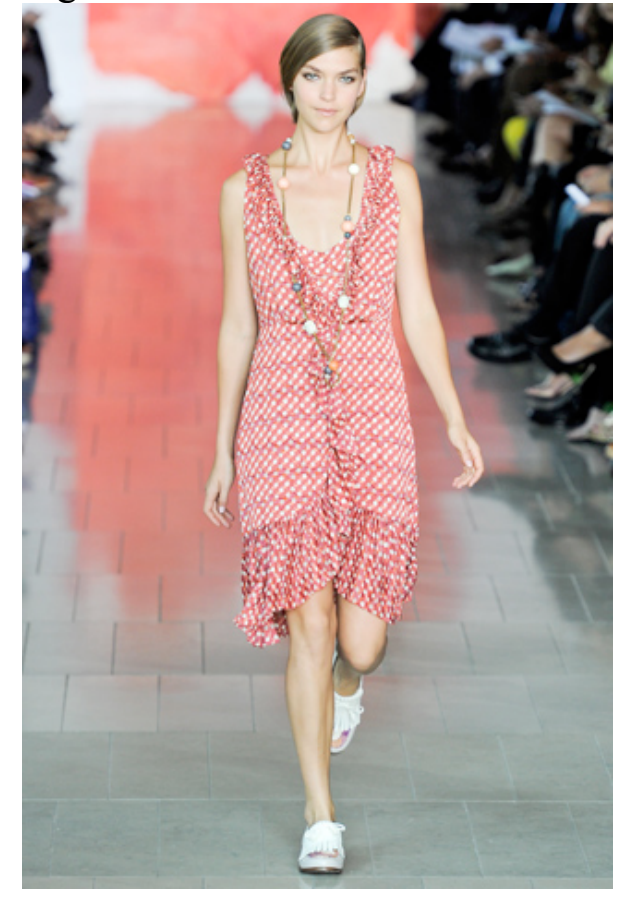

Figure e

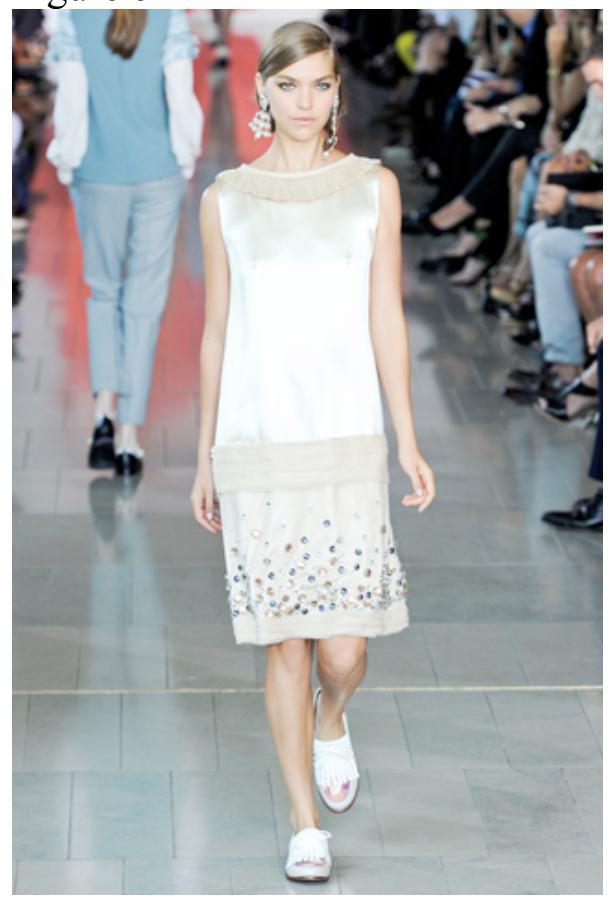

Figure $\mathrm{f}$

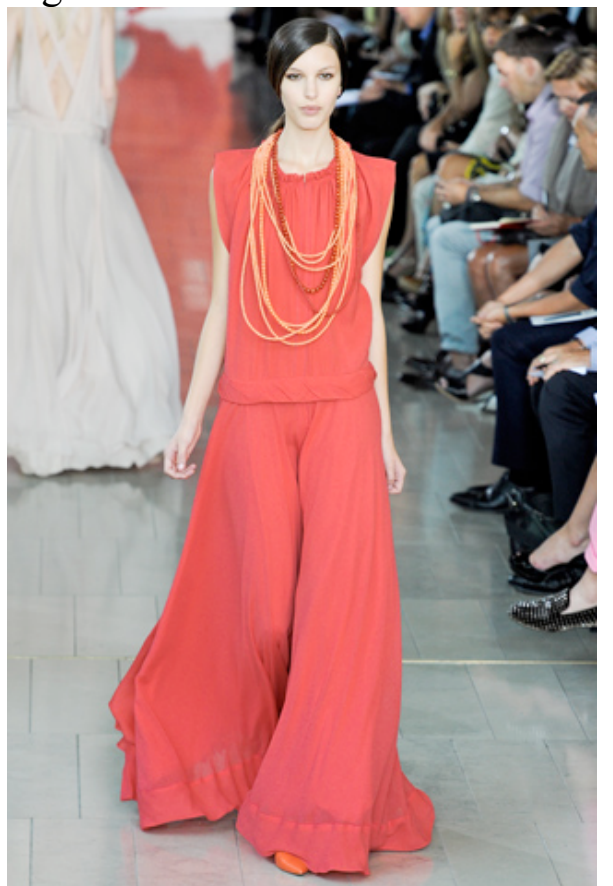

A-3 Tory Burch's Collections Spring 2012 ready-to-wear. A) First look, B) Middle Look C) Last look. [Vlamos, Yannis. Spring 2012 Ready-to-wear Tory Burch. 2011. Photograph. Style.com. Style.com. Condé Nast. Web. Dec. 2011.] 
APPENDIX A-4

Figure a

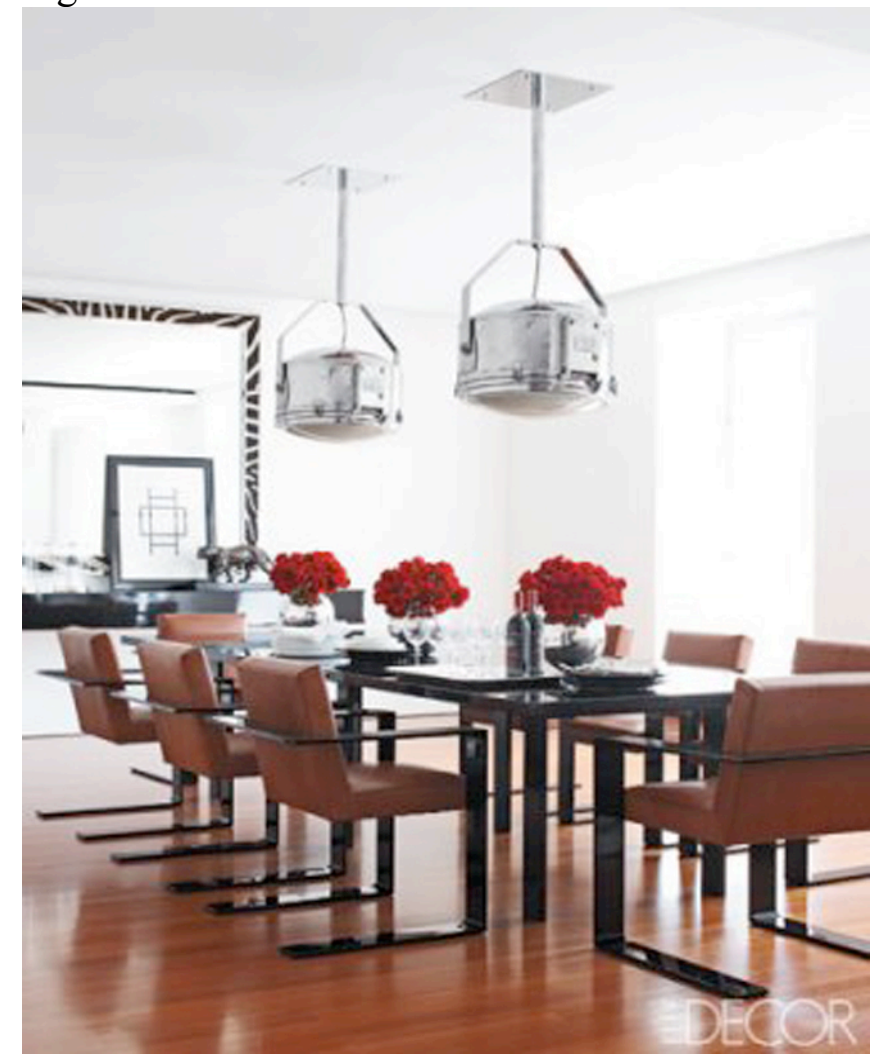

Figure b

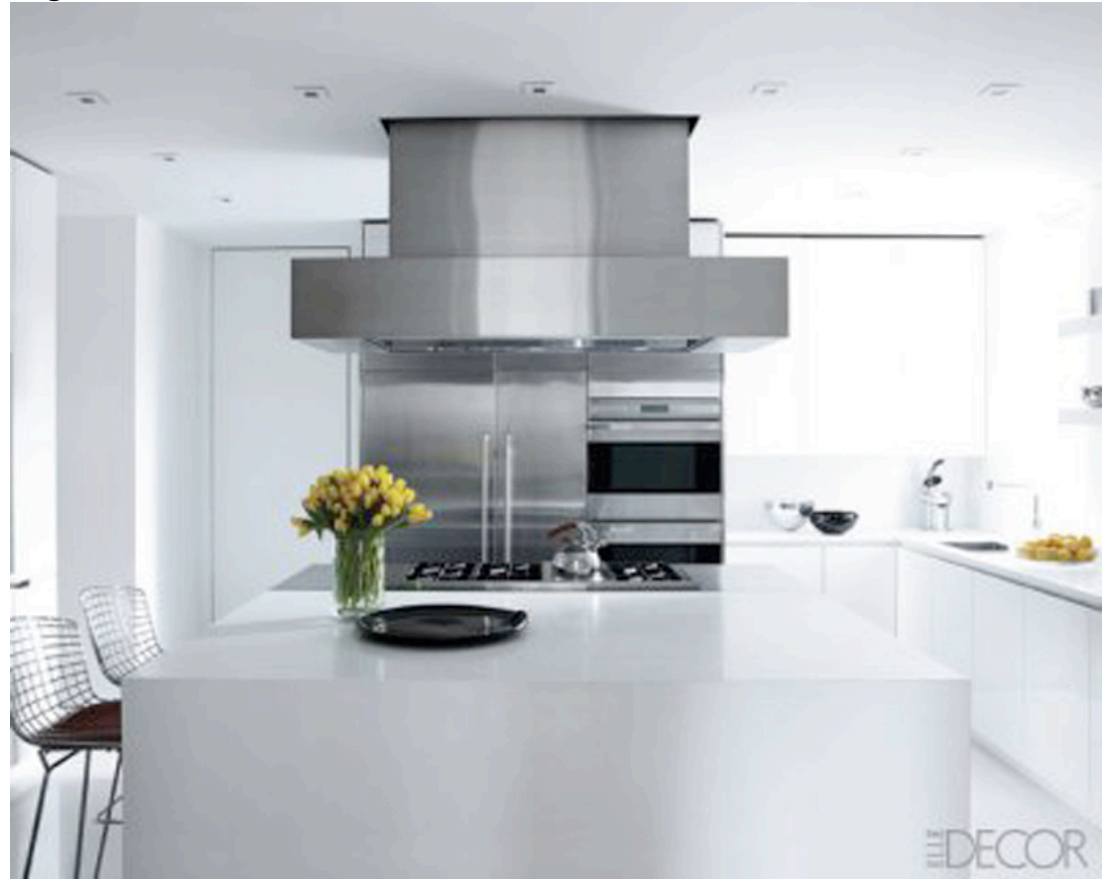

A-4 Ralph Lauren's Home Interior. [Abranowicz, William. Ralph Lauren's Chic Retreat. 20120.

Photograph. Elle Decor, New York. Elle Decor. Hearst Communications Inc. Web. Dec. 2011.] 
Figure c

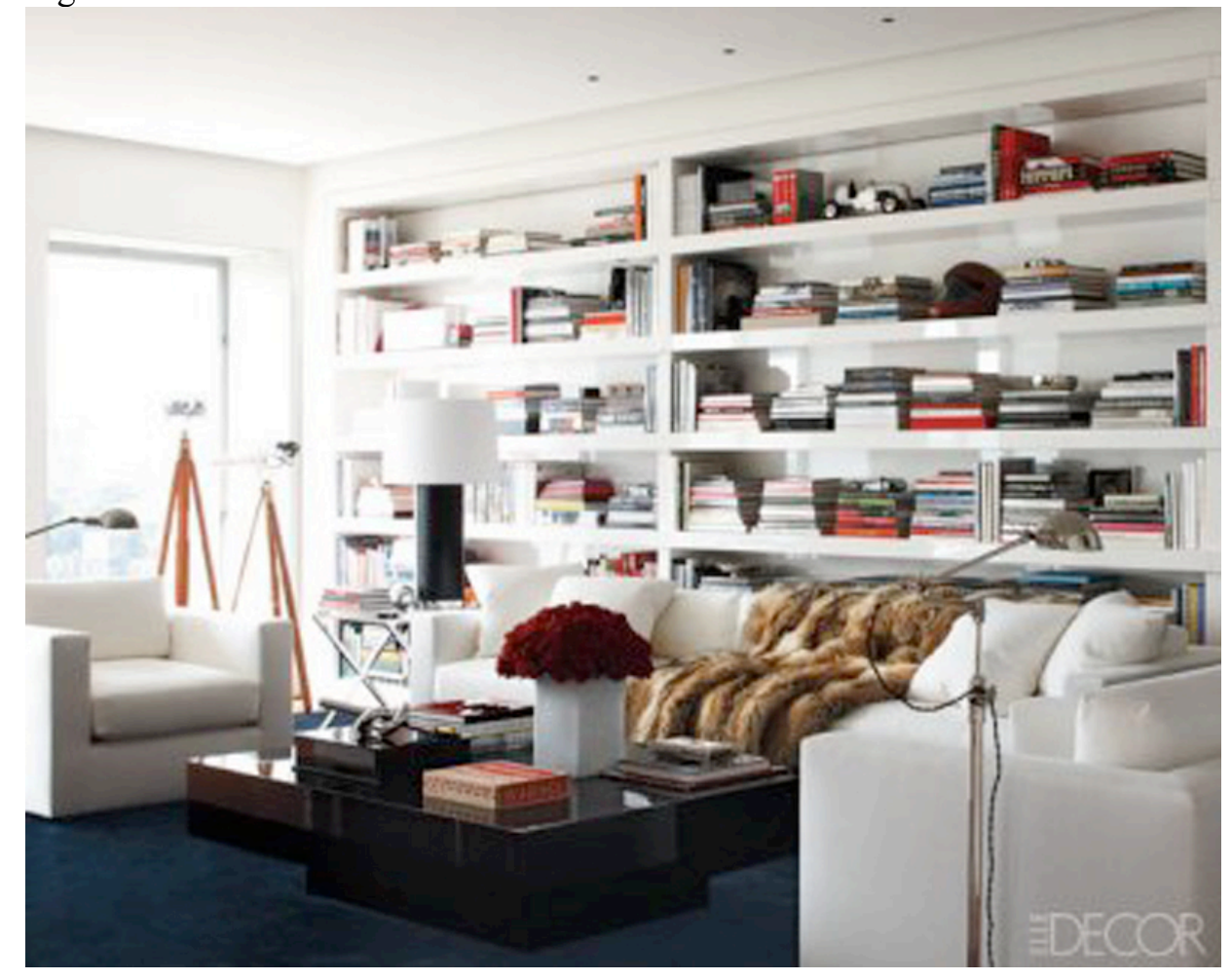

Figure d

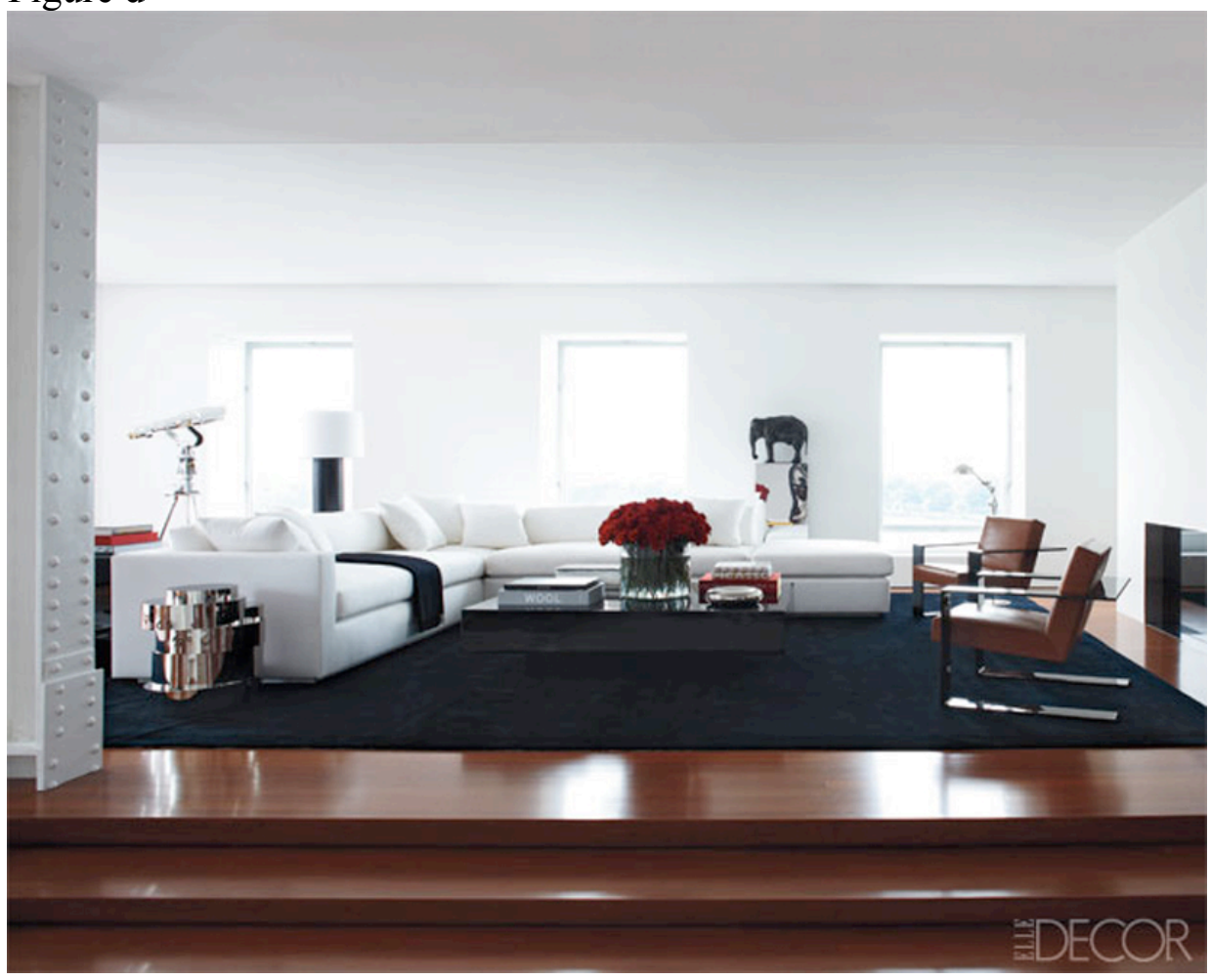

A-4 (Continued) Ralph Lauren's Home Interior. 
Figure e

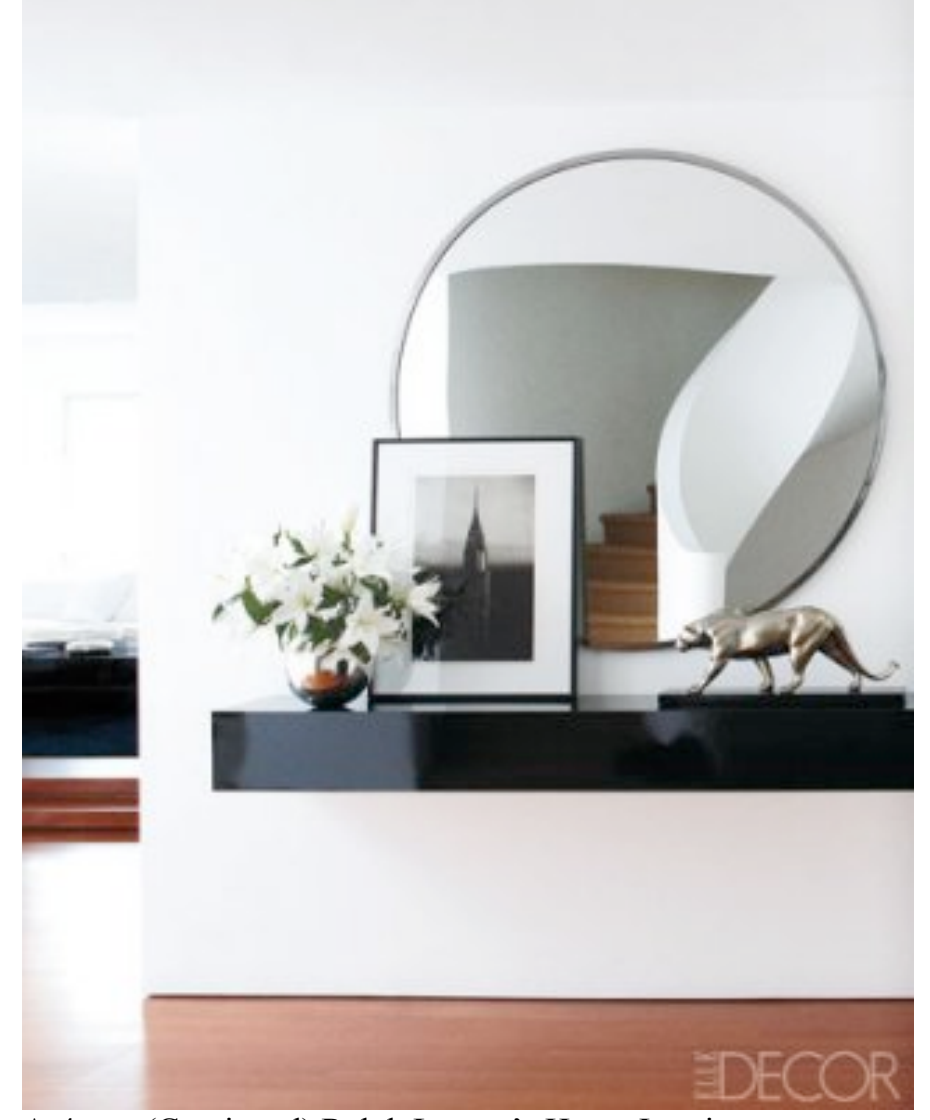

A-4 (Continued) Ralph Lauren's Home Interior. 
APPENDIX A-5

Figure a

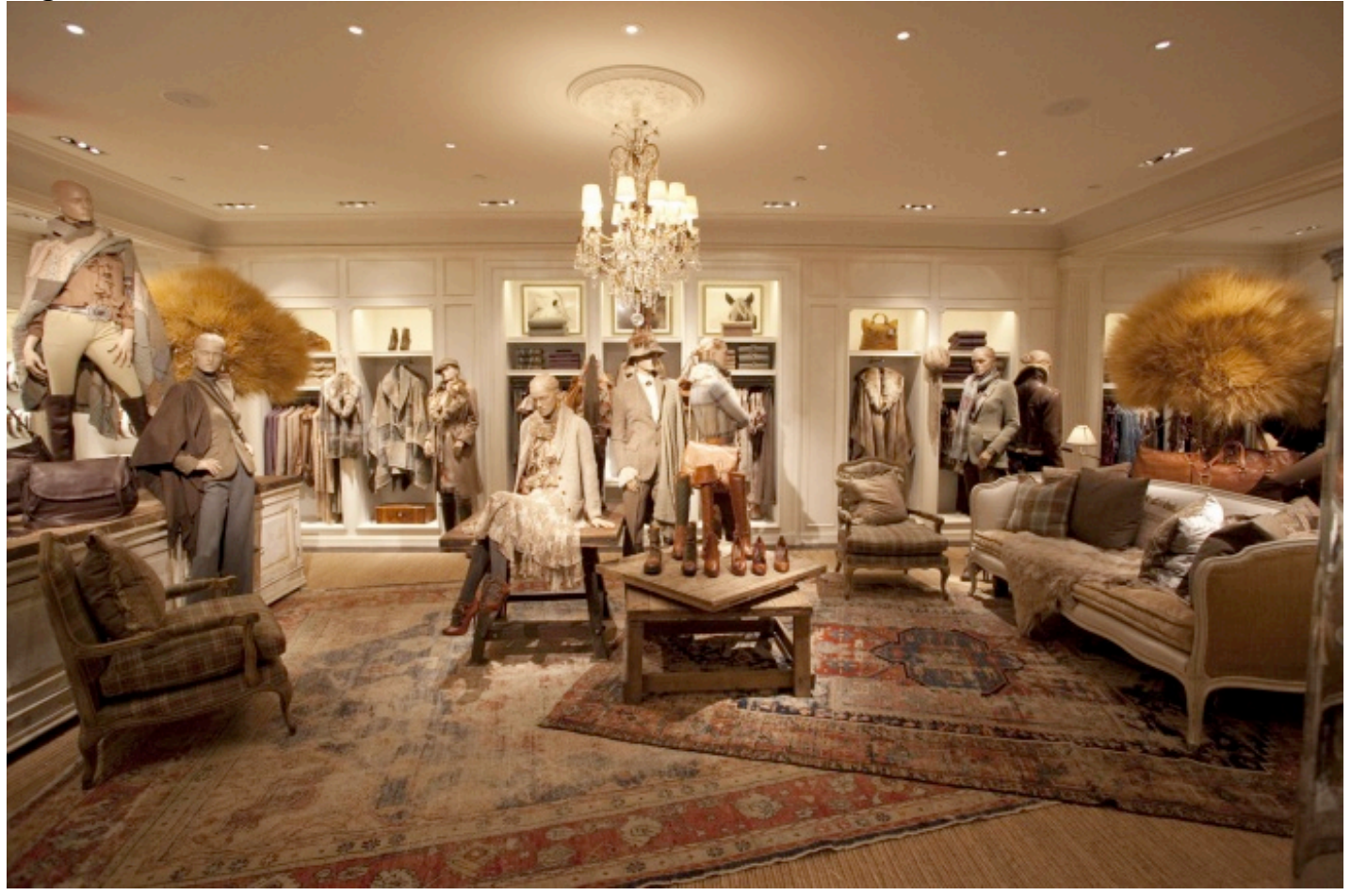

Figure $b$

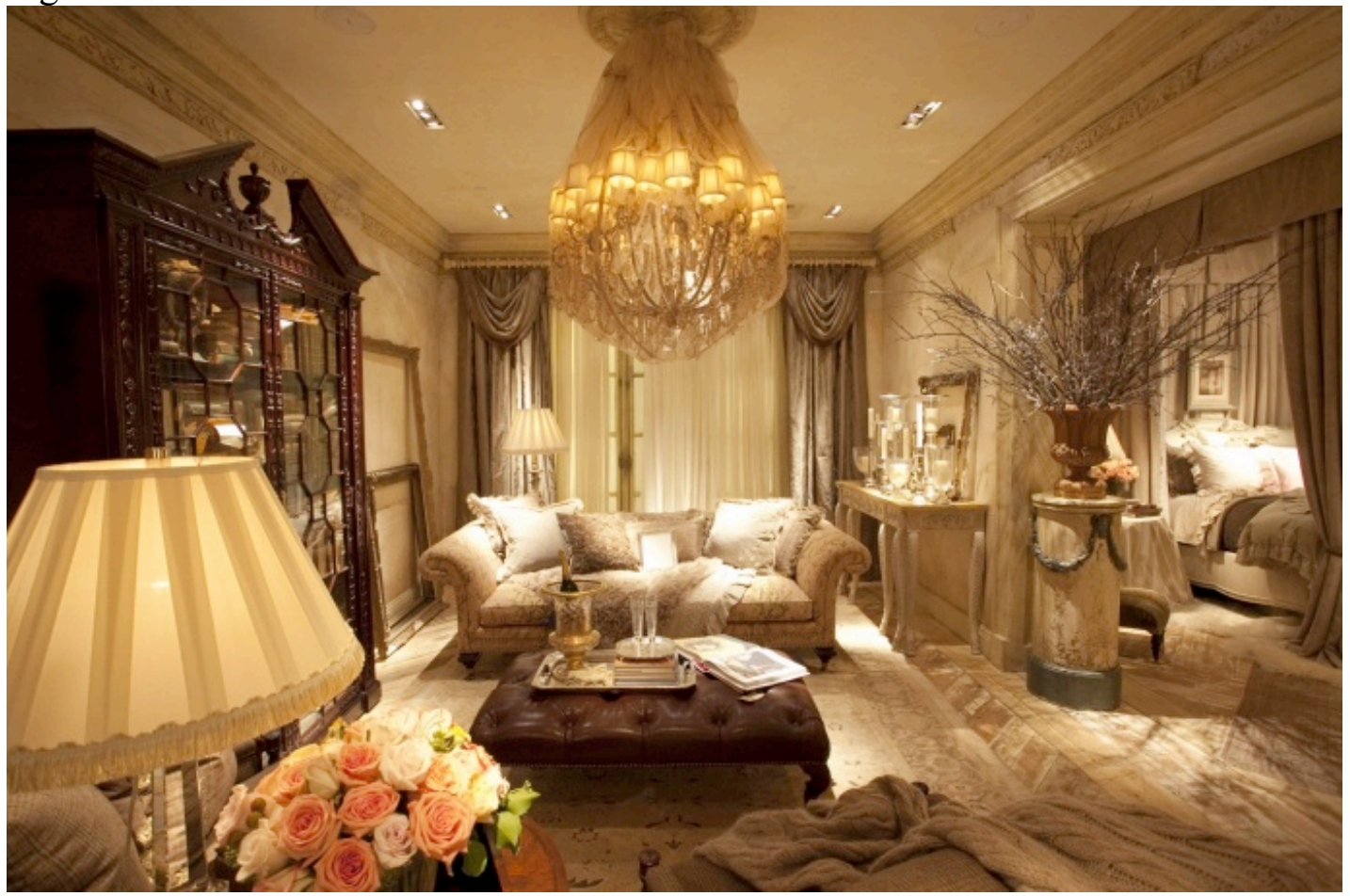

A-5 Ralph Lauren's New York Flagship Store. [Lisnet, Michael. The New Ralph Lauren Store at 888 Madison Avenue. 2010. Photograph. Vogue Daily, New York. Vogue. Condé Nast, 14 Oct. 2010. Web. Dec. 2011.] 
Figure c

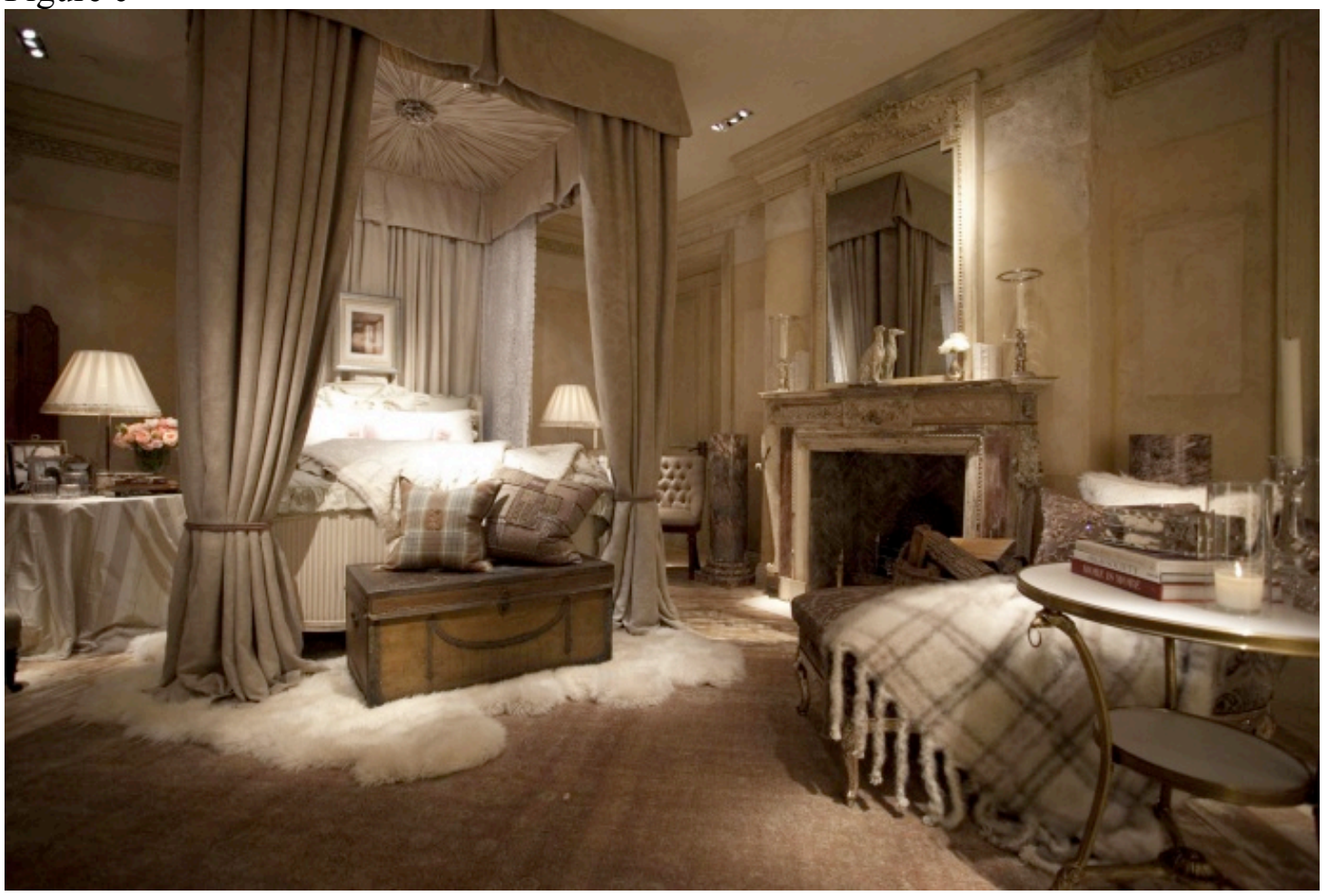

Figure d

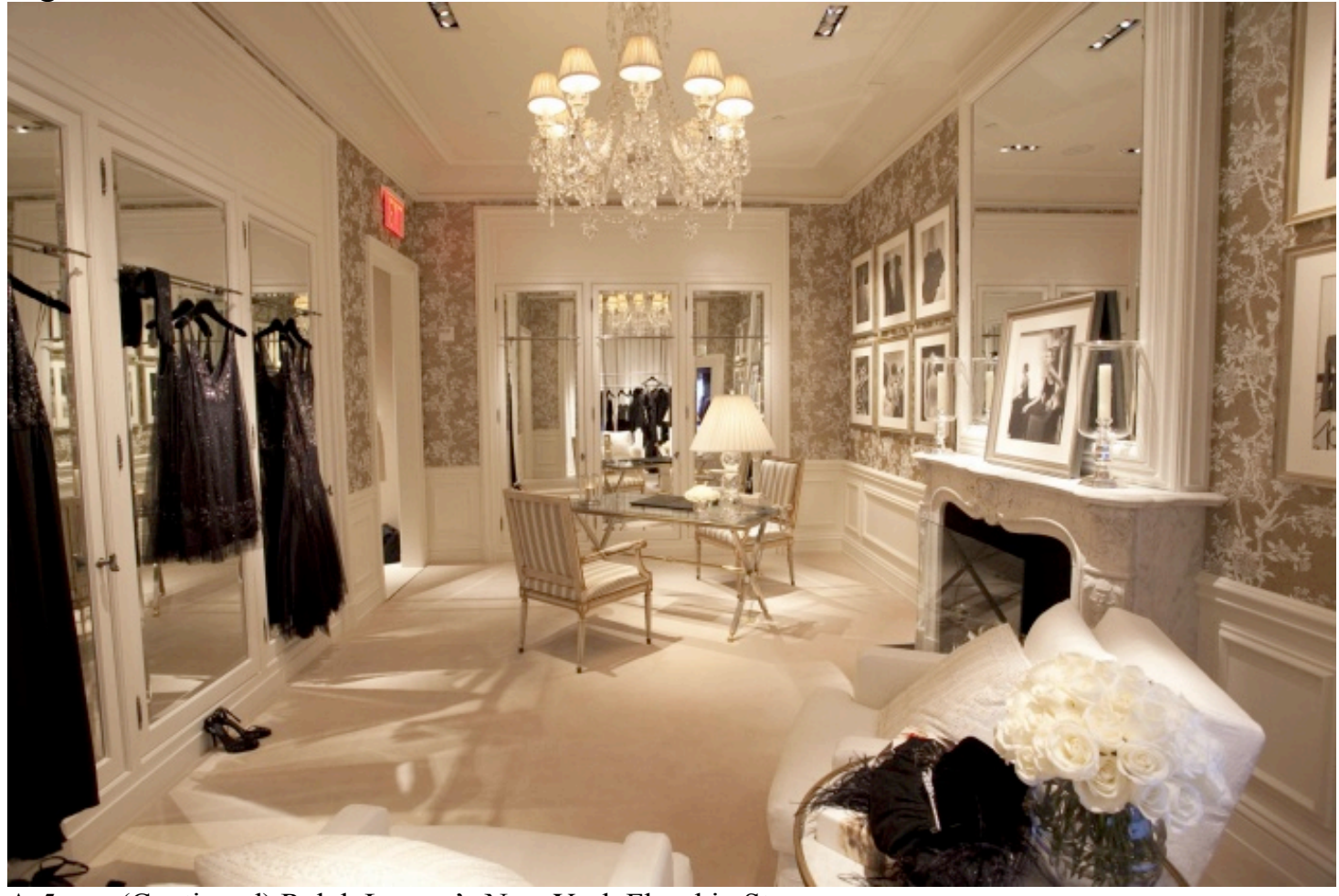

A-5 (Continued) Ralph Lauren's New York Flagship Store. 


\section{APPENDIX A-6}

Figure a

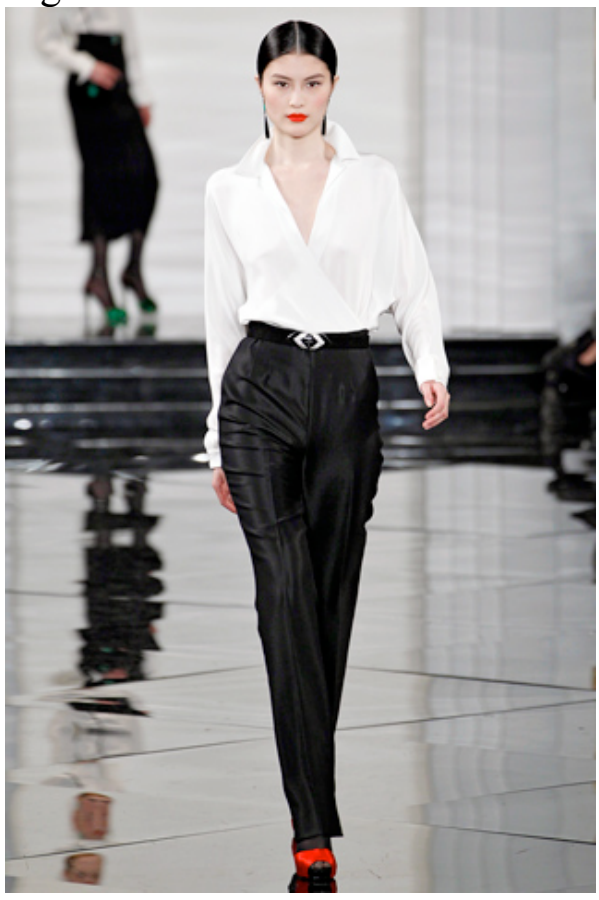

Figure b

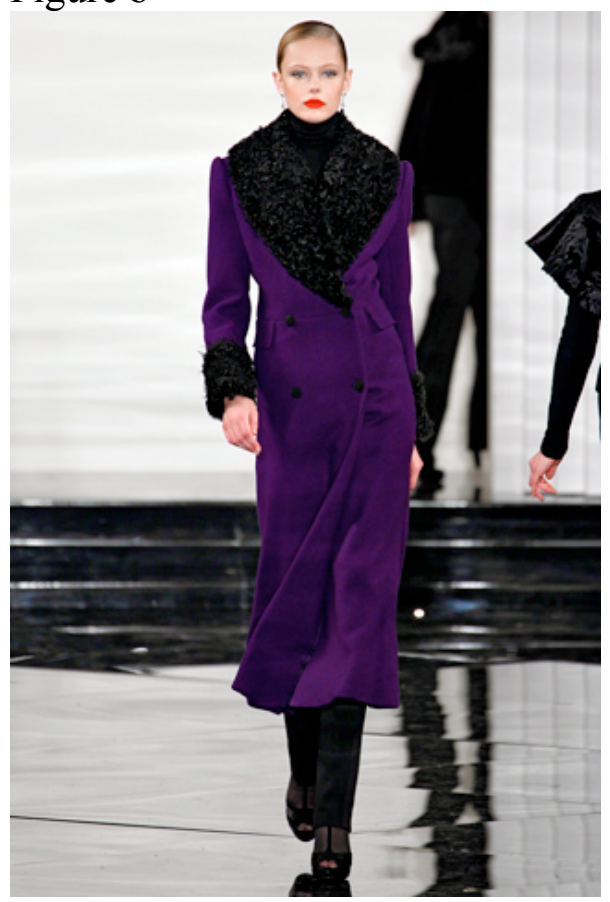

Figure c

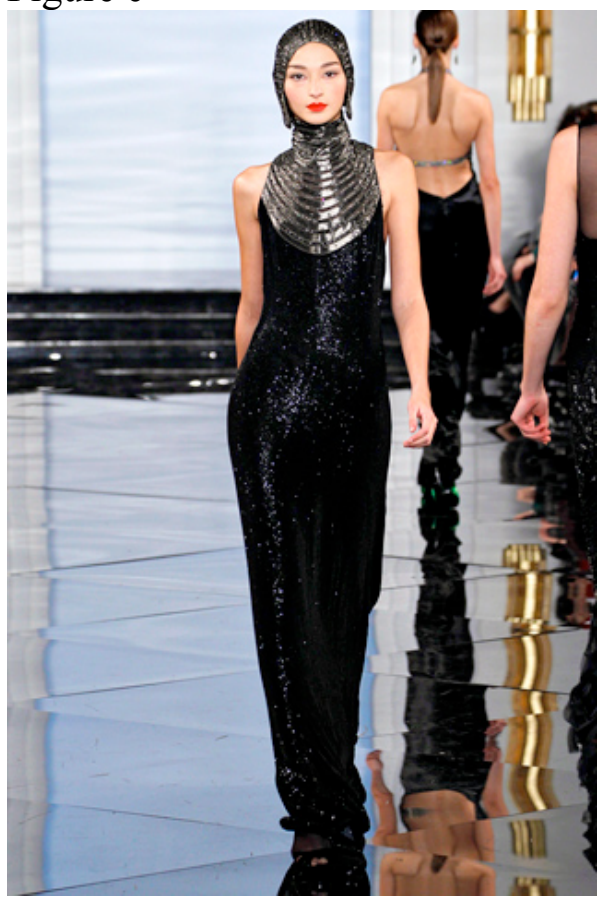

A-6 Ralph Lauren's Collections Fall 2011 ready-to-wear. A) First look, B) Middle Look C) Last look. [Feudi, Monica. Fall 2011 Ready-to-wear Ralph Lauren. 2011. Photograph. Style.com. Style.com. Condé Nast. Web. Dec. 2011.] 
Figure d

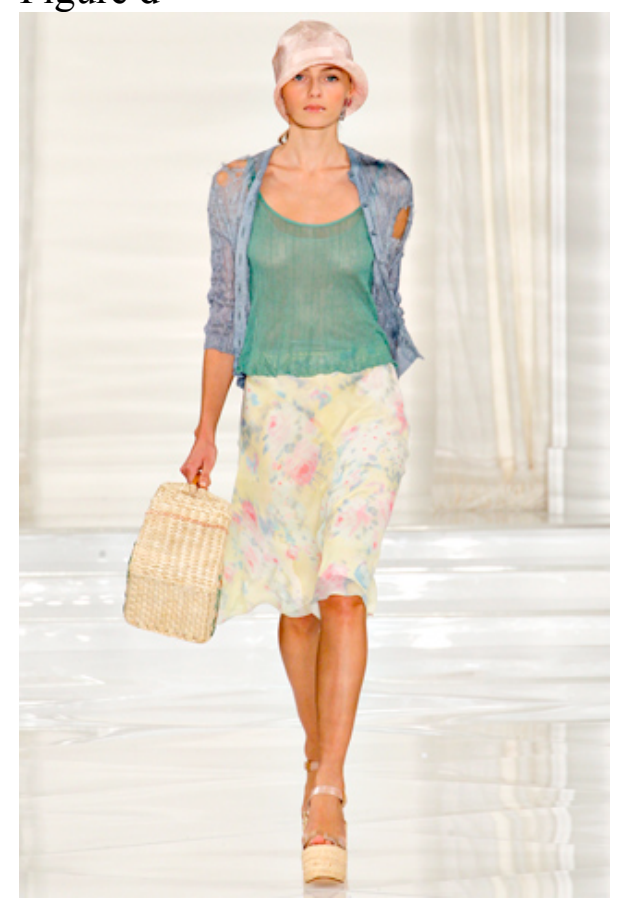

Figure e

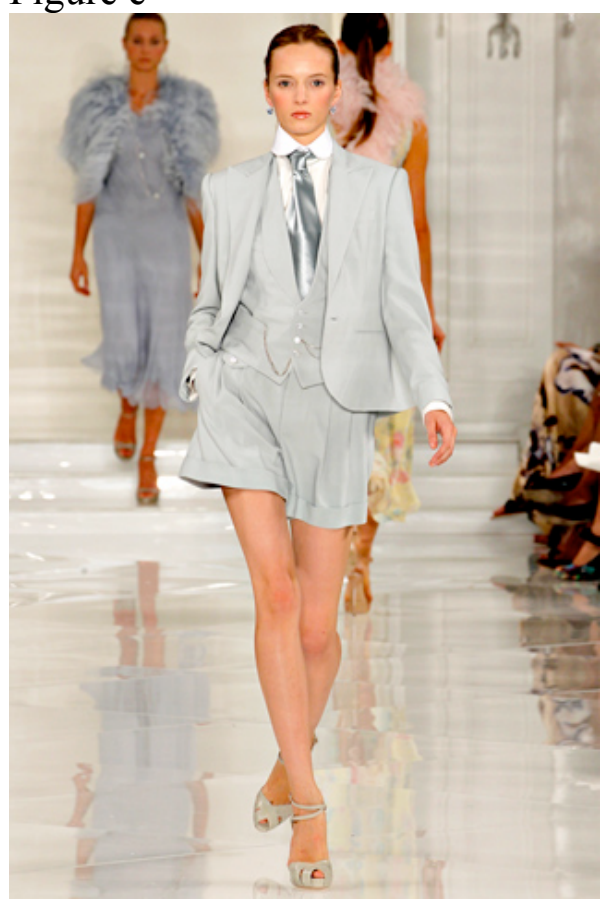

Figure f

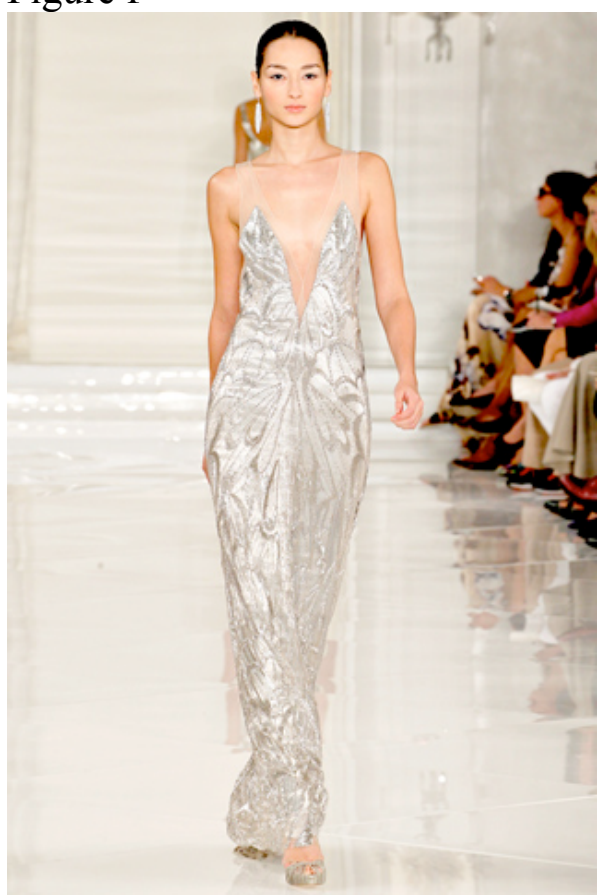

A-6 Ralph Lauren's Collections Spring 2012 ready-to-wear. A) First look, B) Middle Look C) Last look. [Feudi, Monica. Spring 2012 Ready-to-wear Ralph Lauren. 2011. Photograph. Style.com. Style.com. Condé Nast. Web. Dec. 2011.] 
APPENDIX A-7

Figure a

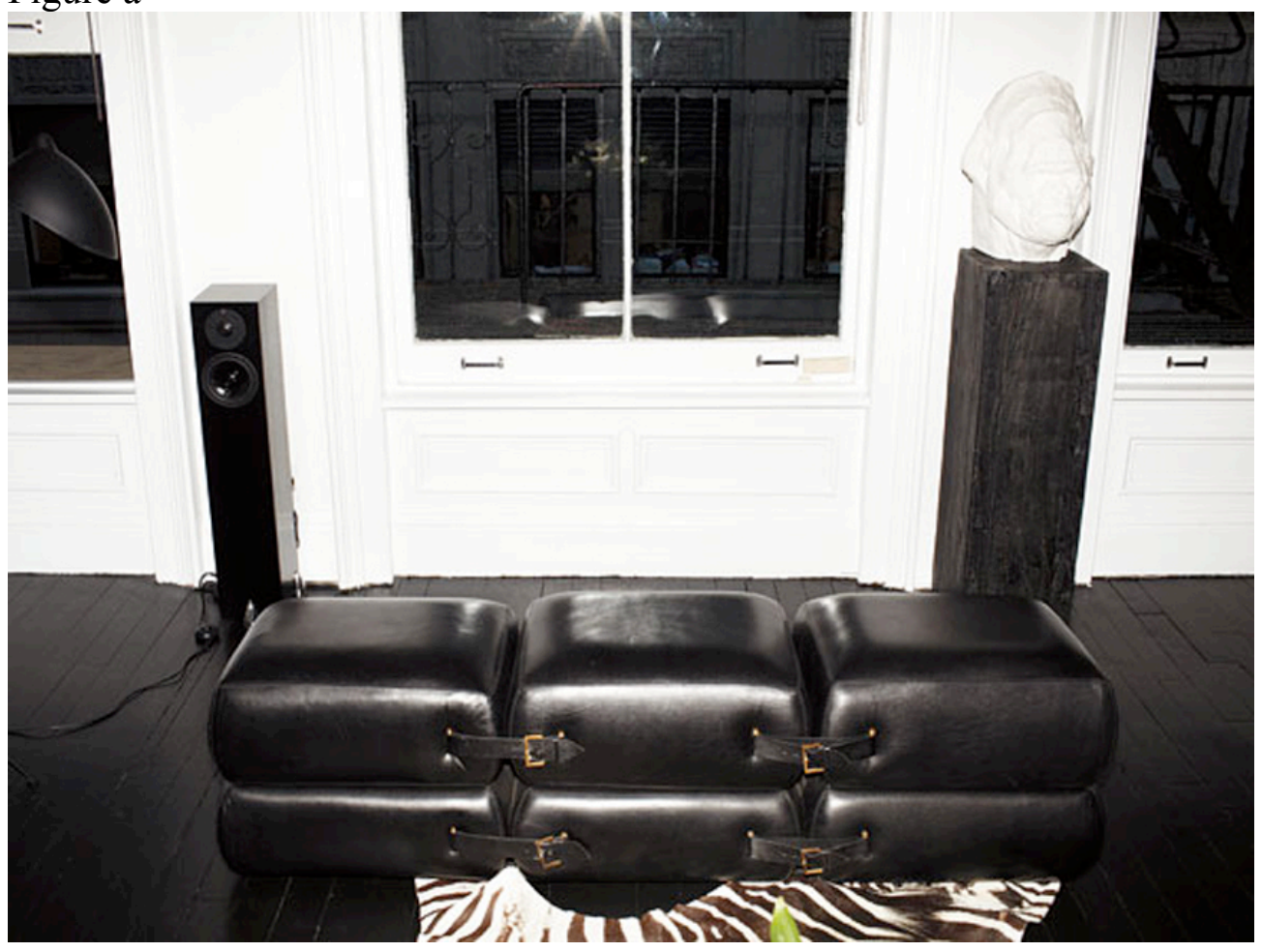

Figure b

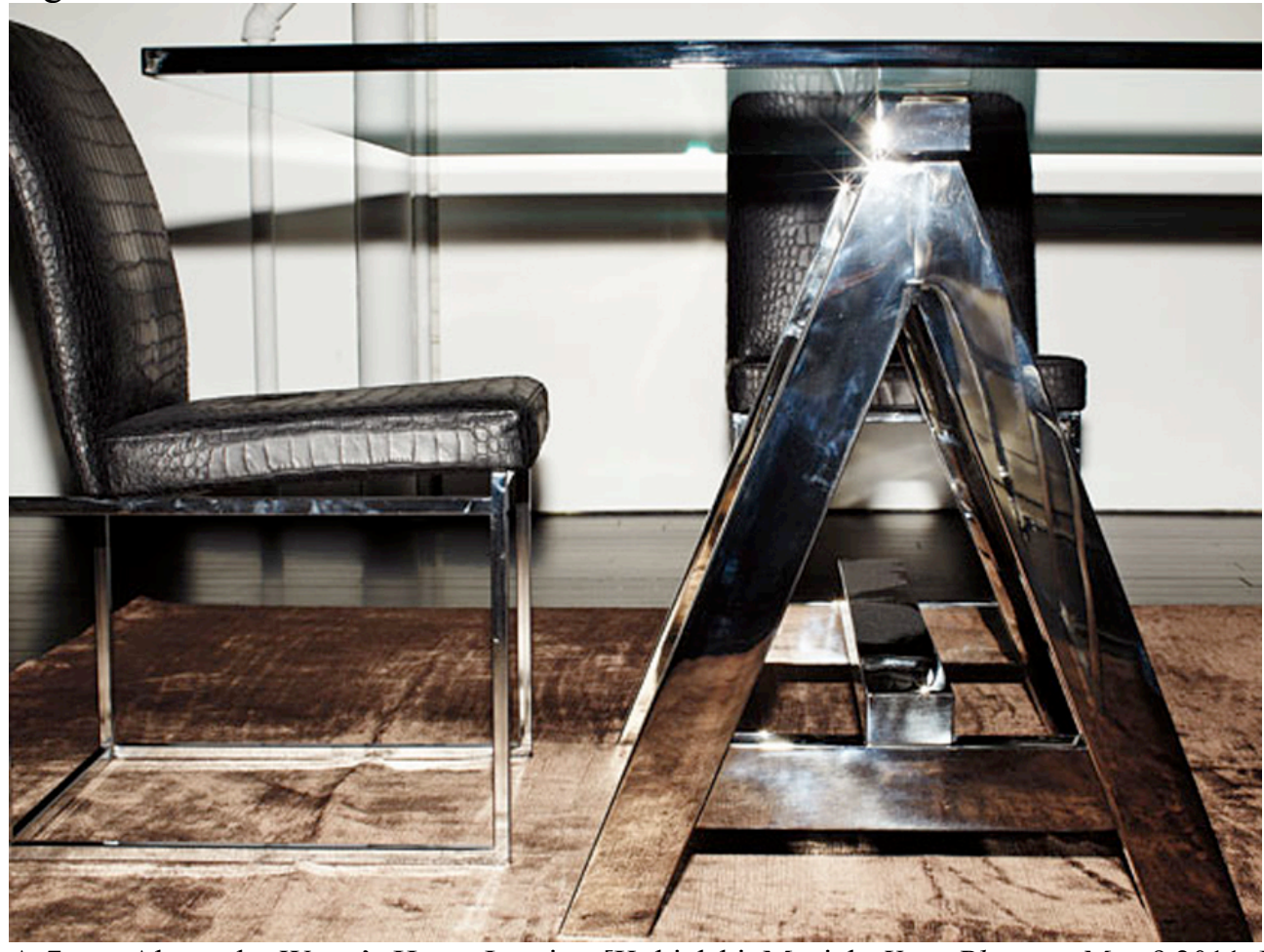

A-7 Alexander Wang's Home Interior. [Kobielski, Maciek. Your Place or Mine? 2011. Photograph. W Magazine, New York. W Magazine. Condé Nast. Web. Dec. 2011.] 
Figure c

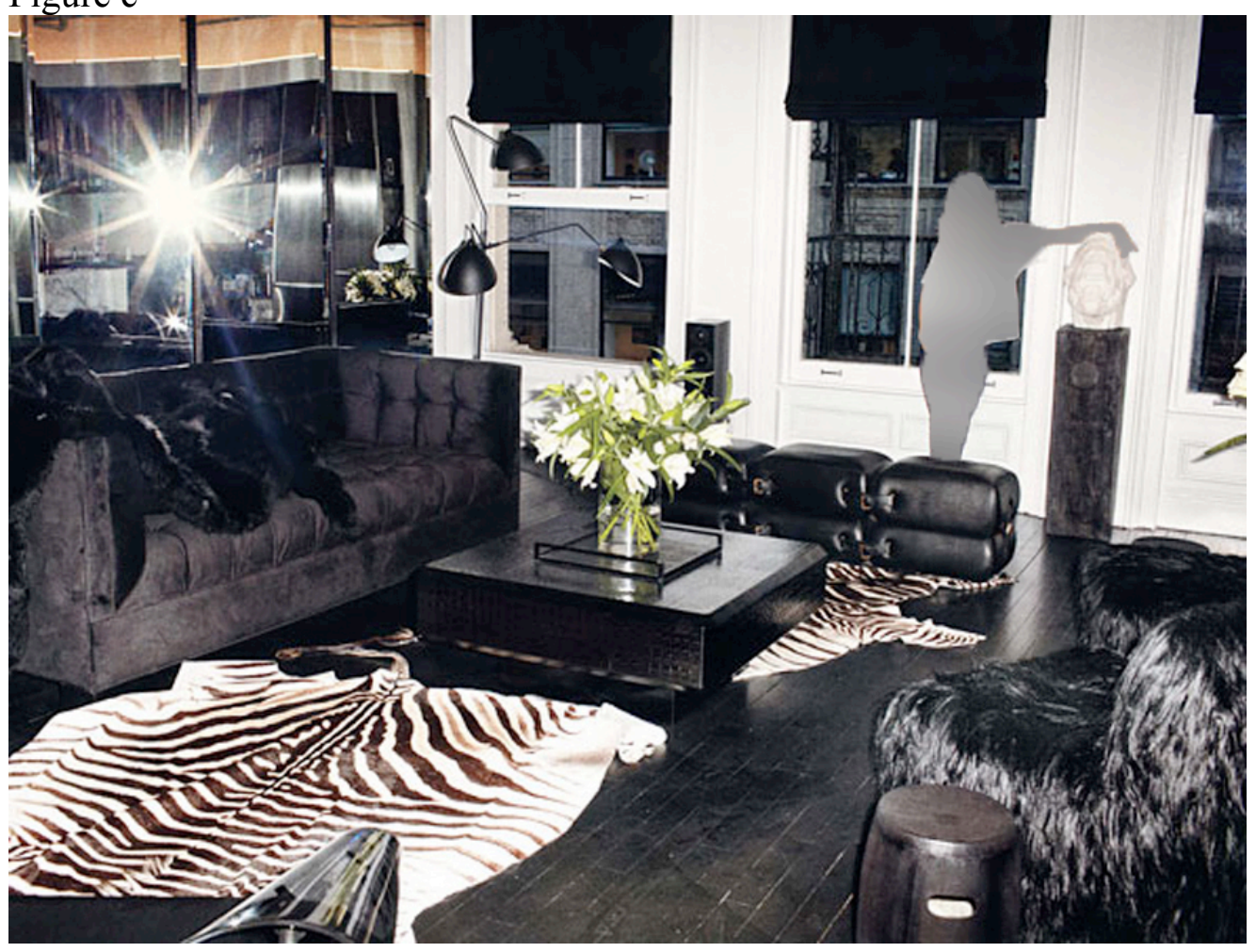

Figure d

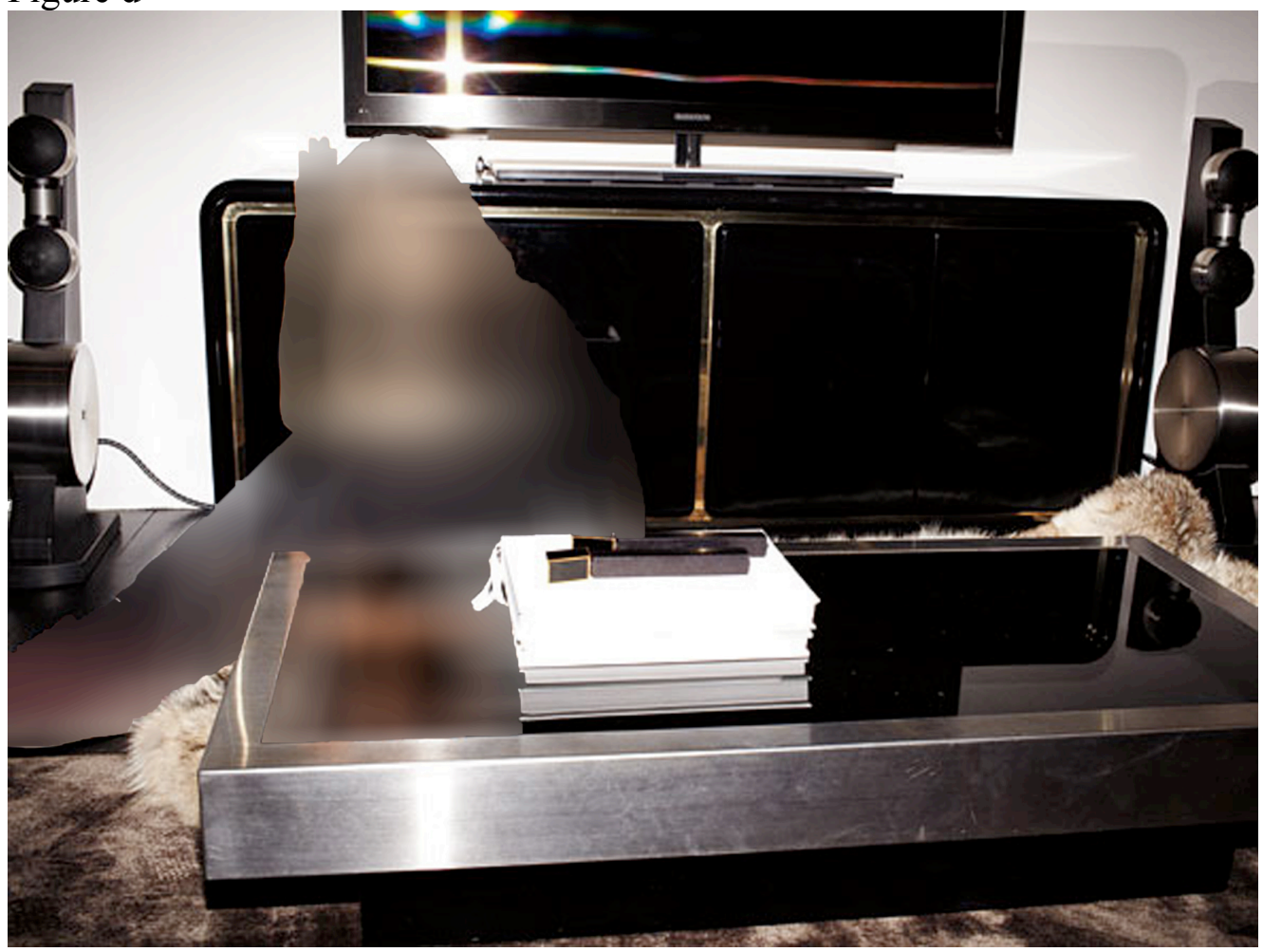

A-7 (Continued). Alexander Wang's Home Interior. 
Figure e

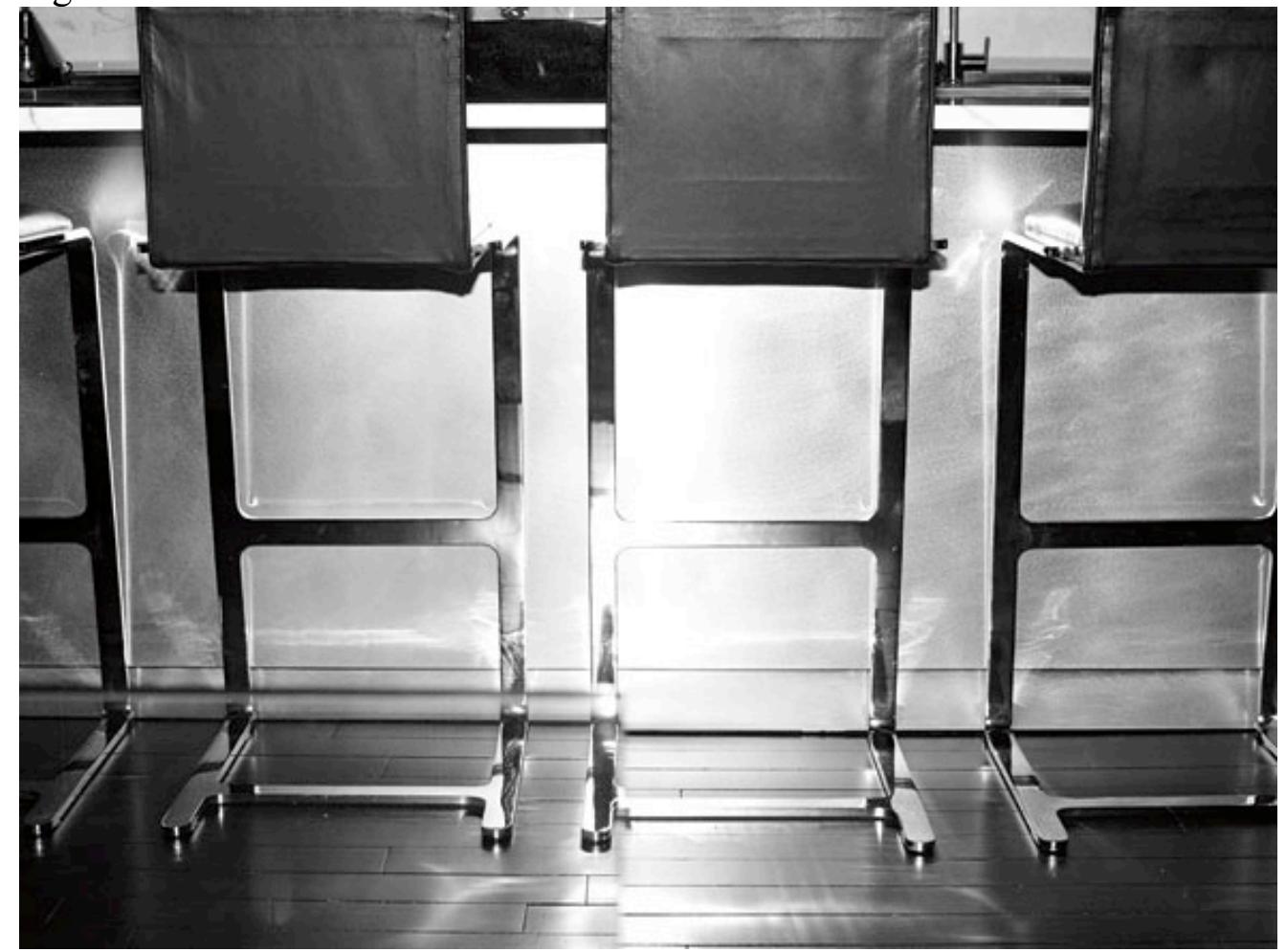

A-7 (Continued). Alexander Wang's Home Interior. 
APPENDIX A-8

Figure a

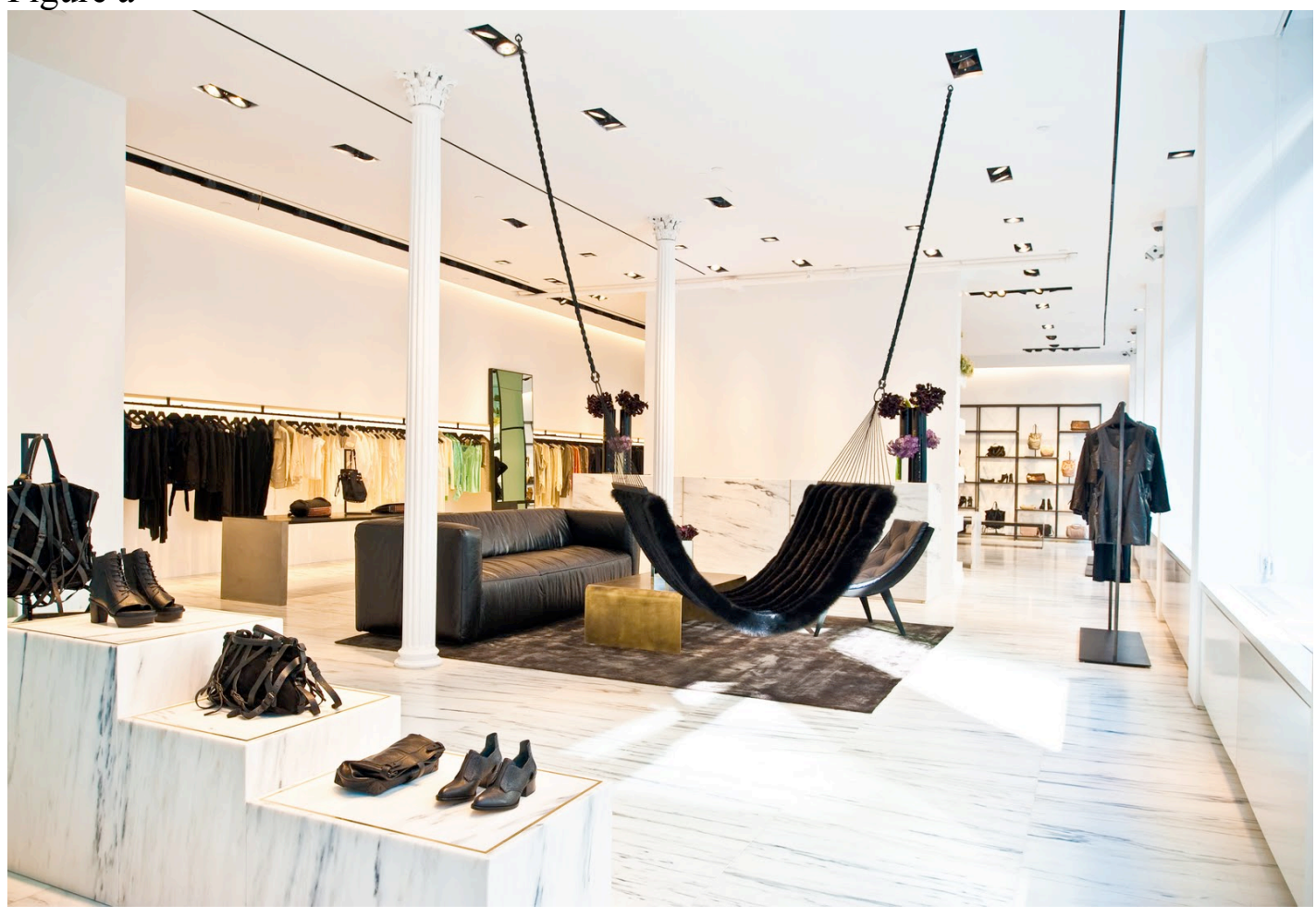

Figure b

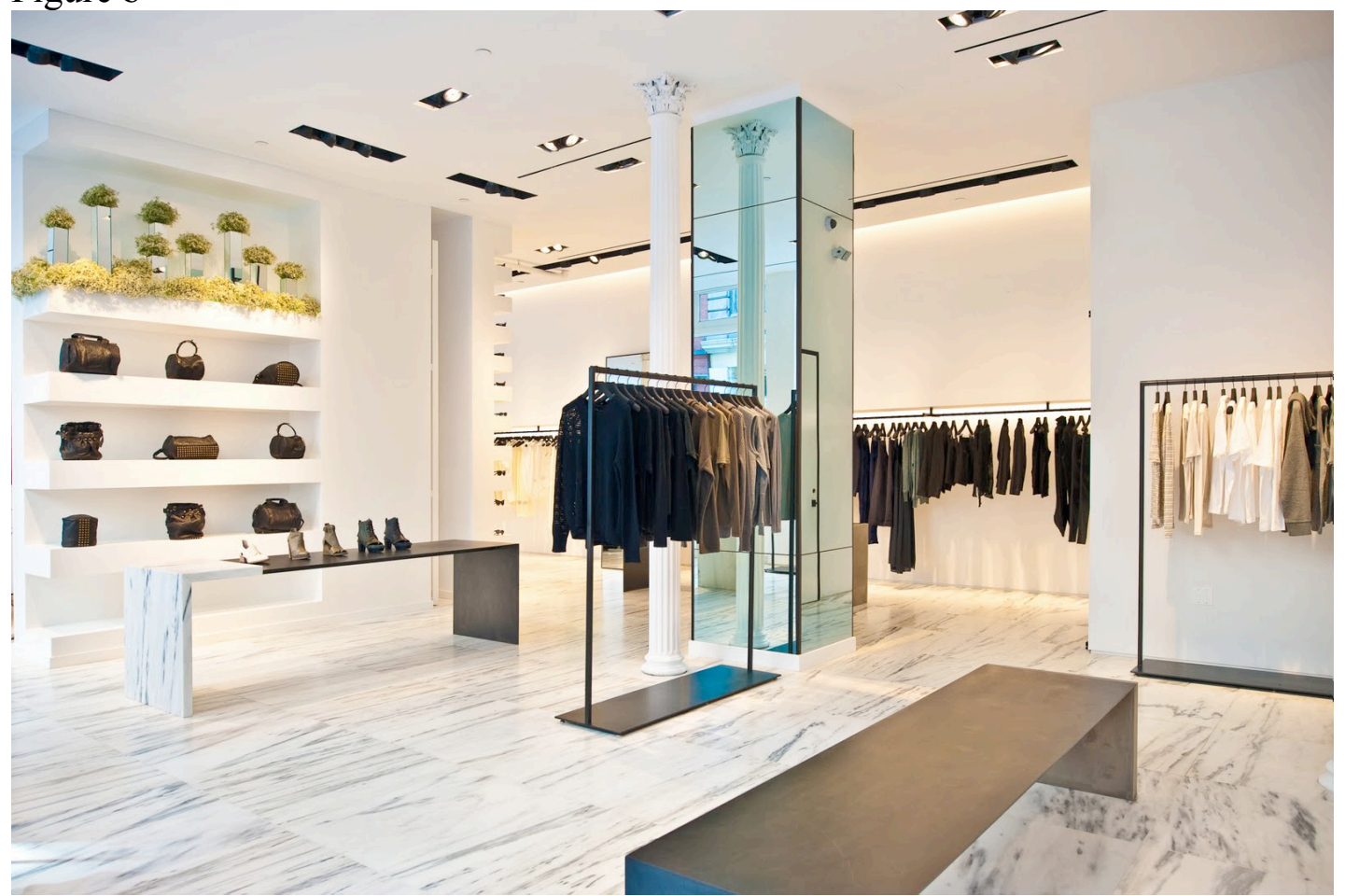

A-8 Alexander Wang's New York Flagship Interior. [Alexander Wang Has a New Store! Photograph. WGSN Americas Blog. WGSN Americas Blog. WGSN, 1 Mar. 2011. Web. Dec. 2011.] 
Figure c

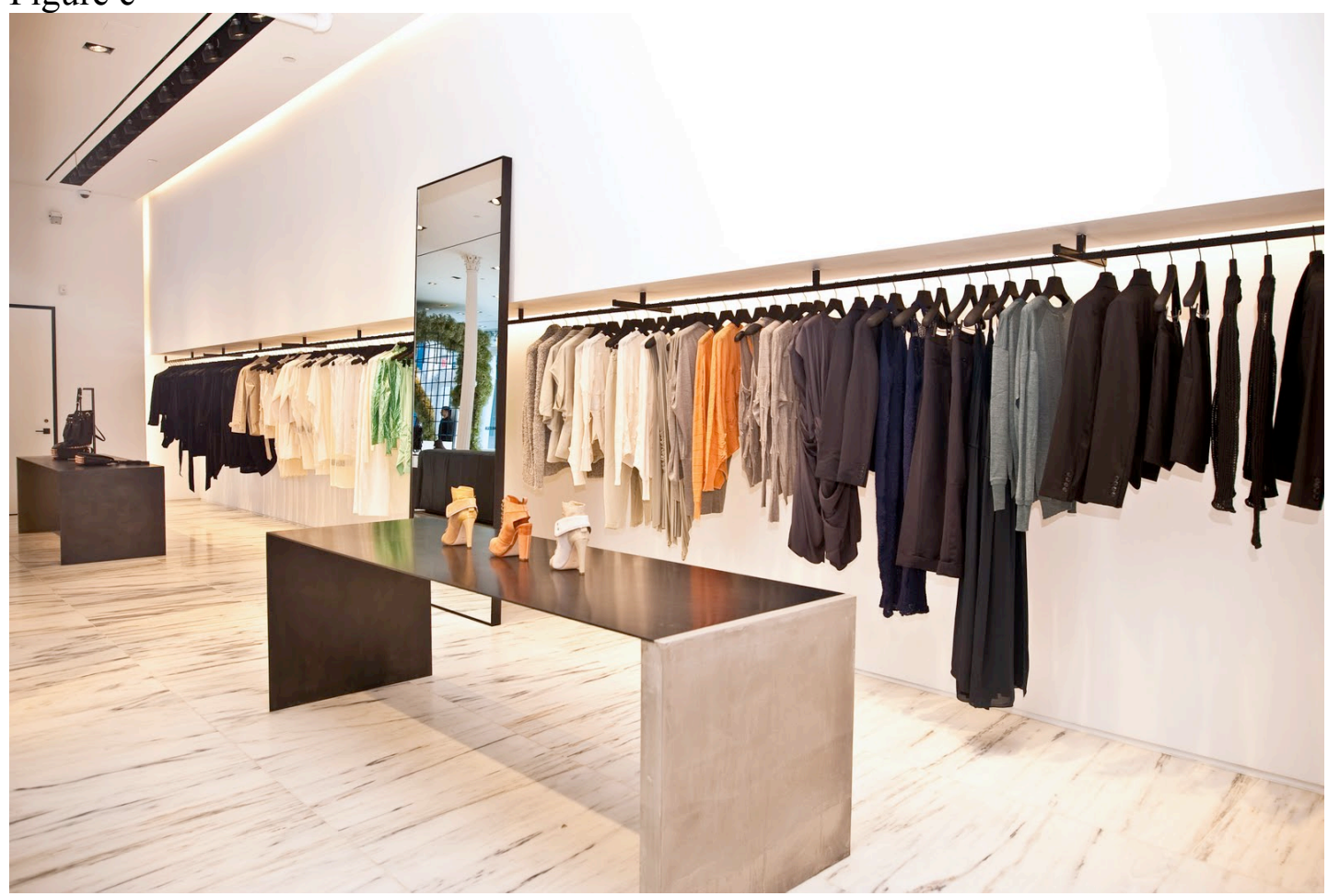

A-2 (Continued). Alexander Wang's New York Flagship Interior.

Figure d

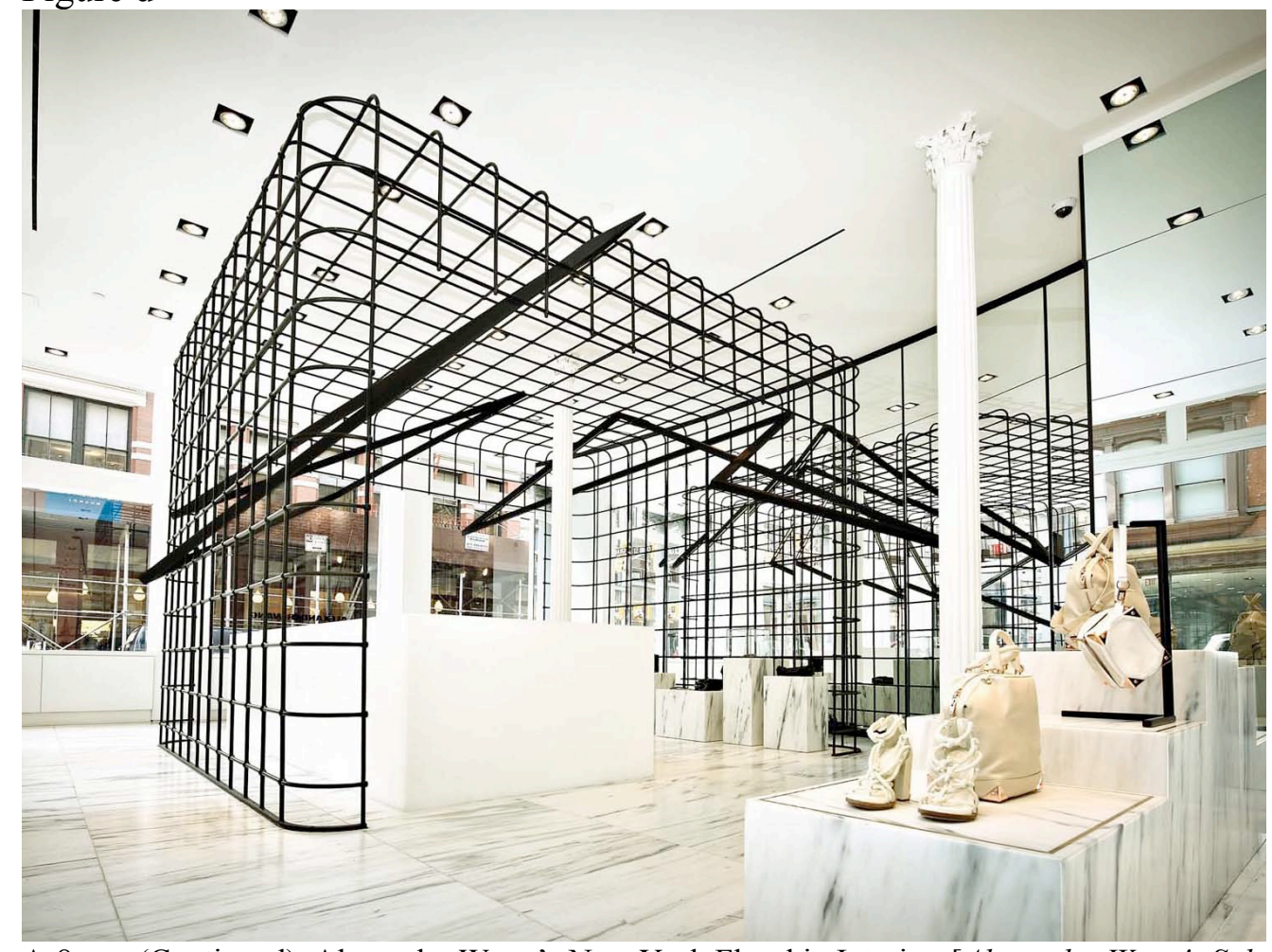

A-8 (Continued). Alexander Wang's New York Flagship Interior. [Alexander Wang's Soho Store. Photograph. Tumblr. Roses for Lilli. Tumblr, 29 Aug. 2011. Web. Dec. 2011.] 


\section{APPENDIX A-9}

\section{Figure a}

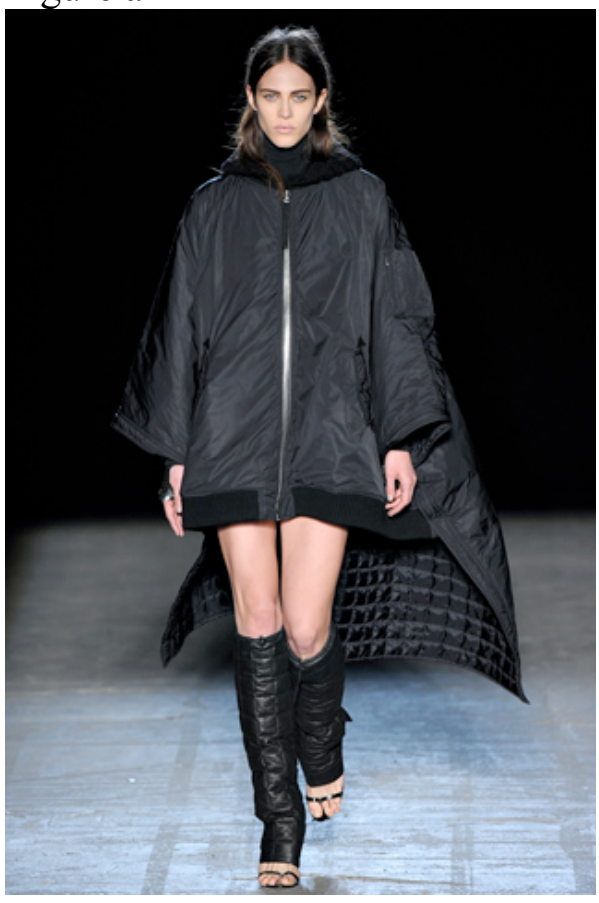

Figure b

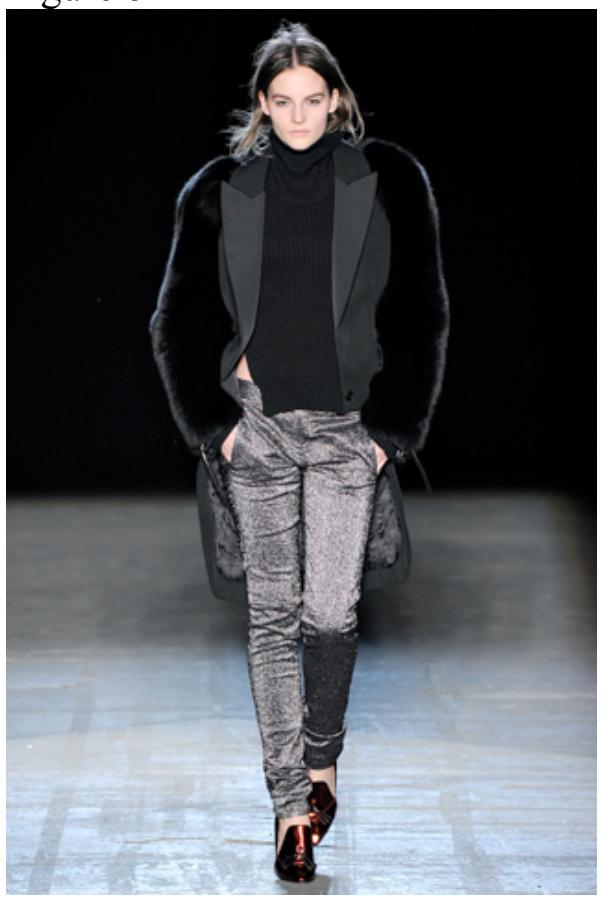

\section{Figure c}

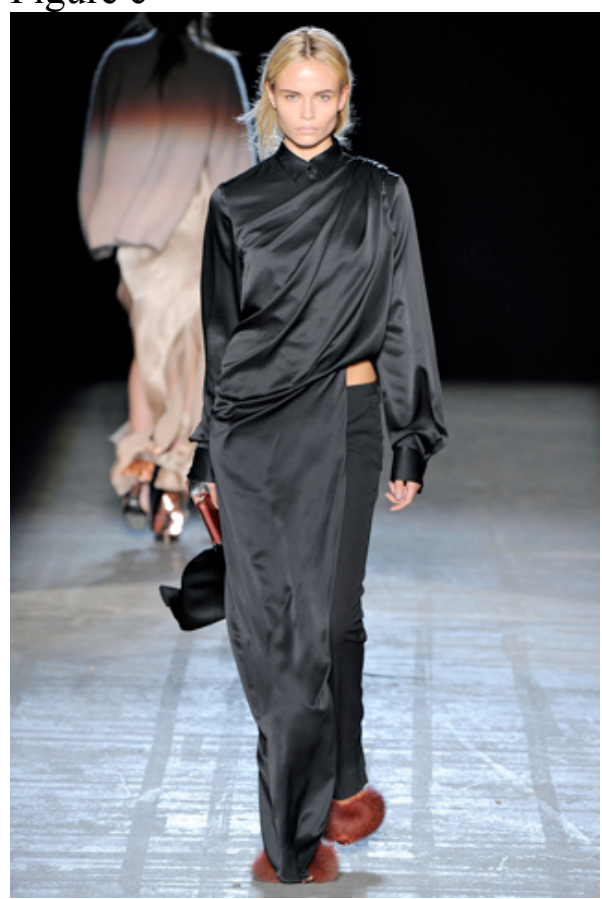

A-9 Alexander Wang's Collections Fall 2011 ready-to-wear. A) First look, B) Middle Look C) Last look. [Vlamos, Yannis. Fall 2011 Ready-to-wear Alexander Wang. 2011. Photograph. Style.com. Style.com. Condé Nast. Web. Dec. 2011.] 
Figure d

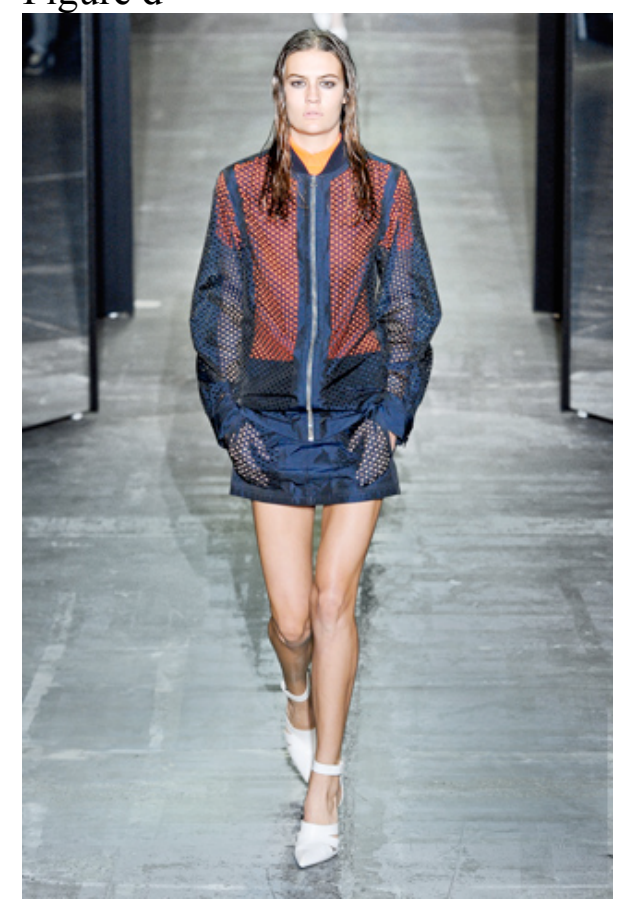

Figure e

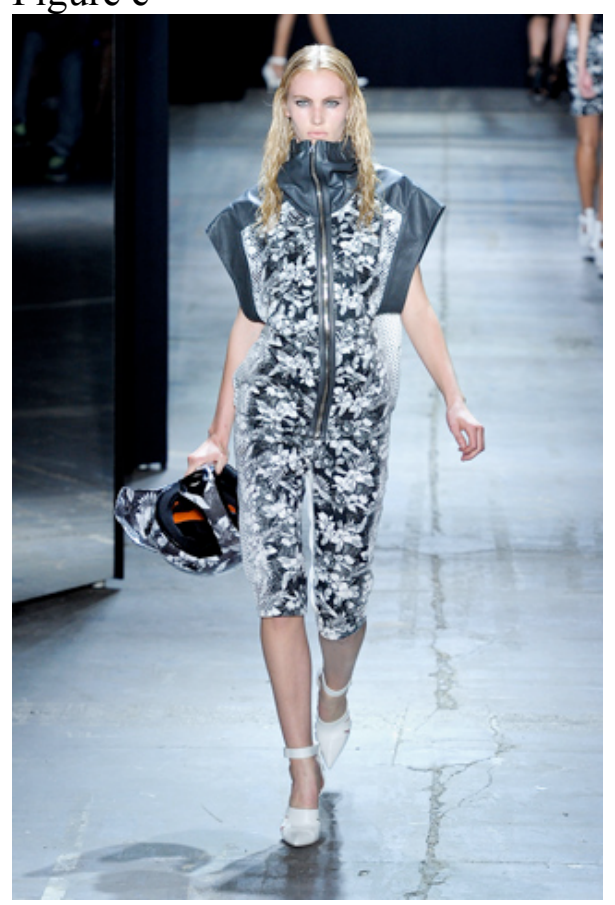

Figure $\mathrm{f}$

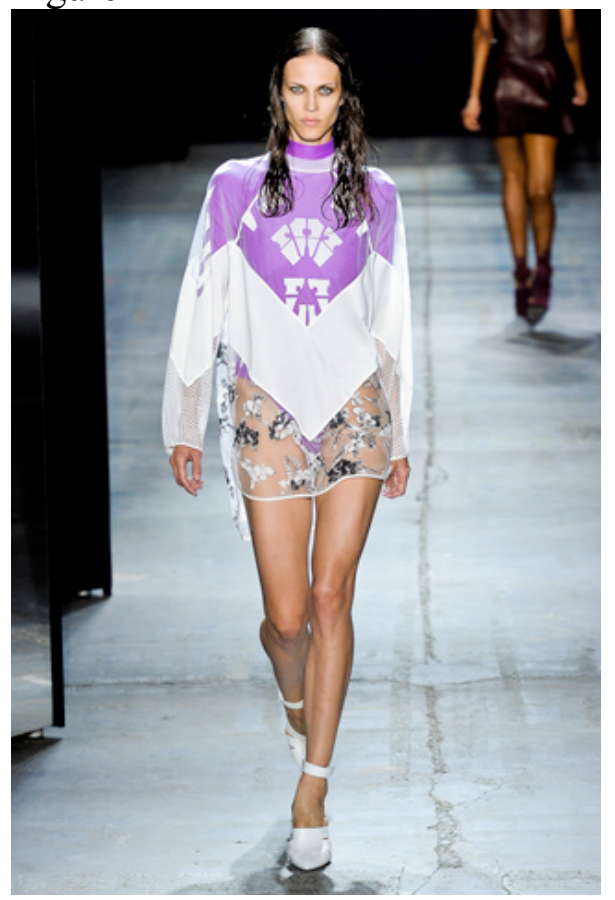

A-9 Alexander Wang's Collections Spring 2012 ready-to-wear. A) First look, B) Middle Look C) Last look. [Vlamos, Yannis. Spring 2012 Ready-to-wear Alexander Wang. 2011. Photograph. Style.com. Style.com. Condé Nast. Web. Dec. 2011.] 


\section{APPENDIX B}

TABLE B-1.

Summary of Image Grouping Exercise Results

\begin{tabular}{|c|c|c|c|c|c|c|}
\hline Informant & & Correct & Images & Incorrect & Images & $\begin{array}{l}\text { Exercise } \\
\text { Duration }\end{array}$ \\
\hline Mary Izen & & & & & & 19 Min \\
\hline \multirow[t]{3}{*}{ Tory Burch } & Home & 4 & Home b, c, d, e & 0 & & \\
\hline & Store & 4 & & 0 & & \\
\hline & Collection & 2 & Spring d, e & 4 & $\begin{array}{l}\text { RL Fall c, } \\
\text { Spring d. AW } \\
\text { Fall a, spring d }\end{array}$ & \\
\hline \multirow[t]{3}{*}{ Ralph Lauren } & Home & 0 & & 0 & & \\
\hline & Store & 4 & Store $a, b, c, d$ & 0 & & \\
\hline & Collection & 4 & $\begin{array}{l}\text { Fall a, b; Spring } \\
\mathrm{e}, \mathrm{f}\end{array}$ & 3 & $\begin{array}{l}\mathrm{TB} \text { fall b, } \\
\text { Spring f. AW } \\
\text { fall b }\end{array}$ & \\
\hline \multirow{3}{*}{$\begin{array}{r}\text { Alexander } \\
\text { Wang }\end{array}$} & Home & 4 & Home a, b, c, d & 3 & RL Home a, b, e & \\
\hline & Store & 4 & & 1 & RL Home c & \\
\hline & Collection & 3 & $\begin{array}{l}\text { Fall c; Spring e, } \\
\mathrm{f}\end{array}$ & 2 & TB Fall a, c & \\
\hline Beth Smith & & & & & & $13 \mathrm{Min}$ \\
\hline \multirow[t]{3}{*}{ Tory Burch } & Home & 5 & & 0 & & \\
\hline & Store & 4 & & 0 & & \\
\hline & Collection & 3 & Fall a, b, c & 3 & RL Fall a, b, c & \\
\hline \multirow[t]{3}{*}{ Ralph Lauren } & Home & 5 & & 0 & & \\
\hline & Store & 4 & & 0 & & \\
\hline & Collection & 3 & Spring d, e, f & 3 & $\begin{array}{l}\text { AW Spring d, e, } \\
\mathrm{f}\end{array}$ & \\
\hline \multirow{3}{*}{$\begin{array}{r}\text { Alexander } \\
\text { Wang }\end{array}$} & Home & 5 & & 0 & & \\
\hline & Store & 4 & & 0 & & \\
\hline & Collection & 3 & Fall a, b, c & 3 & TB Spring $d, e, f$ & \\
\hline Sarah Frank & & & & & & $15 \mathrm{Min}$ \\
\hline \multirow[t]{3}{*}{ Tory Burch } & Home & 0 & & 5 & $\begin{array}{l}\text { RL Home a, b, } \\
\mathrm{c}, \mathrm{d}, \mathrm{e}\end{array}$ & \\
\hline & Store & 3 & Store a, b, c & 1 & TB Home b & \\
\hline & Collection & 4 & $\begin{array}{l}\text { Fall b, c; Spring } \\
d, f\end{array}$ & 2 & AW Spring d, e & \\
\hline \multirow[t]{3}{*}{ Ralph Lauren } & Home & 0 & & 5 & $\begin{array}{l}\text { RL Store b, c. } \\
\text { TB Home a, d, e }\end{array}$ & \\
\hline & Store & 2 & Store a, d & 1 & TB Store d & \\
\hline & Collection & 5 & $\begin{array}{l}\text { Fall a, b; Spring } \\
\text { d, e, f }\end{array}$ & 1 & TB Spring e & \\
\hline \multirow{3}{*}{$\begin{array}{r}\text { Alexander } \\
\text { Wang }\end{array}$} & Home & 4 & Home a, b, c, d & 1 & TB Home c & \\
\hline & Store & 4 & & 0 & & \\
\hline & Collection & 4 & $\begin{array}{l}\text { Fall a, b, c; } \\
\text { Spring f }\end{array}$ & 2 & $\begin{array}{l}\text { RL Fall c. TB } \\
\text { Fall a }\end{array}$ & \\
\hline
\end{tabular}


TABLE B-1 (CONTINUED)

Summary of Image Grouping Exercise Results

\begin{tabular}{|c|c|c|c|c|c|c|}
\hline Pseudonym & & Correct & Images & Incorrect & Images & $\begin{array}{l}\text { Exercise } \\
\text { Duration }\end{array}$ \\
\hline Jane Edwards & & & & & & 12 Min \\
\hline \multirow[t]{3}{*}{ Tory Burch } & Home & 1 & Home c & 5 & $\begin{array}{l}\text { RL Home a, b, d, } \\
\mathrm{e}\end{array}$ & \\
\hline & Store & 2 & Store a, c & 1 & TB Home b & \\
\hline & Collection & 6 & & 0 & & \\
\hline \multirow[t]{3}{*}{ Ralph Lauren } & Home & 0 & & 5 & $\begin{array}{l}\text { RL Store b, c. TB } \\
\text { Home a, d, e }\end{array}$ & \\
\hline & Store & 2 & Store a, d & 2 & TB Store b, d & \\
\hline & Collection & 6 & & 0 & & \\
\hline \multirow{3}{*}{$\begin{array}{r}\text { Alexander } \\
\text { Wang }\end{array}$} & Home & 4 & Home a, b, c, d & 1 & RL Home c & \\
\hline & Store & 4 & & 0 & & \\
\hline & Collection & 6 & & 0 & & \\
\hline Sally Hall & & & & & & 13 Min \\
\hline \multirow[t]{3}{*}{ Tory Burch } & Home & 1 & Home c & 5 & $\begin{array}{l}\text { AW Home a, b, } \\
\mathrm{c}, \mathrm{d}, \mathrm{e}\end{array}$ & \\
\hline & Store & 4 & Store $\mathrm{a}, \mathrm{b}, \mathrm{c}, \mathrm{e}$ & 0 & & \\
\hline & Collection & 3 & $\begin{array}{l}\text { Fall a, b; Spring } \\
\mathrm{d}\end{array}$ & 3 & AW Spring d, e, f & \\
\hline \multirow[t]{3}{*}{ Ralph Lauren } & Home & 0 & & 5 & $\begin{array}{l}\text { RL Store b, c; TB } \\
\text { Home a, d, e }\end{array}$ & \\
\hline & Store & 2 & Store a, d & 1 & TB Home b & \\
\hline & Collection & 5 & $\begin{array}{l}\text { Fallb, c; Spring } \\
\text { d, e, f }\end{array}$ & 1 & AW Fall c & \\
\hline \multirow[t]{3}{*}{$\begin{array}{r}\text { Alexander } \\
\text { Wang }\end{array}$} & Home & 0 & & 5 & $\begin{array}{l}\text { RL Home a, b, c, } \\
\text { d, e }\end{array}$ & \\
\hline & Store & 4 & & 0 & & \\
\hline & Collection & 2 & Fall a, b & 4 & $\begin{array}{l}\text { RL Fall a. TB } \\
\text { Fall c; Spring e, f }\end{array}$ & \\
\hline Laura Lee & & & & & & 12 Min \\
\hline \multirow[t]{3}{*}{ Tory Burch } & Home & 4 & Home a, b, c, d & 1 & RL Home d & \\
\hline & Store & 2 & Store a, c & 1 & AW Store c & \\
\hline & Collection & 5 & $\begin{array}{l}\text { Fall a, b, c; } \\
\text { Spring d, e }\end{array}$ & 1 & AW Spring d & \\
\hline \multirow[t]{3}{*}{ Ralph Lauren } & Home & 0 & & 4 & $\begin{array}{l}\text { RL Store b, c. TB } \\
\text { Home e. TB } \\
\text { Store d }\end{array}$ & \\
\hline & Store & 2 & Store $\mathrm{a}, \mathrm{d}$ & 1 & TB Store b & \\
\hline & Collection & 3 & RL Spring d, e, f & 2 & $\begin{array}{l}\text { TB Spring f. AW } \\
\text { Spring } \mathrm{f}\end{array}$ & \\
\hline \multirow[t]{3}{*}{$\begin{array}{r}\text { Alexander } \\
\text { Wang }\end{array}$} & Home & 4 & Home a, b, c, d & 4 & RL Home a, b, c, & \\
\hline & Store & 3 & Store $\mathrm{a}, \mathrm{b}, \mathrm{d}$ & 0 & & \\
\hline & Collection & 4 & $\begin{array}{l}\text { Fall a, b, c; } \\
\text { Spring e }\end{array}$ & 3 & RL Fall a, b, c & \\
\hline
\end{tabular}




\section{LIST OF REFERNCES}

Aaker, Jennifer L. "Dimensions of Brand Personality." Journal of Marketing Research 34.3 (1997): 347-56. JStor. Web. 6 Mar. 2011.

Abranowicz, William. Ralph Lauren's Chic Retreat. 20120. Photograph. Elle Decor, New York. Elle Decor. Hearst Communications Inc. Web. Dec. 2011.

Allen, Chris T., Susan Fournier, and Felicia Miller. "Brands and Their Meaning Makers." Handbook of Consumer Psychology. Ed. Curtis P. Haugtvedt, Paul Herr, and Frank R. Kardes. New York: Lawrence Erlbaum Associates, 2008. 781-822. Print. Anonymous. Alexander Wang Has a New Store! Photograph. WGSN Americas Blog. WGSN Americas Blog. WGSN, 1 Mar. 2011. Web. Dec. 2011.

Anonymous. Tory On: 797 Madison Avenue. 2011. Photograph. The Tory Blog. Tory

Burch. Tory Burch LLC, 9 Sept. 2011. Web. Dec. 2011.

Azoulay, Audrey, and Jean-Noel Kapferer. "Do Brand Personality Scales Really Measure Brand Personality?" Journal of Brand Management 11.2 (2003): 143-55.

ABI/INFORM Global. Nov. 2003. Web. 13 May 2011.

Barber, Gerald M., and James E. Burt. Elementary Statistics for Geographers. New York: Guilford, 1996. Print.

Batey, Mark. Brand Meaning. New York: Routledge, 2008. Print.

Bell, Philip. "Content Analysis of Visual Images." Handbook of Visual Analysis. Ed. Theo

Van Leeuwen. London: SAGE, 2001. 10-34. Print.

Brengman, Malaika, and Kim Willems. "Determinants of Fashion Store Personality: a

Consumer Perspective." Journal of Product \& Brand Management 18.5 (2009): 346-55. Web. 
Byrne, Bridget. "Qualitative Interviewing." Researching Society and Culture. Ed. Clive Seale. 2nd ed. London: SAGE, 2004. 179-92. Print.

Cagan, Jonathan, and Craig M. Vogel. Creating Breakthrough Products: Innovation From Product Planning to Program Approval. Upper Saddle River, NJ: Prentice Hall, 2007. Print.

Costello, Paul. Step into Tory Burch's Home. 2009. Photograph. Elle Magazine, New York. Elle. Hearst Communications Inc. Web. Dec. 2011.

Cupchik, Gerald C., Ute Ritterfield, and Julia Levin. "Incidental Learning of Features from Interior Living Spaces." Journal of Environmental Psychology 23 (2003): 189-97. Web.

Edwards, Jane (pseudonym). Personal Interview. 3 Mar. 2012

Foss, Sonja K. "Theory of Visual Rhetoric." Handbook of Visual Communication: Theory, Methods, and Media. Ed. Ken Smith, Sandra Moriarty, Gretchen Barbatsis, and Keith Kenney. Mahwah, NJ [u.a.: Erlbaum, 2005. 141-65. Print.

Feudi, Monica. Fall 2011 Ready-to-wear Ralph Lauren. 2011. Photograph. Style.com. Style.com. Condé Nast. Web. Dec. 2011.

Feudi, Monica. Spring 2012 Ready-to-wear Ralph Lauren. 2011. Photograph. Style.com. Style.com. Condé Nast. Web. Dec. 2011.

Frank, Sarah (pseudonym). Personal Interview. 29 Feb. 2012

Goffman, Erving. The Presentation of Self in Everyday Life. Garden City: N.Y.,Doubleday Anchor, 1959. Print.

Garofalo, Alessandro. Fall 2011 Ready-to-wear Tory Burch. 2011. Photograph. Style.com. Style.com. Condé Nast. Web. Dec. 2011. 
Hall, Sally (pseudonym). Personal Interview. 3 Mar. 2012

Hogan, Bernie. "The Presentation of Self in the Age of Social Media: Distinguishing Performances and Exhibitions Online." Bulletin of Science, Technology \& Society 30.6 (2010): 377-86. Web.

Holbrook, Morris B., Michael R. Solomon, and Stephen Bell. "A Reexamination of SelfMonitoring and Judgments of Furniture Design." Home Economics Research Journal 19.1 (1990): 6-16. Web.

Izen, Mary (pseudonym). Personal Interview. 26, Feb. 2012

Johnson, Carla, and Lee, Monle, and Carla Johnson. Principles of Advertising: A Global Perspective. New York: Haworth, 2005. Print.

Keller, Kevin Lane. Strategic Brand Management: Building, Measuring, and Managing Brand Equity. 2nd ed. Upper Saddle River, NJ: Prentice Hall, 2003. Print.

Kobielski, Maciek. Your Place or Mine? 2011. Photograph. W Magazine, New York. $W$ Magazine. Condé Nast. Web. Dec. 2011.

Kozinets, Robert V., John F. Sherry, et al. "Themed Flagship Brand Stores in the New Millenium: Theory, Practice, and Prospects." Journal of Retailing 78.1 (2002): 1729. Web.

Krippendorff, Klaus. Content Analysis: An Introduction to Its Methodology. Thousand Oaks, CA: Sage, 2004. Print.

Kumar, Ranjit. Research Methodology: A Step-by-Step Guide for Beginners. Los Angeles: SAGE, 2011. Print.

Lindstrom, M. Clicks, Bricks and Brands. London: Kogan Page, 2002. Print.

Lee, Laura (pseudonym). Personal Interview. 5 Mar. 2012 
Lindquist, Jay D. "Meaning of Image." Journal of Retailing 50.4 (1974-75): 29-38. Web.

Lisnet, Michael. The New Ralph Lauren Store at 888 Madison Avenue. 2010. Photograph. Vogue Daily, New York. Vogue. Condé Nast, 14 Oct. 2010. Web. Dec. 2011.

Malhotra, Naresh K. A Scale to Measure Self-Concepts, Person Concepts, and Product Concepts. 1999. Handbook of Marketing Scales: Multi-item Measures for Marketing and Consumer Behavior Research. By William O. Bearden and Richard G. Netemeyer. 2nd ed. Thousand Oaks, CA: Sage Publications, 1999. 42-43. Print. Maxwell, Joseph Alex. Qualitative Research Design: An Interactive Approach. Thousand Oaks, CA: Sage Publications, 2005. Print.

McNabb, David E. Research Methods in Public Administration and Nonprofit Management: Quantitative and Qualitative Approaches. Armonk, NY: M.E. Sharpe, 2002. Print.

Miller, Hugh. The Presentation of Self in Electronic Life: Goffman on the Internet. Conference Paper. Embodied Knowledge and Virtual Space Conference Goldsmiths' College, University of London, 1995. Print.

Mirzoeff, Nicholas. An Introduction to Visual Culture. London: Routledge, 2009. Print.

Morrison, Margaret A. Using Qualitative Research in Advertising: Strategies, Techniques, and Applications. Thousand Oaks, CA: Sage, 2002. Print.

Moser, Mike. United We Brand: How to Create a Cohesive Brand That's Seen, Heard, and Remembered. Boston: Harvard Business School, 2003. Print.

Nandan, Shiva. "An Exploration of the Brand Identity Brand Image Linkage: a Communications Perspective." Journal of Brand Management 12.4 (2005): 26478. ABI/INFORM Global. Web. 
Perry, Alycia, and David Wisnom. Before the Brand: Creating the Unique DNA of an Enduring Brand Identity. New York: McGraw-Hill, 2003. Print.

Potvin, John. "The Velvet Masquerade: Fashion, Interior Design, and the Furnished Body." Fashion, Interior Design and the Contours of Modern Identity. Ed. Alla Myzelev. Farnham: Ashgate, 2010. 1-17. Print.

Rogoff, Irit. "Studying Visual Culture." 2001. The Visual Culture Reader. Ed. Nicholas Mirzoeff. 2nd ed. London [u.a.: Routledge, 2002. 24-34. Print.

Rowley, Jennifer. "Online Branding." Online Information Review 28.2 (2004): 131-38. Emerald Online. Emerald Group Publishing Ltd, 2004. Web. Sept. 2011.

Sadalla, Edward K., Beth Vershure, and Jeffrey Burroughs. "Identity Symbolism in Housing." Environment and Behavior 19.5 (1987): 569-87. Web.

Saldaña, Johnny. The Coding Manual for Qualitative Researchers. London: Sage, 2009. Print.

Schroeder, Jonathan E. "Visual Consumption in the Image Economy." Elusive Consumption. Ed. Karin M. Ekstrom and Helene Brembeck. Oxford: Berg, 2004. 229-44. Print.

Schultz, Don E., and Heidi F. Schultz. IMC, the Next Generation: Five Steps for Delivering Value and Measuring Financial Returns. New York: McGraw-Hill, 2004. Print.

Smith, Beth (pseudonym). Personal Interview. 28 Feb. 2012

Stemler, Steve. "An Overview of Content Analysis." Practical Assessment, Research \& Evaluation 7.17 (2001). Web. Mar. 2012. 
Stephenson, G. M. "Applied Social Psychology." Ed. M. Hewstone, W. Stroebe, and G. Stephenson. Introduction to Social Psychology. 2nd ed. Oxford: Blackwell, 1996. Print.

Vaid, Helen. Branding: Brand Strategy, Design, and Implementation of Corporate and Product Identity. New York, NY: Watson-Guptill, 2003. Print.

Vlamos, Yannis. Fall 2011 Ready-to-wear Alexander Wang. 2011. Photograph. Style.com. Style.com. Condé Nast. Web. Dec. 2011.

Vlamos, Yannis. Spring 2012 Ready-to-wear Alexander Wang. 2011. Photograph. Style.com. Style.com. Condé Nast. Web. Dec. 2011.

Vlamos, Yannis. Spring 2012 Ready-to-wear Tory Burch. 2011. Photograph. Style.com. Style.com. Condé Nast. Web. Dec. 2011.

Wilson, Margaret A., and Nicola E. Mackenzie. "Social Attributions Based on Domestic Interiors." Journal of Environmental Psychology 20 (2000): 343-54. Scholars Portal Journals. Web. Jan. 2012. 